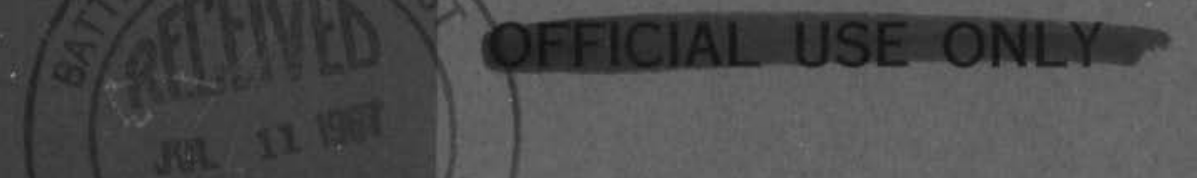

BNWL-468

$2-$

PACIFIC NORTHWEST LABORATORY

RESEARCH

and

MONTHLY ACTIVITIES REPORT

FOR MAY 1967

\title{
DEVELOPMENT
}

REPORT

\author{
DIVISION \\ OF \\ REACTOR DEVELOPMENT AND TECHNOLOGY \\ PROGRAMS
}

JUNE 1967

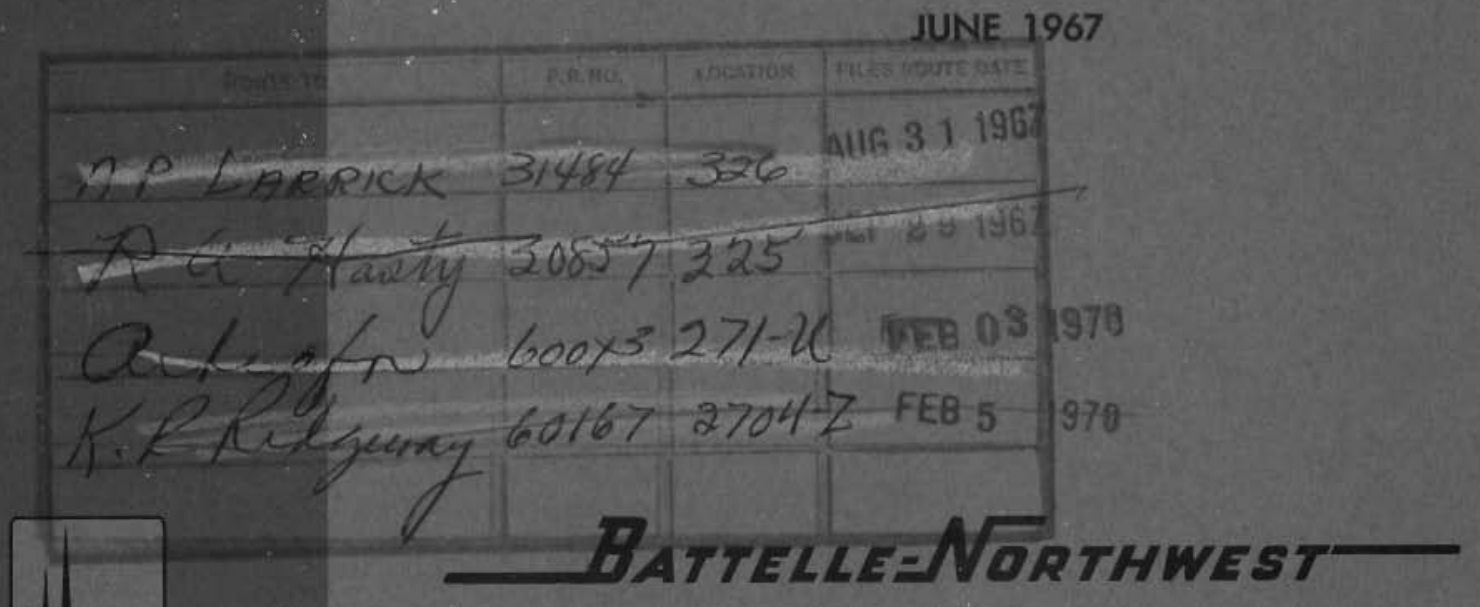

BATTELLE MEMORIAL INSTITUTE / PACIFIC NORTHWEST LABORATORY

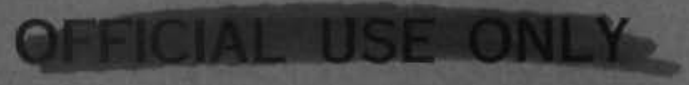


INFORMATION CONCERNING USE OF THIS REPORT

PATRNT STTHLS

This document copys Mincesil ls tronsmitted in advance of penteht clearance, is mode avoliable in confidence solely lor vie in performonct of unatk under sonfracts with the U. S. Afomic Energy Commis.

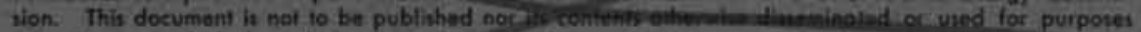
other then specified obove before patentsepproval for wuch release ot use has been secured, upan iequest. from the Chief, Chicago Patent Geverp, U, S. Atomic Enmrgy Commiation, 9800 Sa. Cass Are.s. Argonne, IIlinois:

\section{PRELIMINARY REPOKT}

This report cantains information of a preliminary nature prepared in the caush of wark unde Alomic Energy Commistion Contract ATt4S-1)-1830. This information is subject to cortectien ar modifico tion upen the collection and evaluation of additional data.

\section{LEGAL NOTTCE}

This report was prepared as on accoumt of Gavernment sponsored work. Nelither the United States nor the Commission, nor any perian acting os behalf of the Coministiont:

A. Makes any warranty or representation, expressed or implied, with respect to the occuracy, completeness, or usefulness of the information contained in this report or that the use of any intarnation. apparatus, method, or process disclosed in this repart may not infringe privately owned rights or

B. Assumes any. liabilties with respect to the use of, or for damages reviliting fram the use of ony information, opporatus, method, or process disclosed in this report.

As used in the above, "person acting on behalf of the Commission" Includes any employee or controctor of the Commission, or employee of such confractor, to the extent that such employee or can: tractor of the Commissios, or employee of such contractor prepares, disseminates, or provides occess to: any information pursuant to his smployment or controct with the Commission, of his employment with such contractor.

\section{PACIFIC NORTHWEST LABORATORY} RICHLAND, WASHINGTON

operated by

BATTELLE MEMORIAL INSTITUTE

for the

UNITED STATES ATOMIC ENERGY COMMISSION UNDER CONTRACT AT(45-1)-1830

PRINTED BY/FOR THE U.S. ATOMIC ENERGY COMMISSION 


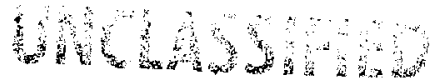

33679000606055

BNWL -468

$$
\text { UC-2 }
$$

Special Distribution

\author{
PACIFIC NORTHWEST LABORATORY \\ MONTHLY ACTIVITIES REPORT \\ FOR MAY 1967
}

AEC DIVISION OF

REACTOR DEVELOPMENT AND TECHNOLOGY PROGRAMS

\author{
By \\ The Staff of Battelle-Northwest \\ S. L. Fawcett, Di rector
}

June 1967

PACIFIC NORTHWEST LABORATORY

RICHLAND, WASHINGTON 
CIVILIAN POWER REACTORS

Liquid Metal Fast Breeder Reactor . . . . . . . . . 17

Nuclear Systems and Concepts Analysis . . . . . . . 18

Conceptual Reactor Design Studies . . . . . . . . 20

HTGR Graphite . . . . . . . . . . . . . . . . . . 23

USAEC-AECL Cooperative Program . . . . . . . . . . 23

APPLIED AND REACTOR PHYSICS

Plutonlum Criticalıty Studies . . . . . . . . . . 25

Phoenlx Fuel Reactor Program . . . . . . . . . . . 26

High Temperature Reactor Lattıce Physics Studies. . . 31

REACTOR FUELS AND MATERIALS

Fast Fuels Oxides and Nitrides......... . . . 38

Basic Swelling Studies ............. . . 39

Nondestructive Testing . . . . . . . . . . . . . 40

Nuclear Ceramics . . . . . . . . . . . . . . . 44

Nuclear Graphıte . . . . . . . . . . . . . . . 45

Irradiation Damage to Reactor Metals... . . . . . 50

ATR Gas Loop Operation and Maintenance . . . . . . . 59

Metallic Fuels Development . . . . . . . . . . . 62

Fast Reactor Dosimetry and Damage Analyses . . . . . = 64

ENGINEERING DEVELCPMENT

Neutron Flux Monitors . . . . . . . . . . . . . . 65

Microwave and infrared Detection of Coolant Impurities and Measurement of In-Reactor Temperatures . . . . . Upstream Bolling Burnout... . . . . . . . . . . 69

PLUTONIUM UTILIZATION PROGRAM

Fuels Development . . . . . . . ., . . . , 70

Reactor Physics . . . . . . . . . . . . . . . 75

Materials Development . . . . . . . . . . . . . 79

Reactor Engineering Development . . . . . . . . . 80

Test Reactor Operation ................ . 81

EBWR Demonstration Program . . . . . : . . . . . 84

NUCLEAR SAFETY

Contalnment Systems Experiment . . . . . . . . . . 85

Pressure Vessel Crack Monıtoring . . . . . . . . 89

Fission Product Aerosol Contalnment . . . . . . . . . 90

Columbia River Sedımentation Studıes . . . . . . . . . 91

Disposal of Reactor Off-Gas into Soll Systems . . . . 91

Geophysical Exploration of Rattlesnake \#l Well . . . 91

Simulation Modeling of Expected Thermal Generation

in Selected River Systems... . . . . . . . . 92

Radioactive Waste Solidification . . . . . . . . 92 


\section{SUMMARY}

\section{CIVILIAN POWER REACTORS}

\section{Liquid Metal Fast Breeder Reactor}

Effects of variations in volume ratios of molten fuel to solid fuel on oxygen distribution and integrated thermal conductivity to melting in $\mathrm{UO}_{2} .02, \mathrm{UO}_{2} .05$, and $\mathrm{UO}_{2} .15$ were investigated analytically. Results of the calculations showed as much as $50 \%$ variation in the conductivity integral to melting (for $\mathrm{UO}_{2.15}$ ) depending upon extent of melting.

Irradiation specimens contalning $\mathrm{UO}_{1} .90, \mathrm{UO}_{2}, 00, \mathrm{UO}_{2} .02, \mathrm{UO}_{2} .05$, and $\mathrm{UO}_{2} .15$ were pneumatically impacted in integrai stainless steei sheaths:

The initial series of six comparative irradiations, designed to measure the effects of varying $\mathrm{O} / \mathrm{M}$ between 1.92 and 2.00 on the power rating required for melting in $\mathrm{UO}_{2}-25$ wto $\mathrm{PuO}_{2}$, is in progress.

\section{Nuclear Systems and Concepts Analysis}

Final debugging of various codes was completed and cases representing final Phase II calculation were set up for machine computation to be run in early June. Conversion of the LP codes from the 1107 to the 1108 is nearing completion.

Equations were developed to represent net leakages and thus represent exact $\mathrm{P} 1$ behavior in multigroup diffusion. The level of effort needed to produce results is less than that needed in full Pl calculations. By starting at high energy, direct calculations produce the net leakage for a given group.

\section{Conceptual Reactor Design Studies.}

The revised parametric study for a steam-cooled fast reactor has been completed using the ORNL cross section set.

Investigation of the effects of rod sizes, cross section set, and $2 \mathrm{D}$ effects are under way.

New analytical methods have been developed for predicting the pumping power requirements and for designing the fuel cladding of the SCFR. The pumping power calculations have been debugged and incorporated into the MIMIC design simulation. The cladding design calculations are currently being debugged. 
Gross heat capacity calculations have been completed for the . major streams in the North Atlantic Slope Basins, Maine to Connecticut.

\section{HTGR Graphıte}

Surface areas of sampies Irradiated to about $0.7 \times 10^{21} \mathrm{nvt}$ ( $\mathrm{E} 0.18 \mathrm{MeV}$ ) at $875 \mathrm{C}$ were measured. Any changes which resulted from irradiation appear to be small.

\section{USAEC-AECL Cooperatıve Program}

Unlaxial creep tests performed on longltudinal sections of Zr$2.5 \mathrm{Nb}$ pressure tubing at $31.6 \mathrm{Kg} / \mathrm{mm}^{2}(45,000 \mathrm{psi}$ and $300 \mathrm{C}$ resulted in a faster in-reactor creep rate $\left(2 \times 10^{-4} \mathrm{hr}^{-1}\right.$ ) than for the corresponding creep rate $\left.13 \times 10^{-5} \mathrm{hr}^{-1}\right)$ for the unirradiated control specimen.

A report describing the analytic phase of the program cited in the title was issued, and the first unrestricted distribution was made on May 17. The title of this report is "Cross-Flow Mixing Between Parallel Flow Channels During Bolling - Part 1 - Cobra Computer Program for Coolant Bolling in Rod Arrays" (BNWL-371 Pt 1). A report describing the first part of the experimentai phase of the program is currently under preparation, and 1 t will be issued as BNWL-371 Pt 2 .

Crack propagation tests on zirconlum-2.5\% Nb pressure tubing shows that hydriding drastically reduces the hoop strength at fallure for specimens with short slots, but when the slot length is 4 inches, the hydrided condition exhibits as great a resistance to failure and crack propagation as the unhydrided condition.

\section{APPLIED AND REACTOR PHYSICS}

\section{Plutonium Criticality Studies}

Analysis of data from activation measurements in plutonium assemblies with $\mathrm{Mn}$, In, and $\mathrm{Pu}$ was continued. Calculations of intracellular flux distributions utilizing the DTF IV code were found to be in poor agreement with experiment.

Experiments were continued in support of the Gas-Cooled Fast Reactor (GCFR) program. A series of irradiations were performed in undermoderated, homogeneous, and heterogeneous plutonium assemblies for determining intraceliular flux distributions and flux spectra indices. The H/Pu ratıos of the assemblies were 5 and 8. 


\section{Phoenix Fuel Reactor Program}

Analysis of the approach-to-critical data from the CAF-Phoenix experiments has been completed.

The CAF-Phoenix theory-experiment correlation report is in rough draft form.

Power peaking measurements have been made in the fuel plates in the PRCF-Phoenix core. Measurements have shown that the core is subcritical with three of the eight shims fully withdrawn.

Preliminary analysis of power distributions from the PRCF experiment indicates that the peak to average power may be significantly lower than the calculated value.

The digital computer code, MACABRE II, for thermal hydraulic analysis of the MTR is now operational on the local Univac 1107.

Drawings have been completed and bids submitted for fabrication of two fuel boxes containing flux wires for hydraulic testing at the MTR facility.

New Al-Pu fuel plates are being prepared for an MTR experiment to replace the plates, previously prepared, which had internal defects.

Analytical studies are being made of the application of Phoenix fuels in the PRTR and the CNSG.

\section{High Temperature Reactor Physics studies}

The completion of systems design tests on the High Temperature Lattice Test Reactor (HTLTR) were delayed because of excessive noise on signal and control leads and various minor problems in the horizontal control and vertical safety rod systems.

The Gas Analysis System and the building radiation monitors were accepted by Reactor Operations. A Project Punch List is being reviewed in anticipation of close-out of the Project.

The high temperature $(1000 \mathrm{C})$ test run of one oscillator was completed satisfactorily during the month. Additional test samples were removed and examined.

operating programs for the reactor control system and administrative documents are being completed satisfactorily. 


\section{REACTOR FUELS AND MATERIALS}

\section{Fast Fuels Oxides and Nitrides}

The time cycle for the synthesis of UN and PuN has been decreased significantly by more efficient equipment utilization.

A marked increase in grinding efficiency and, subsequently, the sinterability of the nitride powers, has been realized by optimizing ball-mill speed and using smaller diameter tungsten carbide balls as the grinding media.

An experimental mixed nıtride fuel pln, GEH-14-743, was discharged from the ETR after successful irradiation to $2000 \mathrm{MWd}$ / tonne. During irradiation the linear heat generation rate of the $\frac{1}{4} "$ OD $x$ " long fuel pin was $-33 \mathrm{kw} / \mathrm{ft}$, and the measured surface temperature was $750 \mathrm{C}$. Irradiation of two other nitride fuel pins operating under similar conditions in the MTR is continuing to scheduled exposures of at least 20,000 MWd/tonne.

Compatibility testing was begun on 304 stainless steel clad sodium-bonded and helium-bonded mixed UN - 20 wto PuN. Wetting of sodium on the nitride pellets appeared to be complete.

\section{Basic Swelling Studies}

Capsule P-I $4\left(700 \mathrm{C}, 500 \mathrm{ps}, 0.2-0.8\right.$ at. $\frac{\circ}{0}$ BU) was charged into a reactor and is operating as designed. Two other capsules continue to operate successfully, and construction is either complete or in the final stages on three other capsules.

Preliminary examination of specimens recovered from capsule $\mathrm{P}-15\left(700 \mathrm{C}, 1000 \mathrm{ps}, 0.2-0.8\right.$ at. $\left.\frac{\circ}{8} \mathrm{BU}\right)$ revealed little swelling or distortion.

\section{Nondestructive Testing}

A total of twenty-one test specimens for use in the development of an ultrasonic method for detecting radiation embrittlement in pressure vessel steels, have now been encapsulated, mounted in a multispecimen capsule, and sent to the ETR for exposure during cycle 90. (Twelve specimens were sent for inclusion in cycle 89 during Aprili.

Work to provide an EDPM program to produce ultrasonic pulse characteristics through the use of Kautz functions continued. Debugging of the Kautz function EDPM program was somewhat successful, and the algorithm for using the first pair of Kautz functions was verıfied. 
Development of a Laguerre polynominal generator, for use in analyzing pulsed eddy current signals, was initiated. Breadboarding of the first section was completed. An alternate arrangement of matrix element value adjustment potentiometers was conceived, and a breadboard was fabricated. Testing of both breadboards is in progress.

Observations of the interference resulting from a simulated ultrasonic surface reflection and the reflection from a simulated near surface defect were conducted. Signal processing circuitry to control the parameters associated with these simulated conditions was constructed.

Work is continuing on the development of a stable thermal transducer. A second unit was fabricated, and testing is in process. A prototype infrared imaging system design was initiated.

Studies to investigate the theoretical and practical aspects of eddy current sensing probe design and to beneficlally apply the information obtained continued. Specifically, the problem of the relationship of coil geometry to coll sensitivity was studied, and it was verified that colls having ID/OD ratios approaching 1 were most sensitive.

\section{Nuclear Ceramıcs}

Equipment and materials have been prepared for detalled study of the synthesis of nitrides by carbothermic reduction under nitrogen. A caustic fusion Kjeldahl method for nitrogen analyses is being developed.

The electrical conductivity of polycrystalline ThO2 was measured in a reducing atmosphere from 750 to $2780 \mathrm{C}$.

Transmission electron microscopy of sintered $\mathrm{UO}_{2}$ and pneumatically impacted $\mathrm{UO}_{2}$ showed well-defined grain boundaries, pores, and apparent inclusions and other defects. Cathodic etching resulted in fine striations and a granular surface structure.

Single crystal $\mathrm{UO}_{2}$ specimens were prepared and exchanged for use in basic studies and information exchange.

\section{Nuclear Graphite}

Approxlmately half the samples from the failed capsule, GEH-1313, are included in the current high temperature capsule, GEH-13-14, for irradiation in the ETR. Capsule assembly is complete, and a planned 3-cycle irradiation will begin in June. 
Two pins from the EBR-II graphite test were disassembled. All graphite specimens were in good condition after a peak exposure estimated at $1.5 \times 10^{22}$ nvt at $750 \mathrm{C}$. Two pins for thermocouple irradiations are at EBR-II ready for charging when space becomes available.

The long-term irradiation capsule H-3-15 is operating satisfactorily in the GETR. Two transverse NC-8 samples which had expanded $20 \%$ under high temperature 1 rradlation had no mechanical strength, whereas similar samples which had expanded only $2 \%$ had the same tensile strength as virgin material.

The H-3-25 graphite capsule is operating satisfactorily in the GETR. Discharge is scheduled for June.

Stored-energy measurements were completed on $\mathrm{NC}-7$ and $\mathrm{NC}-8$ graphite samples.

A comparison of structural features between two types of graphite microscopy specimens prepared by different mechanical techniques indicates that specimens prepared in the absence of forelgn materials are superior for oxidation measurements. Lacelike networks are produced during microwave-induced oxidation but not during thermal oxidation. Impurities appear to possess considerable mobility and tend to cluster during oxidation

\section{Irradiation Damage to Reactor Metals}

Arrangements to procure quantities of FV-548, Inconel 625, and In-102 alloys for program research are continuing.

Analysis of the disassembled GEH-22-3 liquid metal capsule has revealed means for improving capsule design.

The Zener-Holloman parameter obeys a power law relationship with stress for both in-reactor and out-of-reactor creep data for 304 stain less steel over the temperature range of 500 to $900 \mathrm{C}$. A slight deviation in this relationship is observed below $500 \mathrm{C}$.

Tensile data for AISI 316 stainless steel irradiated to about $1.38 \times 10^{21} \mathrm{n} / \mathrm{cm}^{2}$ ( $\mathrm{E} 1 \mathrm{MeV}$ and tested at temperatures to $750 \mathrm{C}$ have been obtained. Analysis of the data for both unirradiated and irradiated specimens is in progress.

The hydrogen effusion characteristics of carburized 18-8 type stainless steel have been investigated and are found to be essentially unaffected by the presence of a carbide layer on the hydrogen desorption surface. 
Stress-rupture tests at $1350 \mathrm{~F}(732 \mathrm{C})$ on specimens of Inconel600 and Inconel X-250 irradiated at $540 \mathrm{~F}(732 \mathrm{C})$ to a fast fluence of $1 \times 1020 \mathrm{n} / \mathrm{cm}^{2}$ ( $\mathrm{E}, 1 \mathrm{MeV}$ ) indicate a reduction by about one-third in rupture life.

Stress-rupture tests at $1350 \mathrm{~F}(732 \mathrm{C})$ on unirradiated specimens of Hastelloy $\mathrm{x}-280$ indicate that thermomechanical treatments increase rupture life by reducing creep rates.

Six of eleven participants in the dosimetry intercalibration program have submitted results. The spectrum in the MTR Rabbit Facility used to irradiate the calibration specimens used for this program has been calculated and forwarded to all participants.

Titanium and niobium corrosion specimens exposed four cycles in the ETR G-7 loop are undergoing postirradiation examination.

Examination of size effects with respect to fracture toughness in A302-B pressure vessel steel using the DCB specimen geometry is nearing completion. Because of the large through-the-thickness toughness gradient which has been observed in the plate, considerable difficulty has been encountered in obtaining unambiguous results concerning size effects. There are indications, however, that when a through-the-thickness toughness profile exists, the tougher portions of the material control the fracture strength.

Fracture toughness was not observed to differ significantly for hydrogen levels of 50, 100, and $400 \mathrm{ppm}$ in $\mathrm{zircaloy}-2$ irradiated to $3 \times 10^{20} \mathrm{n} / \mathrm{cm}^{2}$ (E $1 \mathrm{MeV}$ in the ETR G-7 loop.

Design work on 321-A Building renovation and installation of support facilities is approximately $30 \%$ complete. The support system for flowing sodlum test loop will be shipped from the vendor during the last week of May. The use of a commercial solvent, Dowanol "EB," has been shown to be safe and effective for removing sodium from specimens and equipment.

Corrosion samples exposed at temperature for times to 1930 hrs in the ATR model loop continue to show the welght change trend previously reported. Contamination of niobium and niobium alloys is due to oxygen and carbon as major contaminants and nitrogen as a minor contaminant. The carbon is in the form of surface carbide layers, while the oxygen is dissolved in the metal. Contamination of pure niobium results in increased strength and reduced ductility. $\mathrm{Niobium-1 \%}$ zirconium exhibits less strengthening than niobium, but about the same reduction in ductility. Niobium alloy Nb 752 (Nb$10 \mathrm{~W}-2.5 \mathrm{Zr})$ undergoes a drastic reduction in ductility as a result of contamination. The nickel alloys Hastelloy $X$ and Incoloy 800 are oxidized during exposure in the vertical test section of the model gas loop. 
Gas temperatures and maximum specimen temperatures in the ATR helium loop test section were calculated for an assumed gammaheating profile. Calculations were made for two representative test assemblies, at helium flow rates of $2000 \mathrm{lb} / \mathrm{hr}$ and $4000 \mathrm{lb} /$ hr, with inlet temperatures of $1200 \mathrm{~F}, 1500 \mathrm{~F}$, and $1800 \mathrm{~F}(648 \mathrm{C}$, $815 \mathrm{C}$, and $982 \mathrm{Cl}$.

The model gas loop has operated a total of 3929 hrs since installation of the new heater; this includes 521 hrs during the past month.

A quantitative correlation between the increase in yield stress and the density of defect clusters observed by transmission electron microscopy has been found. The mechanism is based on orowan's model of precipitation hardening where the stress to bow a loop between clusters is given by $=i b(N d) 1 / 2$ where $N$ is the volume density of clusters and $d$ is the cluster diameter. Experiments are under way to quantitatively verify this relation.

Experiments to resolve the role of carbon in damage recovery in iron in the temperature range $25 \mathrm{C}$ to $350 \mathrm{C}$ have been initiated. Much confusion exists in the literature at present as to whether vacancles or carbon atoms are moving in this temperature range.

A paper describing studies of radiation damage by the techniques of thermally activated flow was presented at the Battelle Colloquium on Dislocation Dynamics held May $1-6$ at Harrison Hot Springs, Canada.

\section{ATR Gas Loop Operation and Maintenance}

Contract submittals for the ATR gas loop are being reviewed and comments issued to the architect-engineer. Review of the vendor data has uncovered discrepancies in areas of section III analysis and final operation of the units. These problems are being resolved with the successful bidders.

Work is progressing on developing adequate inspection techniques for the analytical system and other critical components of the ATR gas loop.

Metalinc Fuels Development

Three Th - 2.5 wto U - 1.0 wto $\mathrm{Zr}$ fuel elements continue their irradiation in the $\mathrm{P}-7$ hot water loop at the ETR. Exposures range from 8400 to 18,100 MWd/tonne with corresponding volume increases from 0.9 to $3.5 \%$. 
Hollow core uranium fuel elements have been successfully irradiated in the ETR $M-3$ hot water loop facility to a maximum exposure of $4123 \mathrm{MWd} /$ tonne. All elements continue to show a slight volume decrease although no significant change in diameter can be detected on visual examination in the ETR basin. Eight fuel elements, irradiated to a maximum exposure of 2675 MWd/tonne, have been shipped to the Battelle Research Reactor for neutron radiography to help determine the character of the internal axial hole.

\section{ENGINEERING DEVELOPMENT}

Neutron Flux Monitors

Fabrication of the test assembly for the improved U-234 U-235 regenerative thermal neutron flux detectors and other detector types commenced following acquisition of all ten sensors.

Microwave and Infrared Detection of Coolant Impurities and Measurement of In-Reactor Temperatures

To achieve improved high temperature performance on the experimental microwave system for measuring moisture in reactor coolant helium gas, development of heterodyning and oscillator stability techniques was initiated.

\section{Upstream Boiling Burnout}

Analysis of data recently obtained with an electrically heated test section 0.435 inch ID and 70 inches long was continued. These data showed that the existence of upstream boiling burnout requires that the deposition rate of droplets from the central core of the annular two-phase flow pattern be an increasing function of coolant enthalpy. Several tentative explanations for this behavior were proposed and evaluated.

\section{PLUTONIUM UTILIZATION PROGRAM}

Fuels Development

Gamma and $\mathrm{x}$-ray spectra analysis measurements are being made at monthly intervals on Shippingport and Yankee plutonium samples to determine the Am-241 growth in the high exposure recycled plutonium. Gamma, x-ray surface dose rates are also being measured on Shippingport $\mathrm{PuO}_{2}$ to correlate the Am-24l build-in to the total dose rate 
from the $\mathrm{PuO}_{2}$. Both surface dose rate and neutron yield measurements were also made on Shippingport plutonium metal.

Isotopic analyses are continuing, with the Yankee fuel samples essentially completed, and work was started on 20 \% $\mathrm{PuO}_{2}-$ $\mathrm{UO}_{2}$ mixed oxide fuel from the EBR-II. Plutonium from Dresden fuel was also received and is ready for analyses.

The underwater profilometer, for inspecting FERTF fuel rods, will be delivered on plant at month's end.

The underwater tray for the assembly of FERTF fuel elements has been installed in the PRTR basin.

Four fuel rods instrumented to measure fuel rod gas temperature and pressure are operating satisfactorlly in PRTR.

An intentionally defected, Zircaloy-clad, 7-rod cluster (approximately 33 inches long) was fabricated and sent to the ETR for irradiation testing in the $\mathrm{P}-7$ loop.

Six fuel capsules containing vibrationally compacted $\mathrm{UO}_{2}$ (5.01\% U-235 enriched) were fabricated and shipped to NRTS for irradiation testing in TREAT. Two of the capsules were subjected to transient irradiations.

Three vibrationally compacted HPD fuel rods were destructively examined after irradiation in PRTR at maximum linear rod power generations of $16.8,17.0$, and $17.9 \mathrm{kw} / \mathrm{ft}$, respectively. A $19-$ rod cluster element containing hot pressed $\mathrm{UO}_{2}-2$ wto $\mathrm{PuO}_{2}$ pellet fuel has been irradiated in the FERTF to an average burnup of approximately $300 \mathrm{MWd} /$ tonne with maximum fuel temperatures of about $2500 \mathrm{C}$. A thin crud deposit has been observed on the surfaces of HPD elements irradiated in PRTR during some fuel examinations. A prototype FERTF test element is undergoing long-term fretting and wear tests in EDEL loop.

\section{Reactor Physics}

Reactivity and power distribution calculations have been performed for two-zone loadings of $\mathrm{Th}-3.7$ wt\% $\mathrm{U}-235$ and $\mathrm{UO}_{2}-2$ wt\% $\mathrm{PuO}_{2}$ in the PRTR.

Final analysis of the data from moaerator level coefficient, boron worth and sensitivity, and loss of coolant measurements in the Batch Core loading in the PRTR has been completed.

Calculations have been made to estimate the effect of fuel rod. bowing in the 8-rod FERTF element. 
Analysis of the reactivity oscillator experiments in PRTR has produced a value of the prompt neutron lifetime (i) which is in good agreement with earlier calculated values.

The use of isotopic dilution techniques with Nd-148 to determine fuel burnup has begun. Initial comparisons with the older Cs-137 methods are inconclusive.

Analysis of fuel burnup in $\mathrm{UO}_{2}$ fuels irradiated in the PRTR is progressing. Differences in cross section ratios due to spectral changes between rings of rods in the 19-rod clusters have not been detectable.

Because commercial procurement of $\mathrm{PRCF}$ test rods could not be accomplished during FY-1967, approximately 250 rods are being fabricated onsite. Offsite commercial procurement to obtain the balance of the rods during FY-1968 is now being completed.

As a result of recent development work, emphasis on preparation of $\mathrm{PuO}_{2}$ spheres has been changed from pneumatic-impaction and jetmilling to arc-fusion and induction-plasma spheroidizing.

Experiments in the PCTR with $\mathrm{PuO}_{2}$ particles prepared by pneumatic-impaction and jet-miling show a general decrease in reactivity with increasing particle sizes from $0,100,200,350$ microns. The data from the zero micron size do not seem to be consistent at present with the data from the larger sizes.

Recent changes in BARNS-II to permit numerical integration of resonance region contributions to group cross sections are still being debugged.

Programs received from Brookhaven recently have been compiled and are now on tapes. Program ETOM has been successfully executed for the isotope lithium-6.

Program RIFF RAFF has been converted for use on the Univac 1108.

A computer code, PLTAPE, has been written to generate a plotting tape with the output of the neutron scattering code, NUTSCAT.

Extra statistical uncertainty is introduced by the method used to account for absorption in the RBU Monte Carlo code.

A computer program has been written which determines the deadtime of a counting system using counting data from a decaying isotope. 
Materials Development

An examination of a sample of lon exchange resin from the PRTR primary system failed to explain the pressure drop observed on the bed in use.

Postirradiation examination of PRTR process tube 5690 indicates that accelerated oxidation occurred on the inner tube surface.

\section{Test Reactor Operation}

The PRTR operated to 57 MW to produce 518 MWd during May. Reactor power was limited to temporary fuel element rod power limits of $16.8,17.7$, and $18.6 \mathrm{kw} /$ it for PRTR Test 136-l. During the startup of 5/9/67, a primary flow measurement discrepancy caused an actual power of $58 \mathrm{MW}$ and a speciflc fuel rod power of $19.2 \mathrm{kw} / \mathrm{ft}$ for a short time. PRTR Test 136-l was interrupted to replace a fuel rod in the test element and to continue the test at $18.6 \mathrm{kw} / \mathrm{ft}$.

The total exposure for the PRTR is 754 MW of which 641 MW have been accumulated by the 55 fuel element batch core.

Solıds (crud) levels in the primary system continued under good control with pH 7 operation. The concentration of crud in the primary coolant system is less than $0.5 \mathrm{ppm}$.

An interlock has been installed between the moderator level and the shutdown valve to provide a positive moderator level limitation of less than 104 inches.

\section{EBWR Demonstration Program}

The first shipment of fuel irradiated in the EBWR has been recelved at $\mathrm{PNL}$.

\section{NUCLEAR SAFETY}

\section{Contalnment Systems Experiment}

Recent data from alr leakage rate tests were analyzed to investigate the variation of leakage rate with test pressure. Individual leaks showed a variation close to that expected with laminar flow in the leak path with one exception. Test results at low and intermedlate test pressures were extrapolated to the maximum test pressure. by means of a formula based on laminar flow. Agreement of extrapolated and observed results was reasonably good. 
A small scale containment test was performed, primarily to expose painted coupons to a mixed aerosol containing iodine, cesium, and ruthenium. The coupons are being used to evaluate pressure spray solutions for decontamination of the containment vessels. Results of samples from this run were retrieved, sorted, and tabulated by the computer controlled data acquisition system.

An analysis was performed to evaluate the necessity of providing large recirculating pumps on the CSE reactor simulator to accurately simulate coolant motion prior to a primary system rupture. It was determined that this coolant motion would not have a measurable effect on the blowdown rate of a typical BWR, and, therefore, it was concluded that the addition of large recirculating pumps to CSE would not be necessary for valid results to be obtained from blowdown studies.

Paint compatibility studies with various candidate containment system decontamination reagents show that solutions of sodium lauryl sulfate, N-lauryl myristyl-B-aminopropionic acid, OPG, and Turco 4521, cause no surface changes in seven hours at $80 \mathrm{C}$.

\section{Pressure Vessel Crack Monitoring}

The effort to detect and classify flaw growth in reactor pressure piping continued. Four additional burst tests were conducted, and the resulting data prepared to be sent to the Naval Laboratory at Corona, California, for reduction.

The market survey of the low noise preamplifiers was concluded with the selection of a very good unit.

Transducer fabrication is proceeding, and one three-layer unit is under test. Material to fabricate high temperature lithiumniobate ( $1000 \mathrm{~F})$ transducers has been ordered.

\section{Fission Product Aerosol Containment}

Two additional spray removal runs were performed using the 3. 6 cubic meter spray chamber. A significant observation was that the fraction of liquid delivered to the wall of the total sprayed was virtually as effective as that delivered as droplets, volume for volume.

Initial measurement of the partition coefficient of methyl iodide at $50 \mathrm{C}$ was $(11.4$ for a methyl iodide concentration of $2 \times 10^{-7} \mathrm{M}$. This was in reasonable agreement with early estimates made by workers in England. 
Columbia River Sedimentation Studies

Routine sampling and radiochemical analysis of Columbia River water and sediment at Beaver Army Terminal and at Astoria is scheduled to begin June 1967 .

\section{Disposal of Reactor off-Gas into Soll Systems} NRTS .

Plans were made for modeling the chosen injection site at

\section{Geophysical Exploration of Rattlesnake \#l Well}

Reopening and reconditioning of the Rattlesnake \#I Well began on May 29.

\section{Simulation Modeling of Expected Thermal Generation in Selected River Systems}

Statistical evaluation of the effects of Dresden Two and Three on the Illinois River indicate approximately 50\% equilibration of the heat release at the point of 47 miles downstream.

\section{Radioactive Waste Solidification}

A WSEP spray solidification run successfully filled an 8-inch diameter pot containing $2 \mathrm{kw}$ of radioheat. Inspection after use of an internal mix spray nozzle revealed no excessive deposits inside of the calciner.

The last design verification test was completed with the phosphate glass process. Reasonable success was achieved for the first time with a PW-1 flowsheet. The equipment is being prepared for cell installation.

Progress on the Solids Storage Engineering Test Facility is satisfactory. 
DIVISION OF REACTOR DEVELOPMENT AND TECHNOLOGY PROGRAMS (F. W. Albaugh)

\author{
CIVILIAN POWER REACTORS
}

Liquid Metal Fast Breeder Reactor (R.E. Nightingale)

Stoichiometry Effects in oxide Fuels

Part I: Oxygen Redistribution and Power Rating Required for Melting in Partıally Molten $\mathrm{UO}_{2} \pm \mathrm{x}$. Effects of variations in volume ratios of molten fuel to solid tuel on oxygen distribution and integrated thermal conductivity to melting in $\mathrm{UO}_{2} .02, \mathrm{UO}_{2} .05$, and $\mathrm{UO}_{2} .15$ were investigated analytically. The method employed the solidus-liquidus curves derived from previous measurements of oxygen redistribution in these materials during molten-center irradiation and published results on excess oxygen effects on $\mathrm{UO}_{2}$ thermal conductivity. The model considered oxygen depletion of the solid as the oxygen-enriched liquid region increased in size until the nominal solid composition reached $\mathrm{UO}_{2} .00$. As the molten zone increased beyond this point, the only effect was to reduce the $O / U$ ratio of the liquid. As oxygen depletion of the solid takes place, the thermal conductivity increases. The integrated conductivity to melting thus varies as a function of melt radius from a minimum with zero melting to that for $\mathrm{UO}_{2} .00$ at some finite melt radius. Results of the calculations showed as much as $50 \%$ variation in the conductivity integral to melting (for $\mathrm{UO}_{2}$.15) depending upon extent of melting. The procedure also yielded an independent computation of the extent of melting which should have existed in $\mathrm{UO}_{2}+\mathrm{x}$ specimens previously irradiated. Results agreed fairly well with observations.

The final report covering this phase of this work was completed and is being prepared for publication. The final draft of a topical report on convection heat transfer in molten center fuels was approved and returned to Technical Publications for duplicating and distribution.

Part II: Oxygen Redistribution in UO $2 \pm x$ Fuels Operating Without center Melting. Irradiation specimens containing VO1.90, V02.00, $\mathrm{UO}_{2} .02$, $\mathrm{UO}_{2} .05$, and $\mathrm{UO}_{2} .15$ were pneumatically impacted in integral stainless steel sheaths. These were subsequently machined to final shape and end plugs welded in place. Specimens will be irradiated at nominally $21 \mathrm{kw} / \mathrm{ft}$ during May.

Part III: Stoichiometry Effects in $\mathrm{UO}_{2}-\mathrm{PuO} 2$ Fuels. The initial series of six comparative irradiations, designed to measure the effects of varying $\mathrm{O} / \mathrm{M}$ between 1.92 and 2.00 on the power rating required for melting in $\mathrm{UO}_{2}-25$ wto $\mathrm{PuO}_{2}$, is in progress. Fuel delivery was delayed by failure of the sintering furnace. Delivery 
during May with irradiation in early June is still possible. All nonfissile hardware, including brackets, sheaths, and end plugs, were fabricated. A production test was processed by DUN, and approval to irradiate was granted.

Nuclear Systems and Concepts Analysis (E.A. Eschbach)

Systems Analysis Task Force Activities

Most of the May effort was devoted to completing debugging of various codes and setting up the following cases to represent final Phase II calculations:

1. LWR with enriched uranium.

2. LWR with enriched uranium and full plutonium recycle.

3. LWR with enriched uranium and LMFBR.

4. LWR with enriched uranium and MSBR.

5. LWR and HWOCR with enriched uranium.

6. All reactors.

7. All reactors and fossile plants.

The cases include discounting at six percent, the condensed matrix, two load factor histories for each plant, modified fossil cost regions, and relaxed reactor introduction restraints. All cases except (7) do not consider fossil plants.

Modification to LPOUT has been delayed due to PACTOLUS difficulties which have been overcome. The portion of IPOUT that reads and processes PACTOLUS information has been keypunched. Core limitations are becoming a problem and with the expanded reactor codes will necessitate using the drum as scratch storage.

Work will soon be completed on revisions to Fossil Fuel Plant capital costs. It is hoped that through redefinition of fuel cost areas, a more definitive fossil plant can be represented. Redefinition of fuel cost area requires revising the projections of electrical demand. 


\section{On Fast Reactor Diffusion Theory Leakage}

In reactor calculations involving a significant number of fast groups, the elastic scatter is extremely nonisotropic with respect to energy group to group transfers. If one sets down the Boltzmann neutron transport equation and attempts to reduce it in some approximation to a multigroup diffusion equation, difficulties are encountered which make the approximation quite poor in some cases. The alternative usually suggested in the literature at this point is an "exact" Pl approximation. In fact, however, one can get exact $\mathrm{Pl}$ behavior in what still constitutes essentially diffusion theory since the quantity of interest from Pl theory is primarily only the net leakage rather than the three current components in some representation.

Exactly equivalent to the Pl equations, the transport equation may be written in terms of the scalar flux or the zeroth angular moment of the vector flux and the vector current or the first angular moment of the vector flux. How this is reduced depends upon the result's intended use. If preserving the reaction rate is more desirable than getting the "best" estimate of $k$, the multiplication constant, then it is desirable to integrate over the desired energy group structure using a unit weight function. This is what is done most frequently.

The key point to be made is that exact $P l$ behavior is obtained with a level of effort in between full Pl calculations and diffusion calculations. The new terms are a function of only the groups of lower index than the group in question. Hence, by starting at high energy, one may work directly down to the desired net leakage for a given energy group. 


\section{Conceptual Reactor Design Stuâles (J.C. Fox)}

$\underline{\text { Steam-Cooled Fast Reactor }}$

The revised set of parametric cases as shown in the first table was completed, using the ORNI cross sections. These results have not yet been fully analyzed; however, the enrichments needed to achieve 50,000 MWd/tonne average batch burnup and the resulting breeding ratios are tabulated in the second table.

The values of initial reactivity needed to achieve 50,000 MWd/ tonne batch burnup were determined by carrying out burnup calculations with a point model code using the 26-group Russian cross section set as modified by Little, Hardie, and Maas.(1) This determination was carried out for the 80001 cases and assumed to also hold for the 60001 and 10,0001 cases. Only case oa breeds to the extent that $\mathrm{k}$ continues to rise at 50,000 MWd/tonne. At that point the $k$ is 1.04 which is well within reason. The final $k$ for all other cases is 1.01. These initial $\mathrm{k}$ requirements are used to select as initial enrichment from the ORNL cross section parametric survey. The Russian set was used because it was available in an automated system. Current calculations are studyıng the effect on initial k required of using the Russian set rather than the ORNL data.

\section{Parametric Cases Covering Steam-Cooled Fast Reactors}

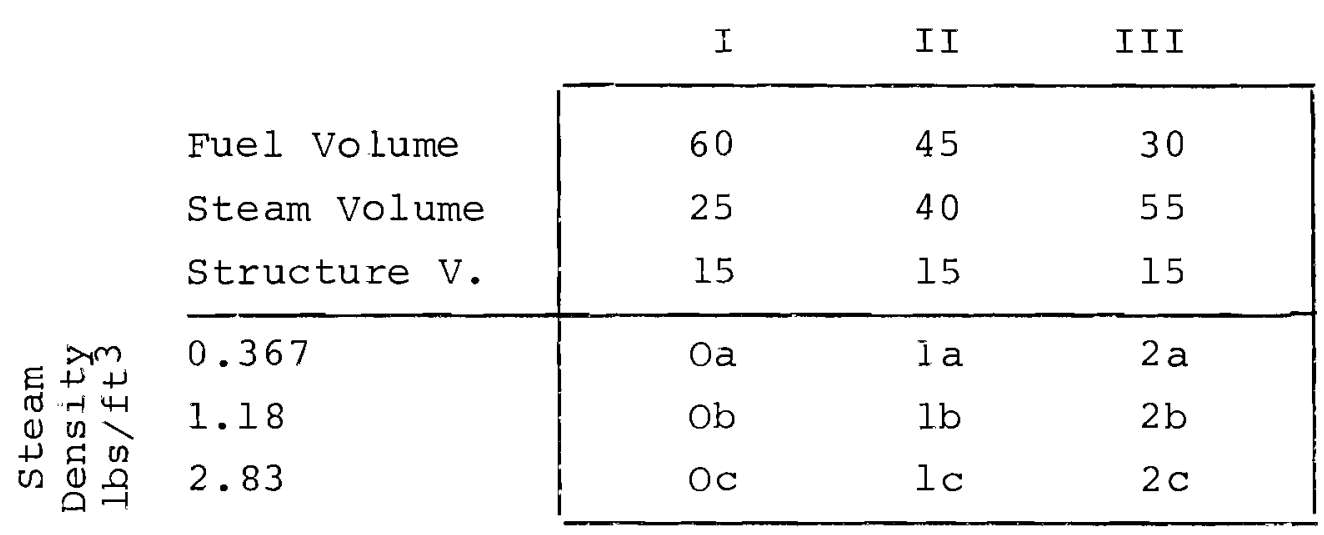

Calculations now under way, which will be completed by the June 2 lst meeting in Oak Ridge, include 2D effects, rod size effects, and sensitivity to cross section set determinations.

(1) BNWL-347. 
Steam-Cooled Fast Reactor--

Enrichment to Achieve 50,000 MWd/tonne Average Burnup

\begin{tabular}{|c|c|c|c|c|c|c|}
\hline Size & & Case & $\mathrm{k}_{\text {Initial }}$ & Enrichment & $\begin{array}{c}\text { Breeding } \\
\text { Ratio } \\
\end{array}$ & $\begin{array}{c}\text { Breeding } \\
\text { Ratio }\end{array}$ \\
\hline 6,000 & $x$ & $\mathrm{Oa}$ & 1.01 & 11.70 & 1.170 & 1.385 \\
\hline 8,000 & e & $\mathrm{Oa}$ & 1.01 & 11.40 & 1.195 & 1.380 \\
\hline 10,000 & $\hat{x}$ & $\mathrm{Oa}$ & 1.01 & 11.25 & 1.215 & 1.385 \\
\hline 6,000 & $\ell$ & $\mathrm{Ob}$ & 1.013 & 11.70 & 1.070 & 1.250 \\
\hline 8,000 & $\ell$ & $\mathrm{Ob}$ & 1.013 & 11.40 & 1.100 & 1.247 \\
\hline 10,000 & e & $\mathrm{Ob}$ & 1.013 & 11.25 & 1.110 & 1.242 \\
\hline 6,000 & 2 & Oc & 1.064 & 13.10 & 0.855 & 0.975 \\
\hline 8,000 & ¿ & OC & 1.064 & 12.70 & 0.882 & 0.975 \\
\hline 10,000 & $\ell$ & Oc & 1.064 & 12.60 & 0.880 & 0.987 \\
\hline 6,000 & $\hat{\imath}$ & $1 a$ & 1.016 & 13.50 & 1.005 & 1.300 \\
\hline 8,000 & $\dot{x}$ & $1 a$ & 1.016 & 13.10 & 1.040 & 1.278 \\
\hline 10,000 & $\ell$ & $1 a$ & 1.016 & 13.05 & 1.040 & 1.250 \\
\hline 6,000 & $\ell$ & 1b & 1.047 & 14.50 & 0.860 & 1.065 \\
\hline 8,000 & $\ell$ & $1 \mathrm{~b}$ & 1.047 & 14.10 & 0.885 & 1.055 \\
\hline 10,000 & $x$ & $1 b$ & 1.047 & 13.75 & 0.905 & 1.065 \\
\hline 6,000 & $\dot{x}$ & $1 \mathrm{c}$ & 1.050 & 14.70 & 0.760 & 0.91 \\
\hline 8,000 & x & $1 \mathrm{C}$ & 1.050 & 14.50 & 0.760 & 0.88 \\
\hline 10,000 & $\ell$ & $1 \mathrm{c}$ & 1.050 & 14.10 & 0.790 & 0.89 \\
\hline 6,000 & $\ell$ & $2 a$ & 1.077 & 19.60 & 0.670 & 0.975 \\
\hline 8,000 & $\ell$ & $2 a$ & 1.077 & 18.65 & 0.710 & 0.975 \\
\hline 10,000 & $\dot{x}$ & $2 a$ & 1.077 & 18.05 & 0.735 & 0.980 \\
\hline 6,000 & $\ell$ & $2 b$ & 1.107 & 21.10 & 0.57 & 0.765 \\
\hline 8,000 & $\chi$ & $2 b$ & 1.107 & 20.05 & 0.605 & 0.785 \\
\hline 10,000 & c & $2 \mathrm{~b}$ & 1.107 & 19.40 & 0.635 & 0.785 \\
\hline 6,000 & $\ell$ & $2 \mathrm{c}$ & 1.138 & 23.00 & 0.48 & 0.66 \\
\hline 8,000 & $\hat{x}$ & $2 c$ & 1.138 & 22.2 & 0.52 & 0.65 \\
\hline 10,000 & $\ell$ & $2 \mathrm{C}$ & 1.138 & 21.6 & 0.54 & 0.65 \\
\hline
\end{tabular}


The portion of the design simulation which penalizes the cycle efficiency for the work done by the steam circulator has been revised. The amount of work required for an isothermal compression process between the inlet pressure of the circulator and the core inlet pressure has replaced the previous analysis. The new approach is simpler than the old, and the new pumping power values check reasonably well with the specific designs.

The methods used to determine the helium prepressurization necessary in the fuel pins, to prevent the clad from collapsing and to size the fission gas plenum at the end of the fuel pin, were changed. The new analysis is more rigorous and should yield better comparisons between existing SCFR designs and those generated in the PNL parametrıc study.

For a given clad $O D$ and thickness, the helium prepressurization is determined from an elastic buckling analysis of the cladding. The allowable stress, in this case, is the unirradiated $0.2 \%$ offset yleld strength of Inconel 625 at $1300 \mathrm{~F} / 700 \mathrm{C}$. A maximum initial ellipticity (maximum clad OD minus minimum clad OD) of 0.002" was assumed for the cladding.

The fission gas plenum is then sized such that the primary stress in the clad will not cause a rupture in twice the time the clad will be in tension. Unirradıated stress-rupture properties of Inconel 625 at $1300 \mathrm{~F}(700 \mathrm{C})$ are used as allowable stresses in this analysis. A factor of two is applied to the necessary time to rupture to estimate the effects of Irradiation.

The new calculations are currently being debugged before inclusion in the MIMIC design simulation of the SCFR.

Additional limited sensitivity studies have been performed to identify other problem areas in the design simulation before extensive studies must be run.

Thermal Sink Limitation Study

Gross heat capacity (1.e., the amount of heat required to raise the temperature of the stream $1 \mathrm{~F}$ ) calculations have been completed for the major streams in the North Atlantic Slope Basins, Maine to Connecticut.

Streams studied in this area are the Androscoggin, Connecticut, Kennebec, Merrimac, Penobscot, and St, John Rivers. 
HTGR Graphite (R.E. Nightingale)

Graphite Surface Area Measurements

As a result of the accident which necessitated the replacement of the GEH-13-13 capsule, it was possible to perform interim surface area measurements on four of the graphite samples before they were installed in a new capsule. These samples had received an exposure of about $0.7 \mathrm{x} 1021$ nvt ( $\mathrm{E} 0.18 \mathrm{MeV}$ ) at a temperature of $875 \mathrm{C}$. No weight change occurred, and so the surface area results are unaffected by oxidation. However, the length of the samples had contracted on an average of about $0.1 \%$. The surface area changes are tabulated below.

\begin{tabular}{lcc}
\multicolumn{1}{c}{ Samples } & Initial $\mathrm{c}, \mathrm{m}^{2} / \mathrm{g}$ & Final $\sigma, \mathrm{m}^{2} / \mathrm{g}$ \\
$234-304$ & 0.488 & 0.441 \\
$66-12-203$ & 0.283 & 0.275 \\
$66-9-212$ & 0.290 & 0.290 \\
NC8-358 & 0.509 & 0.509
\end{tabular}

The surface area changes which occurred during this irradiation were very small.

USAEC-AECL Cooperative Program (J.J. Cadwel1)

In-Reactor Measurements of Creep in Zr-2.5 Nb Alloy

Uniaxial creep tests performed on longitudinal sections of pressure tube material at $31.6 \mathrm{Kg} / \mathrm{mm}^{2}(45,000 \mathrm{psi})$ and $300 \mathrm{C}$ have resulted in a faster in-reactor creep rate than the corresponding creep rate for the unirradiated control specimen. The in-reactor minimum creep rate was $2 \times 10^{-4} \mathrm{hr}^{-1}$ whereas the control creep rate was $3 \times 10^{-5} \mathrm{hr}^{-1}$. The strain prior to the onset of third stage creep was greater than 6\%. The in-reactor specimen ruptured in 163 hrs, while the control specimen is still in test after 1500 hrs.

\section{Cross-Flow Mixing Between Parallel Flow Channels During Boiling}

The purpose of this combined analytic and experimental program has been to develop methods of predicting cross-channel mixing during two-phase flow in rod bundle fuel elements. This cross-channel mixing is important in the analysis of fuel element performance and in the determination of possible boiling burnout conditions for cluster-type fuels. A report describing the analytic phase of this program has been issued, and the first unrestricted distribution was made on May 17. The title of this report is "Cross-Flow Mixing Between Parallel Flow Channels During Boiling - Part I - COBRA - Computer Program for Coolant Boiling in Rod Arrays," (BNWL-37l Pt 1). 
A report describing the first part of the experimental phase of this program is currently under preparation. In this part, an electrically heated test section was considered that simulated two subchannels formed by rods on a square array located adjacent to rods on a triangular array. Measurements were made of subchannel flow rates and exit enthalpies, and this information was used to determine mixing durlng boiling. This report will be issued as BNWL-371 Pt 2 .

Evaluation of Zirconium-2.5\% Nb Pressure Tubing

The general objective of this program is to evaluate $\mathrm{Zr}-2.5 \mathrm{Nb}$ as a pressure tube material with reference to the tests and reactor experience that has been obtained on Zircaloy-2 pressure tubes.

Crack propagation tests were completed on slotted test specimens which have been heat treated and then hydrided to a uniform hydrogen concentration of about $300 \mathrm{ppm}$. (The heat treatment given these test speclmens prior to hydriding 15 as follows: water quench from $880 \mathrm{C}$, cold work $15 \%$, and age at $500 \mathrm{C}$ for $24 \mathrm{hrs}$. The aging time was modified by use of a Larson-Miller equation to take into account the time at temperature (about $50 \mathrm{hrs}$ at $400 \mathrm{C}$ ) required for hydriding.' The hoop stress at fallure for specimens with slots $1 / 2, L \frac{1}{2}, 2 \frac{1}{2}$, and 4 inches in length were $100,000 ! 1 / 2 "$; $\left.39,000\left(1 \frac{1}{2}\right) ; 10,000\left(2 \frac{1}{2}\right) ; 4,20014 "\right) ;$ and 16,800 (4") psi, respectively. Comparable heat treated specimens in the unhydrided condition with slots of $1 / 2,1 \frac{1}{2}, 2 \frac{1}{2}$, and 4 inches in length were $32,000\left(1,2 ": ; 38,000\left(1 \frac{1}{2} "\right) ; 29,000\left(2 \frac{1}{2} "\right) ;\right.$ and $13,000(4 ")$ psi, respectively.

Comparison of these hoop strengths at fallure for the hydrided and unhydrided conditions show that hydriding ärastically reduced the hoop strength for all slot lengths except the 4-inch long slot. In the case of the 4-inch long slot, the hydrided condition exhibits as great or greater resistance to fallure and crack propagation than does the unhydrided condition.

Three heat treated speclmens were pressuce cycled to produce fatigue failure. The heat treatment given these test specimens consisted of water quenching from $880 \mathrm{C}$ followed by $15 \%$ cold working and aglng at $500 \mathrm{C}$ for $24 \mathrm{hrs}$. In all three tests the amplitude and peak hoop stresses 10 to 23,000 psl) were the same. Each test specimen contained an artificlal flaw produced by electrical discharge machining on the outside surface. The electrical discharge miled (EDM) slots were semiclrcular in shape with a maximum width of $0.010 \mathrm{inch}$. The radil of the EDM slots tested were 0.075 inch, 0.100 inch, and 0.125 inch respectively. In these three tests leakage of the tubular test plece occurred at a crack length of about 0.41 inch as measured at the outside surface. Fallure occurred at fatigue crack lengths ranging from about 1.08 to 1.4 
inches. Calculated stress intensification factors for "throughwall" cracks ranged from about 84 to $115 \mathrm{ksi} \sqrt{\mathrm{in}}$. Tests with semicircular slot radii of 0.050 inch and 0.025 inch are now under way.

\section{APPLIED AND REACTOR PHYSICS}

\section{Plutonium Criticality Studies (E.D. Clayton)}

Integral Neutron Spectra Measurements in Heterogeneous Plutonium Fueled Assemblies

Analysis of data from activation measurements has continued. The data being analyzed were obtained from previous irradiations with small pins of $\mathrm{Mn}$, In, and $\mathrm{Pu}$ in plutonium fueled assemblies. The critical assemblies were comprised of alternate slabs of $\mathrm{PuO}_{2}-$ polystyrene and Plexiglas. The DTF IV Code, with multigroup constants from GAMTEC-II, was used to calculate reaction rates for the slab reactor consisting of alternate layers of 2 -inch thick $\mathrm{Plexiglas}$ and fuel bearing material (average $\mathrm{H} / \mathrm{Pu}$ of core - 35). These calculations were found to be in poor agreement with the measured activities for manganese. The results indicated the slowing down power of Plexiglas to be overestimated by treatment of hydrogen under the free gas model. Attempts are being made to improve the calculations through use of data on scattering obtained from the Evaluated Nuclear Data File (ENDF). The scattering cross sections are currently being placed in the GAMTEC-II library for further evaluation.

The calculated Pu-239 fission activity, based on the normalized Sher (62) Pu thermal cross sections, was in agreement with the measured values except at the Plexiglas-fuel interface, indicating the need for more refined methods of calculation at the moderator-fuel boundary.

Experiments were continued in support of the Gas-cooled Fast Reactor (GCFR) program. The main purpose of the experiments has been to determine if resonance or thermal absorbing material need be incorporated in the GCFR fuel elements to control accidental entry of steam and/or water into the core. The experiments being done for General Atomic make use of existing fuel and are part of the GCFR critical experiment program.

A series of measurements for determining intracellular flux distributions and flux spectra indices were performed during the month with $\mathrm{Mn}$, In, Pu-239, and U-235. The following kinds of irradiations were made: 
1. Irradiations of $\mathrm{Mn}$ and In pins in bare homogeneous assemblies with $\mathrm{H} / \mathrm{Pu}=5$, contalning $\mathrm{Gd}_{2} \mathrm{O}_{3}$ poison layers.

2. Irradiations of $M n$ and In pins in heterogeneous assemblies comprised of layers of fuel and moderator (average $\mathrm{H} / \mathrm{Pu}-8$ ) contalning $\mathrm{Gd}_{2} \mathrm{O}_{3}$ polson layers.

3. Pu-239 and U-235 fission ratio measurements in homogeneous assembly with $\mathrm{H} / \mathrm{Pu}=5$.

\section{Phoenix Fuel Reactor Program (D.D. Lanning)}

MTR-Phoenix Fuel Experiment

CAF-Phoenix Fuel Experiments. Analysis of the approach-tocritical data from the CAF-Phoenix experiments has been completed. The results will be presented at the ANS Meeting in San Diego. The final values from the analyses are:

1. The extrapolated to critical height of the 19 fuel column Be reflected unpoisoned core is $21.3 \pm 0.2$ inches.

2. The polsoned core height is $39.7 \pm 1.2$ Inches.

3. Water replacing the central fuel column increases the critical size 0.78 fuel columns in the radial direction or 1.27 inches in helght.

4. Replacement of the central fuel column with the poison column increases the critical size by 19.23 inches in height.

Analysis of the nolse measurements made in the CAF-Phoenix experiments is continuing.

CAF-Phoenix Fuel Calculations. The detalled analyses of the three CAF experiments have been written in rough draft form. It is intended that this will become part of a formal document which will include both experimental and analytical methods and results for this phase of the MTR-Phoenlx program.

Diffusion theory calculations on the water-reflected assembly have shown that keff decreases by $1.6 \%$ as the number of energy groups $1 \mathrm{~s}$ changed from 4 to 17 groups. Only the two values at 4 and 17 groups were previously known. In order to get some ldea of the general behavior of keff as a function of the number of groups, diffusion theory calculations were performed with 13, 10, 7 , and 4 groups. The successively smal ler numbers of groups were obtained 
by collapsing from the same basic seventeen group structure. The calculated values of $k_{\text {eff }}$ are shown below:

\begin{tabular}{cc} 
Calculated keff, Water-Reflected Assembly \\
\hline Number of Groups & \multicolumn{1}{c}{$\mathrm{k}_{\text {eff }}$} \\
\hline 17 & 0.9445 \\
13 & 0.9452 \\
10 & 0.9465 \\
7 & 0.9497 \\
4 & 0.9605
\end{tabular}

The experimental value of $\mathrm{keff}$ is estimated to be 0.948 for this assembly. Thirteen to seventeen groups are required to provide milii-k convergences in multigroup diffusion theory. This is due to the importance of energy dependent core leakage into the reflector for the hard spectrum Phoenix core.

PRCF-Phoenix Fuel Experiments. The reactivity worths of the safety sheets were measured in the $3 \times 9$ shimmed loading after restacking the beryllium reflector. The subsequent results show an increase of $40 \%$ and $30 \%$, respectively, for the total package and strongest sheet, as compared to the previous Phoenix core. The results of the sheet measurements for various core configurations are tabulated below:

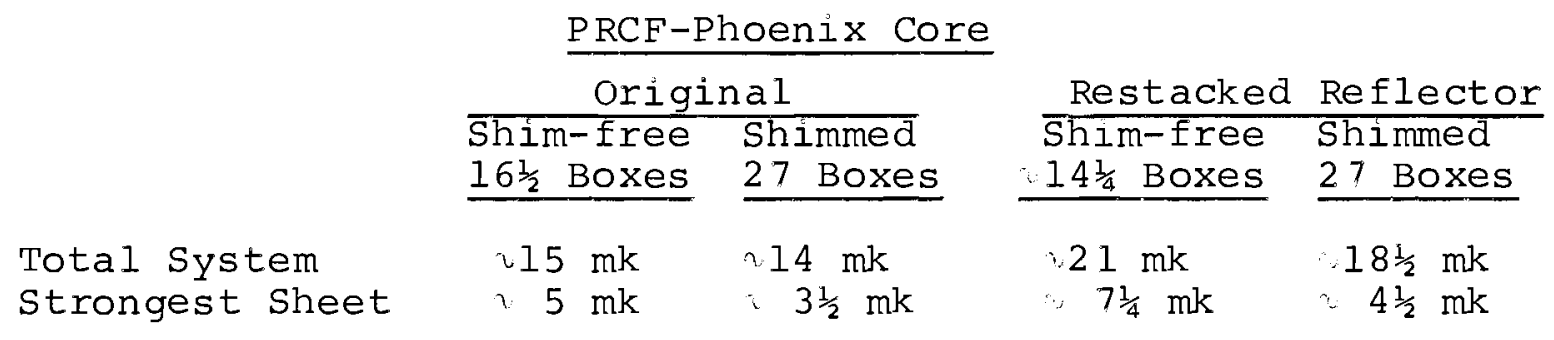

The reactivity worth of $0.1 \%$ change of the entire bank from $59 \%$ was determined to be $21.9 \pm 0.5$ cents and a $1 \%$ change in shim "E" yields a worth of $0.932 \mathrm{mk} / \mathrm{in}$.

Power distributions were measured in the plates of fixed elements and of a fuel follower of a shim which was withdrawn to $59 \%$. The fission product activities in the fuel plates were measured utilizing the gamma scanning facility at the PRCF. The axial traverse of the plates from the fixed element have siown that the axial peak power on the outside plate is located at 5 inches above the bottom of the fuel meat whereas the power spike appears at the bottom edge of the interior plate. Analysis of the horizontal traverse across the fixed element and the axial traverse across the shim plates is in progress. 
"Stuck shim rod" experıments were conducted at the PRCF for this core. The results show that with one outer shim and two inner shims tully withdrawn, the reactor is still subcritical.

Six plates containing tapered fuel cores have been loaded into the reactor, and measurements will be made to determine the effect of the tapered fuel on the power spikes at the bottom of an interior plate in a fixed element. The tuel cores have tapers of $\frac{1}{2} "$ and $1 \frac{1}{2} "$ on opposite ends. The effect of the different tapers wlll be measured by gamma scanning.

The loss of reactivity trom the PRCF core again was encountered, and a series of exploratory measurements have been inıtiated to isolate the cause. It has been noted that by driving the sheets in (instead of dropping them' the effect on the reactor is minimized. Additional studies of this problem are continuing.

PRCF-Phoenix Fuel Calculations. Comparison between PRCF measured power distributions and those calculated by using WHIRLAWAY for a similar configuration show that the experimental peak to average power ratio is smaller than the calculated value. Preliminary estimates indicate that the peaking may be lowered by as much as $30 \%$. The effect of this peak reduction on the allowable MTR operating power is being studied.

The experimental data for the fuel follower have not yet been analyzed; however, the raw data do not show a limiting power peak.

MTR-Phoenıx Fuel Calculatıons

Effect of $\mathrm{L}_{1} 6$ in the Beryllium Reflectors. The amount of Li 6 present in the MTR beryllium refiector ls unknown. An estimate of the equilibrium concentration was made, and 3-D calculations were performed. The $\mathrm{Li}_{1} 6$ was not distributed throughout the Be reflector but was distributed in a region $7.6 \mathrm{~cm}$ thick adjacent to the core. The production is primarily by fast neutrons, and the fast flux is down by a factor of 4 at this somewhat arbitrary cutoff point.

In addition, a 3-D calculation was performed in which all of the $(n, 2 n)$ cross section was removed from the reflector. This calculation was made because it had been assumed that the neutron absorption in the $\mathrm{Li} 6$ and the neutron production in the beryllium were compensating effects. The table lists the results of the calculations.

The $L_{1}{ }^{6}$ concentration in Case 3 is approximately the equilibrium value. Case 4 was calculated to determine the change in the Li concentration. The results of the calculations lead to the conclusion that the $(n, 2 n)$ reaction in the Be reflector does offset the 
neutron absorption by the $\mathrm{Li}^{6}$ buildup in the reflector. These two effects will be investigated in more detail at a later date. In the interim, the effects will either be both in or both out depending upon the code system being used.

Calculations of Various MTR Reflector Assumptions*

\begin{tabular}{|c|c|c|c|}
\hline Case & $\begin{array}{l}N\left(\mathrm{Li}^{6}\right) \\
\mathrm{n} / \mathrm{b}-\mathrm{Cm}\end{array}$ & $\begin{array}{l}\sigma(n, 2 n) \\
\text { in } \\
\text { Reflector }\end{array}$ & $\mathrm{k}_{\mathrm{eff}}$ \\
\hline 1 & 0.0 & No & 1.0801 \\
\hline 2 & 0.0 & Yes & 1.0959 \\
\hline 3 & $3.0 \times 10^{-6}$ & Yes & 1.0782 \\
\hline 4 & $1.0 \times 10^{-5}$ & Yes & 1.0337 \\
\hline
\end{tabular}

MTR Core Thermal Hydraulic Analysis

The digital computer code, MACABRE II, has been adapted to the local Univac 1107 and is now operable. Initial results obtained using this code agree well with results from hand calculations. Detailed analysis of the Phoenix core in the MTR will not proceed using this code, including the influence on heat transfer of corrosive film buildup on the fuel plates. More information regarding operating limits is required and will be obtained through a visit to the MTR facility. This will also provide an opportunity to review input assumptions before proceeding further with the detailed thermal hydraulic analysis.

Last month it was reported that the maximum reactor power at startup would be $24 \mathrm{MW}(t)$ assuming no flux suppressors. The limiting power peaks occur at the bottom of the stationary fuel next to the reflector in locations 25 and 45 . If these peaks were somehow removed without perturbing the power distribution in the remainder of the core, the next limiting power peaks (3.08) occur in the shim rods (positions $24,26,44$, and 46). These peaks are located axially at the bottom of the stationary core or about 10 inches down from the top of the shim follower fuel. An additional hand calculation was made to determine maximum reactor power at startup if these peaks were limiting. The result is $28 \mathrm{MW}(t)$ or $4 \mathrm{MW}(t)$ higher than the limit due to the peaks in locations 25 and 45 . Calculations are now in progress to study the effect on power of the PRCF measured peaks that are somewhat lower than the above computed values.

Drawings have been completed and bids requested for fabricating two MTR Phoenix fuel boxes with 16 simulated fuel plates. These boxes will be hydraulically tested at $140 \%$ of rated MTR flow at 
Idaho and will be used to evaluate an integral flux monitor system. The fuel section and upper end fitting were modified to accommodate a flux monitor wand which is being fabricated at BNW (without the $\mathrm{Pu}$ core in the wire).

The flux monitor wand will consist of a flux wire within a 1/8-inch aluminum tube. A cooling annulus is provided between tube and wire. The flux wire is a 0.050 diameter aluminum wire with a 0.010 to 0.015 diameter Pu core.

A trip is planned to Idaho to review the proposed flux monitor system with the people at INC and discuss further the problems assoclated with shifting the MTR active core for the Phoenix fuel load.

\section{MTR-Phoenix Experiment}

An irradiation experiment is being prepared to test plutonium fuel plates under the operating conditions proposed for the MTR Phoenix experiment. The purpose of the test is to demonstrate fuel stability and in-reactor corrosion resistance as a function of exposure in the Phoenix fuel geometry. Thirty plutonium fuel plates were prepared for the irradiation test in the L-5l loop of the MTR, but the plates had areas of internal core porosity. Metallographic examination showed the areas to be volds and inclusions associated with the cast cores. It was decided that these plates were not sultable for the planned irradiation to high exposures, up to $1 \times 1021$ fissions/CC, for these areas would be sites for fission gas accumulation and swelling.

New plates are being prepared using extruded Al-Pu core material. The cores were extruded to the desired configuration and cut to length. No defects were detected in the extruded fuel by radiography and sectioning. Chemical analysis showed the extrusions to be exceptionally uniform in plutonlum content. The fuel cores will be assembled, rolled, and evaluated before assembly into test sections.

Six fuel plates were prepared with tapered ends for flux peaking tests in the PRCF. An aluminum clad, Al-Pu fueled, flux wire was prepared for PRCF testing. The fuel assembly for the MTR irradiation test was completed, using the reject plates, for tests in the PRCF.

\section{Applications}

A meeting to discuss HFIR-Phoen $1 x$ has been scheduled for June 14 ,

1967. It will be held in conjunction with the ANS Meeting in San Diego. Interested personnel from ORNL and ANL have been contacted and are planning to attend. 
Analytical studies of the physics characteristics of Phoenix fuel loadings in the Plutonium Recycle Test Reactor (PRTR) and the Consolidated Nuclear Steam Generator (CNSG) have begun.

PRTR. Physics calculations have been made for 19-rod clusters of $\mathrm{Al} \overline{\mathrm{Pu}}$ fuel in a PRTR environment. Results to date include: reactivity variation $(\mathrm{k})$ versus $\mathrm{Pu}$ concentration; minimum critical mass; moderator, coolant, and fuel temperature coefficients of reactivity; and core lifetime. Analysis of these systems is continuing.

CNSG. Reactivity and core lifetime calculations have been initiated for the $\mathrm{UO}_{2}$ fueled CNSG-II core design. These calculations will serve as the base case to compare with the Phoenix fueled loadings.

High Temperature Reactor Lattice Physics Studies

Reactor Construction

(R.E. Heineman)

The Gas Analysis System (alpha monitors, moisture monitors, chromatographs, etc.) was checked out during the month. The system was accepted by the Reactor Operations Unit with minor exceptions, one of which was excessive noise on the analog signals.

The building radiation monitors were accepted by the Reactor Operations Unit.

After noting an indicated imbalance of heater power, the two banks of electric heaters which were in question were inspected, tested to half-power, and monitored for distribution of load. Some graphite heater fittings were loose, and all were retorqued to design values. The heater thermocouples were also inspected and their positions checked. The heaters appear ready for the design test.

Extensive monitoring of noise as a function of the time-of-day and correlation with operating equipment led to a recommendation that noise filters be added to the analog signal inputs.

Decals were applied to all piping for identification.

Design changes were initiated to install current and vibration monitors on the main gas blower.

Wire runs from the Vertical Safety Rods (VSR) and the Horizontal Control Rods (HCR) were checked. Acceptance Tests on the HCR were attempted, but not completed. Several problems prevented acceptance of the VSR. Under load (while raising the rods) the motors may reverse and run the rods back into the reactor. Upon 
full insertion the cable may then wind onto the drum in the opposite direction. An extension was welded onto each assembly to assure that this will not happen. Wire runs were added to bring the signal from the intermediate limit switch into the control room for using in sensing the direction of rod travel. With the above information in hand it was recognized that the present "rod in" limit switch monitors only the cable and not the actual position of the VSR. Thus, a method of providing positive information on the position of the VSR Itself is to be added.

Temporary gas system
high temperature fllters.

In anticipation of acceptance of the HCR, VSR, and oscillators during June, project punch list ltems are being reviewed in preparation for close out of the project. Typical items which involve safety are: a second access to the top of the bullding, rails around the top of the reactor, an access ladder to the top of the reactor, a gas tank located outdoors for the auxiliary gasoline motor which drives the reactor room exhaust fan, in an emergency, and protection of the ventilation controls located outside the building.

Reactor Equipment

Oscillators. The light duty osclilator was connected to the HTLTR mockup. It withdrew, osclilated, and reinserted a 45-1b graphite sample at temperatures of $1125 \mathrm{~F}, 1300 \mathrm{~F}, 1550 \mathrm{~F}, 1730 \mathrm{~F}$, and $1890 \mathrm{~F}$. Ten 9-ft oscillations were made at each temperature.

The osclilator was evacuated to $29 \frac{1}{2}$ inches of mercury vacuum and backfilled to 1.9 psi with nitrogen twice at each temperature. This was required because ram extension rods had to be removed and replaced to accommodate withdrawal and reinsertion of the sample.

The oscillator was disconnected from the mockup at the completion of testing, then reconnected and operated for another week for personnel training. This training was terminated when the connector was broken. This was caused by high acceleration forces induced by an erroneous control signal from the logic system. This should not be a problem with the reactor control system.

The heavy duty oscillator is completely fabricated and has been attached to the test stand for cold tests.

The unit was oscillated over the 3-it test distance with an inertia load of 1200 lbs induced by a flywheel and a frictional load of approximately 500 lbs imposed by an air brake. These oscillations have been at about a 15-sec rate rather than the design 
rate of 3 feet in 5 seconds. Additional testing is being performed to investigate the loads imposed during faster cycles. This is being done cautiously because of the high loads created by the steep acceleration ramp furnished by the simulated reactor control system. The results of the testing completed to date have been satisfactory.

The control panels and wiring for the oscillators are complete with the exception of a servo valve amplifier and two power supplies which are being utilized in cold testing of the heavy duty oscillator.

Vertical Safety Rods. VSR operation is being checked out with PMACS as the pre-operational testing schedule permits. The significant items that developed are:

The wiring for the "in" limit indication to the PMACS Watch Channel was incorrect, as shown on the drawings. Energizing the No. I VSR Brake Release Circuit applied 115 Vac at PMACS and damaged some circuit elements. The condition was corrected by providing an isolated SPDT contact and "as-built" information was noted. Instructions were given to check all watch Channel inputs for zero voltage level before connection to PMACS.

After several successful operations, No. 2 VSR brake release action became restricted. The problem, which doesn't affect the safe operation of the VSR, was corrected.

To prevent No. 3 VSR rod from binding, it was necessary to improve alignment of the housing with the reactor opening by enlarging the mounting flange bolt holes.

The brake release circuit for each VSR requires modification to prevent the brake from releasing too soon following brake actuation. This only occurs when a VSR clutch is individually scrammed manually from the control room. When scrammed in this manner, the rod drops on the bottom bumper plate causing the cable to slacken and occasionally disengage the drum guide groove. By using a separate set of contacts on each control room manual switch, the brake release circuit will be held open until the scram switch is reset. The above modification does not affect the safety of the VSR system but does correct a potential operating nuisance.

Horizontal Control Rods. Ten drive units have been delivered to the 318 Building and have been successfully tested with simulated signals from a pulse generator. Feedback pulses were observed with an oscilloscope. The deceleration Bellofram diaphragm had to be replaced on Unit No. 5 when it failed to scram all the way out.

The stepping motor removed from the tenth drive unit will be returned to the manufacturer for repairs. One new motor has been 
ordered as an operating spare. The spare translator section has been delivered to the HTLTR Building.

Programmed Measurement and Control system (PMACS). Some of PMACS analog input signals were standardized. A terminating resistor was applied to all the rod position analog signals to produce $\mathrm{a} \pm 5 \mathrm{v}$ range and capacitive loads were placed across the flow and pressure transducers to eliminate noise.

A heat detector was built and installed in the PDP-7 computer to sense over-temperature conditions directly above the core memory in the computer.

The API (Automatic Priority Interrupt) zero level interrupt has been wired all the way into the computer and is ready to be hooked in.

Problems with the analog multiplexer and rod counter in the Astrodata logic were corrected. Problems that developed in the PDP-7 were also corrected.

The interface for the mechanical oscillators has been wired and checked out.

Reactor Operations

The Systems Design Tests, Operating Specifications, Operating Procedures Manual, and the Operating Qualification Test Questions were issued. Updating will, of course, be necessary as testing or modifications proceed.

Fifteen major control programs were successfully integrated during this reporting period and made operational. After the hardware from the Gas and Heating Systems was proven acceptable, control of the Gas system was achieved in less than one day. The selection of proper control constants at elevated temperature still remains for both the GASCYC and HEAT programs. This effort will be accomplished during the first heat runs over the next two or three months.

The DISPLAY programs and the LOG programs, now in their final programming stages, were used to advantage during the Gas and Heat systems tests. A routine was written to log the seven gas system pressures and flows that can be under automatic control. The operator could select the sampling interval at which 51 (decimal) samples are collected. After the operator selected the particular flow or pressure he desired, the routine normalized the amplitude of the log and displayed it on a storage oscilloscope. Two oscilloscopes were used, so that one may be viewed while pictures are taken. of the other. A single trace or repetitive traces could be called. 
All program states in the Gas Cycle Program except the Gas Heat state (GHE) have been debugged. Automatic control of the reactor pressure was maintained for a short time for purposes of personnel training in preparation for the GAS-HEAT design tests. However, the test was sufficient to demonstrate that pressure abnormalities exist which were not anticipated by the design. This limits the rate of flow of the purge gas stream. Recommendations will be obtained, but the system is operable with some changes in operating procedures.

Flow diagrams of the ROD, SCRAM CHECK, and NUCLEAR programs were reviewed during the month. Initial flow diagrams for the new ROD MONITORING routines which observe rod travel and direction of travel were submitted for review. Up-to-date key board commands (KEP program) were provided at the end of the month.

A temporary program was written to move the vertical and horizontal rods by computer control during their design tests. The regular ROD programs require the safety circuit to be made up before movement can be achieved and thus could not be used for rod-drive checkout.

One program, the VALVE MAINTENANCE program, may not be needed. All maintenance, calibration, and adjustment to the Gas system valves was accomplished with the GASCYC program. This will be resolved.

Procurement of several items of equipment was initiated and/or a commitment to purchase obtained. These include a pulsing circuit for the neutron generator, a tape transport for the computer, two heavy duty teletypewriters, a trip monitor for the independent safety channels, a small gas blower of 150 cfm capacity for the recirculating gas system, and a vibration monitor for the large, main gas blower.

Mockup Run No. 5. Hot testing of the light duty oscillator and connector was completed at the mockup after 12 days of operation at a core temperature of $1000 \mathrm{C}$. The mockup was used to reduce personnel and reactor interference. The mockup has now been cooled, the doors removed, and the test samples extracted.

Maximum water concentrations noted during the run in the various gas streams were: mockup outlet - 1890 vppm; mockup inlet - Il30 vppm; gas cleanup out let - $25 \mathrm{vppm}$. At the end of the run the water concentrations had decreased to: mockup outlet 320 vppm; mockup inlet - 250 vppm; gas cleanup outlet - 20 vppm.

Maximum concentrations of carbon monoxide and carbon dioxide noted during the run were: $2000 \mathrm{vppm}$ and $440 \mathrm{vppm}$, respectively. These respective concentrations had decreased to 1620 vppm and $120 \mathrm{vppm}$ at the end of the run. 
A test of the prototypical heater at full design power was performed when the core temperature had been reduced to $150 \mathrm{C}$. The heater clrcuit was energized and the power adjusted until the three heater elements were generating $48 \mathrm{kw}$. This power level was maintained for approximately 20 minutes until the heater element thermocouples indicated a steady state value. The maximum heater element temperature noted under these conditions was $390 \mathrm{C}$ at an average core temperature of $170 \mathrm{C}$. These data have not yet been evaluated.

\section{Reactor Physics}

Startup and Calibration Experiments. The hot tests of samples to $10 \overline{00} \mathrm{C}$ in the mockup were completed, and the samples were removed and inspected and reweighed. The following effects of the hot test were noted:

1. Copper foil: The foll was annealed and some very slight corrosion was noticed. A slight loss of weight was observed of about $0.2 \%$, and the loss of welght was greater for 5-mil than for 10-mil copper.

2. Rhodlum: The rhodium foll appeared to be unaffected. The weight loss observed was probably due to an error in the initial weight of the sample.

3. Gold: The gold foll appeared unaffected and did not undergo any weight change.

4. Monel wire: The wire was slightly corroded on the surface, and a very slight weight increase occurred. The hard wire was softened

5. Safety blade material: A slight discoloration of the exposed surface was observed. The weight change was negligible.

6. $\mathrm{Gd}_{2} \mathrm{O}_{3}$-graphite material: Corrosion of the surface graphite occurred, exposing $\mathrm{Gd}_{2} \mathrm{O}_{3}$ particles. The corrosion was similar to that of other graphite sample material. It is not expected that this will be a problem when covered with its graphite cladding. About a 5\% weight loss occurred.

7. $\mathrm{Al}_{2} \mathrm{O}_{3}-\mathrm{Sm}_{2} \mathrm{O}_{3}$ balls: No visual change or weight change occurred.

8. Graphite- $\mathrm{Sm}_{2} \mathrm{O}_{3}$ balls: Some corrosion occurred, and about $10 \%$ of the weight was lost. Some weight loss may have occurred in handing. 
9. A sample of insulation brick covered with mortar appeared to hold up well under the reactor environment.

The document describing the startup and Calibration Experiments in dtail is being updated in two respects. Current reactor operating procedures are being submitted, and detail on the data to be obtained in the high temperature runs is being inserted.

The side-to-side flux wire mechanism was made ready for initial experiments. Several minor modifications are being made.

$\mathrm{U}^{233} \mathrm{O}_{2}-\mathrm{ThO}_{2}$ Experiments. Planning continued for the $\mathrm{U}^{23} \mathrm{O}_{2}-\mathrm{ThO}_{2}$ experiments. Temperature coefficient calculations were completed for the 2.86-inch diameter quasi-homogeneous fuel rods, 1.e., 20 by volume graphite fuel rods admixed with $\mathrm{ThO}_{2}$ (1.5 wto U-233). Ignoring thermal expansion, the net coefficient $\underline{1}$ dkx remained positive but increased from to to $1.4 \times 10^{-5} /{ }^{\circ} \mathrm{C}$ over $\bar{k}_{x}$ dT the range of increasing temperature. This result differs from that reported the previous month for a 1.0 inch diameter $\mathrm{ThO}_{2}$ rod (1.5 wto U-233) which also remained positive but decreased in magnitude with increasing temperature. The fuel coefficient, $\frac{1}{p_{0}} \frac{d p}{d T}$, for the quasi-homogeneous rod decreased in magnitude with increasing temperature from -3.4 to $1.5 \times 10^{-5} / 0_{C}$; the corresponding moderator coefficient, $\frac{1}{\mathrm{ofo}_{\mathrm{O}}} \frac{\dot{\mathrm{d}}^{r} \mathrm{f}}{\mathrm{dT}}$
decreased from +3.7 to $3.1 \times 10^{-5} / 0 \mathrm{C}$.

Comparison calculations of effective resonance integrals and Doppler coefficients for a number of $\mathrm{ThO}_{2}$ rods were continued. These rods were investigated previously, both experimentally and theoretically, by Palowitch and Hardy (WAPD-TM-627, Dec. 1966) and theoretically by Segal (Nucl. Sci. \& Eng., Jan. 1967). The GAMTEC-II library was updated to include the resolved resonance data recommended by Stehn, et al (BNL-325, Feb. 1965), the same data used by both Palowitch, et al, and Segal in their analyses. Effective resonance integrals computed using the NR and NRIA approximations are 10 to $20 \%$ lower than obtained by Palowltch, et a1, and Segal. However, quantitative agreement was obtained in the unresolved region where contribution from both $S$ and $P$ wave capture were included in the calculations. The difficulty is in the resolved region where the only differences in calculations were application of the NR and NRIA approximations rather than the more exact Monte Cario and Nordheim integration schemes used by Palowitch, et al, and segal. This latter conclusion will be investigated more thoroughly for several of the more important resonances of Th-232. 
Mixed Nitride Fuel Development

The time cycle for the synthesis of UN and PuN was decreased significantly by more efficient equipment utilization. UN snythesis has been reduced from about a 3 -day cycle to a 2-day cycle. The PuN cycle has been reduced from approximately 20 hrs to about a 12-hr cycle. This permits increasing the synthesis batch size from 25 grams to 50 grams and has pald dividends in quality control, batch acceptability, and housekeeping. X-ray diffraction studies indicate that the last two UN and PuN runs are of good quality.

A marked increase in grinding efficiency and, subsequently, the sinterability of the nitride powders, has been realized by optimizing ball-mill speed and using smaller diameter tungsten carbide balls as the grinding media. Experiments indicated that the particle size of the mixed nitride powder after ball milling was not small enough to result in optimum sinterability. Several steps were taken to improve ball-milling conditıons, malnly, optimizing the ball-mill speed and replacing the 0.040-inch diameter alumina balls with 0.25-inch diameter tungsten carbide balls. These changes have resulted in an increase of sinter density from the 83-84응 theoretical density range to the 88-90\% theoretical density range.

Mixed Nitride Irradiations

An experimental mixed nitride fuel pin, GEH-14-743, was discharged from the ETR after successful irradiation to $2000 \mathrm{MWd} /$ tonne. During irradiation the linear heat generation rate of the $I_{4} " O D \mathrm{x}$ 4" long fuel pin was $33 \mathrm{kw} / \mathrm{ft}$, and the measured surface temperature was $750 \mathrm{C}$.

The fuel pin contained UN-20 wt: PuN sintered pellets having densities between 82 and $86 \%$ of theoretical. The only signficant impurities in the fuel were $4000 \mathrm{ppm}$ oxygen and $1000 \mathrm{ppm}$ carbon. Fuel pellets were contalned in and sodium bonded to $0.015^{\prime \prime}$ thick 304 stalnless steel cladding. The fuel pin was enclosed in a capsule which included two thermocouples. The inner thermocouple measured the pin surface temperature, and the outer one measured the capsule temperature. The inner and outer thermocouples thus provided a means of determining the pin heat generation rate.

Similar capsules, GEH-14-745 and 746, operating under similar conditions, are being irradiated in the MTR. These are scheduled to be irradiated to at least $20,000 \mathrm{MWd}$ /tonne. 
Irradiation conditions for all three capsules are summarized in the following table:

$\begin{array}{lcccc}\text { Capsule No. } & \begin{array}{c}\text { Fuel-to-Clad } \\ \text { Bond }\end{array} & \begin{array}{c}\text { Nominal } \\ \text { Heat Rating, } \\ \text { kw/ft }\end{array} & \begin{array}{c}\text { Nominal } \\ \text { Pin Surface } \\ \text { Temp., }{ }^{\circ}\end{array} & \text { Reactor } \\ \text { GEH-14-743 } & \text { Sodium } & 33 & 750 & \text { ETR } \\ \text { GEH-14-745 } & \text { Sodium } & 32 & 700 & \text { MTR } \\ \text { GEH-14-746 } & \text { Helium } & 30 & 650 & \text { MTR }\end{array}$

Compatibility Experiments on Mixed Nitride Fuels

Two UN - 20 wt\% PuN sodium-bonded, 304 stainless steel clad test capsules, each with a sodium expansion plenum were fabricated and are being heated, one at $650 \mathrm{C}$ for $100 \mathrm{hrs,}$, the other for 1000 hrs. Four similar helium-bonded test capsules were also prepared. Two are being heated with the sodium capsules; the other two are being heated at $1000 \mathrm{C}$ for 100 and 1000 hrs.

Trouble developed in welding the bottom cap and top expansion plenum on the sodium-filled capsules. The sodium melted and flowed into the weld area, preventing the formation of tight welds. The caps have been redesigned to require less welding heat, Low-heat electron-beam welding will be attempted.

Four sodium-bonded capsules having imperfect welds were opened, and the wetting of sodium on the nitrides was visually evaluated. Wetting of sodium on the nitride pellets appeared to be complete.

Basic Sweling Studies (R.D. Leggett)

Irradiation Program

Capsule P-14 $1700 \mathrm{C}, 500 \mathrm{psi}, 0.2-0.8$ at.\% BU; was charged into a reactor and is operating as designed. Problems encountered with the high pressure regulator controlling capsule P-10 $(450 \mathrm{C}, 5000$ psi, 0.2-0.8 at. $\frac{\circ}{8}$ BUl could force the test to be terminated ahead of goal exposure. The status of capsules currently active is indicated below.

\begin{tabular}{|c|c|c|c|c|}
\hline Capsule & Control & Control & Goal & \\
\hline Number & Temo. ${ }^{\circ} \mathrm{C}$ & Pressure & Burnup & Status \\
\hline & & (psi) & $(a t . \circ)^{*}$ & \\
\hline$P-10$ & 450 & 5000 & $0.2-0.8$ & Under irradiation \\
\hline$P-11$ & 550 & 5000 & $0.2-0.8$ & Construction complete \\
\hline$P-12$ & 625 & 5000 & $0.2-0.8$ & Construction complete \\
\hline$P-13$ & 700 & 5000 & $0.2-0.8$ & Under construction \\
\hline$P-14$ & 700 & 500 & $0.2-0.8$ & Under Irradiation \\
\hline$P-15$ & 700 & 1000 & $0.2-0.8$ & Opened in Radiometallurgy \\
\hline$P-16$ & 625 & 1000 & $0.35-0.7$ & Under irradiation \\
\hline
\end{tabular}

*Different burnups are achieved in a single capsule by including specimens of various enrichments. 
The above Irradiation capsules will provide data needed to evaluate the effects of temperature (alpha and beta phase), pressure, burnup, burnup rate, and minor alloying additives on the irradiation behavior of uranium.

Postirradiation Examination

Preliminary examination of specimens consisting of high purity uranium and uranium with dilute alloying additions recovered from capsule $\mathrm{P}-15$ revealed samples in excellent condition with very little swelling or distortion evident. Irradiation temperatures ranged from $670 \mathrm{C}$ to $735 \mathrm{C}$ while estimated burnups ranged from 0.22 at. $\%$ to 0.81 at. $\%$. Both the temperature range and the burnup range were achieved with samples of different enrichment. High burnup samples $(0.43$ and 0.81 at. $\%$ BU) that operated quite close to the alpha-to-beta transformation temperature $(660-670 \mathrm{C})$ contain cracks. The cracks in one sample, whlch operated at $670 \mathrm{C}$, were located on the transition between fine grained alpha and the large grain beta phase which indicates the cracks are due to transformation stresses and irradiation and are not induced by irradiation alone. The cracks in other samples were elther distributed at random or located at sharp notches. All specimens have been transformed either during irradiation due to their proximity to the transformation temperature or during reactor down times due to controlling the capsule at $500 \mathrm{C}$ during shutdown. Specimens with lower burnups (1.0.2 at. 0 ) were in excellent shape with no apparent swelling or distortion. Density measurements are in progress, and optical and electron microscopy will be performed on selected specimens.

\section{Nondestructive Testing (J.C. Spanner)}

Detection of Irradiation Induced Shift in Nil-Ductility-Transition Temperature

Ultrasonic test apparatus for conducting critical angle ultrasonic studies on irradiated test specimens was fabricated, and installation is nearly complete.

Twenty-one test specimens were individually encapsulated and mounted in holders for irradiation in the ETR during cycle \#90. Some of these specimens will be irradlated at low temperature, high flux, and others at high temperature with high and medium $f$ lux. Adaitional specimens are now being prepared for ETR cycles 91 and 92 whlch will provide samples from high and low temperature, medium flux exposures.

The electronıc apparatus for initial tests was "debugged," and . a tunable preamplifier was reworked to enable operation at lower frequencles. Crystal holders were fabricated, and two wide-band crystals were mounted in the test facility. 
The Radiomet "Gatling-Gun" cask will be decontaminated for use as an irradiated specimen storage facility for the subject work. This cask incorporates seven inches of lead shielding which is adequate for the highest radiation level currently anticipated from specimens to be used in the program.

Equipment installation in the 324 Building airlock cell was delayed pending correction of air distribution difficulties in the system serving the building's hot cell complex.

Fundamental Ultrasonic Studies

As mentioned in the previous month's report, the representation of measured ultrasonic pulses by sets of Kautz functions has not been successful to date. It was suspected that either there was some mistake in the EDPM program, or that there was a basic limitation in the analysis which had been overlooked.

To check the validity of the program, a test case was written to provide data from a palr of Kautz functions having known decay rates and frequencies similar to experimentally observed ultrasonic pulses. The test case did not give the expected results and thus enabled location of program errors which have since been corrected.

In addition, hand calculations and evaluations of the first pair of Kautz functions were undertaken to determine if basic limitations exist in pulse analysis. The algorithm for using the first pair was successfully verified. This result, together with the discovery and correction of program errors, has resulted in a more optimistic view toward the successful evaluation of measured ultrasonic data.

Slow turn-around time in EDPM program execution (returns have been delayed as much as one week) has prevented successful program "debugging" during this last month.

Electromagnetic Research

One section of a Laguerre polynominal generator, for use in analyzing pulsed eddy current signals, has been breadboarded using a field effect transistor gate for discharging the integrating capacitance. An alternate arrangement of matrix element value adjustment potentiometers for the multiparameter eddy current test has been built, and the testing of the transcelver section of the multichannel eddy current tubing tester has been started.

One method of expanding nondestructive testing signals on selected orthogonal bases involves the use of unstable analyzing circuits. As a result of the purposeful instability, it is required 
to reset the circuits at the end of each computing period. One section of this type of analyzer for Laguerre functions was breadboarded using a field effect transistor as a capacitor discharge switch. Thus, output voltage can be sacrificed for increased gate repetition frequency. Gate repetition frequency is limited to about $10 \mathrm{kHz}$ due to the reduction of signal at the higher rates.

The discharge switch appears satisfactory for the eddy current test analyzer, but higher switching rates are needed for the ultrasonic applications.

The levers of the trail assembly of four matrix element value adjustment potentiometers for eventual use in the transformation section of the multiparameter eddy current tester have been replaced with plastic discs for improved ease of adjustment. Further evaluation is continuing.

Testing of the transceiver portion of the multichannel eddy current tester has been started, using substitute potentiometers pending delivery of those on order. The high frequency amplifier stages were found to be unstable, and some design changes are being made.

\section{Composite Testing Methods}

Observations of the interference resulting from a simulated ultrasonic surface reflection and a simulated near surface defect reflection as a function of the relative time of occurrence of the two signals were conducted. Continuous variation of the relative time of occurrence of these two damped oscillatory signals gives simulation of the effect of varying the depth of the defect. A signal processing circult has been devised which effectively increases the damping of both the surface and defect reflections, and which permits detection of the simulated defect reflections, and which permits detection of the simulated defect at an earlier time (less depth) than can be done with a simple amplitude detector. After further optimization, this technique will be applied to actual ultrasonic test signals.

Infrared and Thermal Research

A second thermal transducer with a solid spacer has been fabricated. It is believed that this type of transducer will be more stable than past transducers, since its characteristic impedance should remain constant. During tests on the transducer the epoxy bond between the exciter foil and spacer came apart. Since a similar difficulty occurred in the previous transducer, a different 
bonding method appears to be necessary. A silicone bonding rubber has been obtalned for this purpose.

A prototype infrared imaging system is being developed for use in nondestructive testing research and other AEC applications. This unit will be used to determine the thermal uniformity of newly fabricated thermal transducers when it is complete.

Tests on the Barnes $\mathrm{R}-8 \mathrm{~T} 1$ infrared radiometer, after an attempted onsite repair by the manufacturers field representative, showed that its stability was still not within specifications. High stability is needed in development of the new remote transient method. The radiometer was returned to the manufacturer for repairs. Replacement of the internal reference blackbody unit was necessary.

Eddy Current Probe Coil Design

Studies to investigate the theoretical and practical aspects of eddy current sensing probe design and to apply the information obtained to the development of general guidelines for future probe construction continued.

During this reporting period, consideration was given to the problem of determining which probe coil geometry produces the highest sensitivity. Several coaxial probe coils were built for insertion into $1 / 2^{\prime \prime}$ diameter holes in a massive copper plate. The coils all had the same outside diameter $(: 0.497 ")$ and width $(: 0.118 ")$, but the inside diameter varied from 0.030" to 0.450". Data were taken on the impedance of each probe in, and out, of the copper plate at 50,100 , and $200 \mathrm{kHz}$. The fractional change in the amplitude of the coll impedance, when the coll was inserted in copper, was calculated as an approximation of the sensitivity of the probe.

$$
|S|=\frac{\mid z_{\text {alr }}-Z_{c u}}{z_{\text {air }}}
$$

where is = absolute magnitude of sensitivity

$\mathrm{Z}$ air $=$ coil impedance in air
$\mathrm{Z}_{\text {cu }}=$ coil impedance in copper.

It was noted that the probes with the most turns (small ID/OD ratios) had the least sensitivity $(0.25)$, while the probes with fewer turns (larger ID/OD ratios) had sensitivities as high as 0.5. In general, the sensitivity increased as the ID increased. This indicates that probes built with a few turns close to the material to be tested will have greater sensitivity than probes built with all avaliable space filled with wire. These data appear to favor low impedance, high current probes with the limiting case being a 
single turn carrying a very high current. To take advantage of this increase in sensitivity, low impedance tester circuitry which is primarily current sensitive would probably be necessary.

\section{Nuclear Ceramics (R.E. Nightingale)}

Synthesis and Chemical Analysis of Mixed Nitrides

Preparations are nearly completed for detailed studies of carbothermic reduction synthesis of nitrides. Modifications of an existing Astro furnace were finished, and installation of a new unit which will accommodate a fluidized-bed reactor will be completed within two weeks. Calibration was completed on a Lira carbon monoxide monitor for use in making kinetic measurements. Materials were prepared, and experiments will be started within two weeks.

The reactions that will be studied initially are:

$$
\begin{aligned}
& \mathrm{MO}_{2}+2 \mathrm{C}+1 / 2 \mathrm{~N}_{2}(\mathrm{~g})=\mathrm{MN}+2 \mathrm{CO} \\
& \mathrm{M}\left(\mathrm{N}, \mathrm{C}_{\frac{1}{\mathrm{x}}}\right)+\frac{2}{\mathrm{x}} \mathrm{H}_{2}(\mathrm{~g}) \div \mathrm{MN}+\frac{1}{\mathrm{x}} \mathrm{CH}_{4}(\mathrm{~g})
\end{aligned}
$$

A new method for determining nitrogen in mixed uraniumplutonium nitrides is being developed. The method (Kjeldahl fusion) consists of decomposing a nitride sample in a caustic melt and collecting and determining the quantity of ammonia formed. If successful, the analysis will require minimum attention to carry out but should yield good precision $( \pm 0.5 \%)$.

At the present stage of development, we are recovering 95\% of the theoretical nitrogen decomposed from a UN sample; the composition of the UN sample as determined by present analytical methods is $5.40 \%$ nitrogen, 600 ppm oxygen, and 200 ppm carbon.

\section{Electrical Conductivity of $\mathrm{ThO}_{2}$}

The electrical conductivity of polycrystalline $\mathrm{ThO}_{2}$ was measured in a reducing atmosphere from 750 to $2780 \mathrm{C}$. Preliminary results show the electrical conductivity to vary strongly with temperature from $10^{-8} \mathrm{ohm}^{-1} \mathrm{~cm}^{-1}$ at $750 \mathrm{C}$ to $5 \mathrm{ohm}^{-1} \mathrm{~cm}^{-1}$ at $2780 \mathrm{C}$. The log $\sigma$ versus $\frac{1}{T}$ curve is nearly linear, and the conduction is associated with an activation energy of $3.0 \mathrm{eV}$. The dc and ac (to 5000 hertz) conductivity values were the same. 
Microstructure of Sintered and Impacted Oxide Fuels

Transmission electron microscopy of sintered $\mathrm{UO}_{2}$ and pneumatically impacted $\mathrm{UO}_{2}$ showed well defined grain boundaries, pores, and apparent inclusions and other defects. Cathodic etching resulted in fine striations and a granular surface structure; interpretation of this cathodic etching effect has not been completed.

Preparations of transmission electron micrographs of a controlled series of sintered, pneumatically impacted, and single crystal $\mathrm{UO}_{2}$ specimens by both mechanical and chemical thinning are in progress to evaluate the effects of densification method and to compare the surface structures resulting from mechanical thinning, chemical thinning, and cathodic etching.

Routine procedures for mechanical thinning of oxide specimens have been established. However, removal of each specimen from the mount for insertion into the microscope has proved difficult, malnly because of the brittle nature of the very thin (1000 A) ceramic foils. In addition, the pneumatically impacted polycrystalline materials frequently display weak intergranular bonding. Finally, extreme care must be exercised to retain small impurity inclusions which tend to pull out during polishing. Development of improved methods is continuing.

Materials and Information Exchange

Single crystal specimens were prepared, characterized, and sent to Oak Ridge National Laboratory (ORNL, Lawrence Radiation Laboratory (IRL), Pennsylvania State University, and the Georgla Institute of Technology for their use in basic studies. About 200 single crystals of $\mathrm{UO}_{2}$, enriched to about $50 \% \mathrm{U}-235$, were recelved from ORNL for purification and specimen preparation. Arrangements have been completed with LRL and ORNL to exchange some of their high purity UN materials. In addition, $\mathrm{PuO}_{2}$ pellets were provided locally to research personnel for use in basic property and spheroldizing studies.

Nuclear Graphite (R.E. Nightingale)

High Temperature Graphite Irradiations

The capsule, GEH-13-14, has been assembled and is being shipped to the ETR for a 3-cycle irradiation beginning in June. All external parts of the capsule are entirely of 304 stainless steel for greater strength. As with the previous capsule, GEH-13-14 will be moved after one or possıbly two cycles of irradiation, but the increased ruggedness of the capsule and handling experience acquired in the previous transfer should minimize the chance of failure. 
Approximately half of the samples from GEH-13-13 are included. in the current capsule. The remaining samples were rejected either because of high contamination or because of changes in priority among graphite types. Virgin samples occupy the vacated positions. Two solid dials were also included in the capsule to determine the effect of sample size on irradiation behavior at these high temperatures. General Atomic samples occupy the same space as in the previous capsule and also consist of about half new, half irradiated specimens.

\section{EBR-II Irradiatıons}

Two graphite pins have been discharged from EBR-II. The samples all appeared to be in good condition. Maximum exposure on the pins was about $1.5 \times 10^{22} \mathrm{nvt}$ and maximum sample temperature about $750 \mathrm{C}$.

The two thermocouple pins assembled for irradiation in EBR-II are now on standby at the site. They have first priority among BNW pins for inclusion in subassemblies on a space-available basis.

Irradiation of Nuclear Graphite

Graphite irradiation capsule $\mathrm{H}-3-15$ is currently operating satisfactorly at its design temperature. Seven of the original nine thermocouples continue operation.

Two highly irradiated transverse samples of NC-8 type material that were broken in the laboratory during capsule fabrication are being studied. The results of strength and $x$-ray diffraction measurements are tabulated below with unirradiated material as a reference. The sample with $20 \%$ expansion possessed little strength, whereas the sample with $2 \%$ expansion was as strong as the virgin material. Both irradiated samples exhibited c-spacing lattice expansions of only 1\%. It appears that the lärge growth rates observed after turnaround are due to development of macrocracks rather than $\underline{c}-a x i s$ expansion per se.

Additional microscopy studies will be made to determine whether these postulated crack systems are located in the filler or binder areas. 


\begin{tabular}{|c|c|c|c|c|c|c|}
\hline \multirow{2}{*}{ Material } & \multirow{2}{*}{$\begin{array}{l}\text { Exposure and } \\
\text { Temperature }\end{array}$} & \multirow{2}{*}{$\begin{array}{l}\text { Length } \\
\text { Change, \% }\end{array}$} & \multirow{2}{*}{$\begin{array}{l}\text { Lattice } \\
\mathrm{C}_{0, \text { (A) }}\end{array}$} & \multirow{2}{*}{$\begin{array}{r}\text { Parameters } \\
L c \text { (A) }\end{array}$} & \multicolumn{2}{|c|}{ Strength } \\
\hline & & & & & Tensile (psi) & Compression (psi) \\
\hline \multirow[t]{4}{*}{$\mathrm{NC}-8 \quad(1)$} & Unirradiated & --- & 6.717 & 315 & 1015 & 5127 \\
\hline & & & & & 1005 & 4924 \\
\hline & $\begin{array}{l}2.0 \times 10^{22} \text { nvt } \\
\text { a } 750^{\circ} \mathrm{C}\end{array}$ & +2.77 & 6.759 & 103 & 1250 & 5920 \\
\hline & & & & & 1430 & \\
\hline \multirow[t]{5}{*}{$\mathrm{NC}-7$ (1) } & Unirradiated & $-\cdots$ & 6.724 & 338 & 1411 & 3300 \\
\hline & & & & & 1700 & 3477 \\
\hline & $\begin{array}{l}2.4 \times 10^{22} \text { nvt } \\
0800^{\circ} \mathrm{C}\end{array}$ & +19.8 & 6.779 & 77 & $20 *$ & - \\
\hline & & & & & $w *$ & 1635 \\
\hline & & & & & & 850 \\
\hline
\end{tabular}

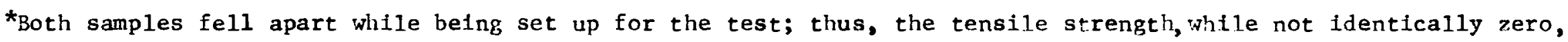
is very low. 
Irradiation of "Dimensionally Stable" Graphites

Capsule H-3-25 continues to operate satisfactorily at the start of the third and final reactor cycle. Five of the original nine thermocouples are now operatıve.

One additional capsule of this type, $\mathrm{H}-3-26$, is planned for Irradiation in August, September, and October; at that time total exposures will reach $1.2 \times 10^{2} 2^{\prime}$ nvt at $1000 \mathrm{C}$.

Stored Energy Measurements

Stored energy measurements were completed on $\mathrm{NC}-7$ and $\mathrm{NC}-8$ graphite samples. The $\mathrm{NC}-7$ sample had expanded 19.8\% upon irradiation at $800 \mathrm{C}$ to $2.4 \mathrm{x} 1022 \mathrm{nvt}$. The total stored energy in the NC-7 sample was $115 \mathrm{cal} / \mathrm{g}$. The $\mathrm{NC}-8$ sample was irradiated at $750 \mathrm{C}$ to $1.97 \times 10^{22}$ nvt. The stored energy in the NC-8 sample, which had a radiation-induced expansion of $2.8 \%$, was $76 \mathrm{cal} / \mathrm{g}$.

Gas-Graphite Reactıons

Most of the graphite specimens which have been examined by electron microscopy in this laboratory to date were made translucent by a final oxidation treatment rather than by a mechanical process. Therefore, it is important that any artifacts which may have been produced by such chemical preparation techniques be properly interpreted with regard to the structures originally present. To ald in this interpretation, two different mechanical procedures have been used to prepare addltional graphite specimens. In the first procedure, graphite discs, with a drilled conical depression in the center, are cut from rod stock by sawing through the bottom of the depression with a fine grained alundum cutoff wheel operating at $27,000 \mathrm{rpm}$ (dlsc specimensi. The second procedure, involves the use of grinding and polishing to thin the specimen while it is supported in an epoxy resin. The sample is polished first on one side and then remounted and thinned and polished on the opposite side. The specimen is then removed from the supporting resin and picked up on copper specimen grids coated with an organic adhesive. This second technique was developed by the Materials Process Development Unit.

During the past month a comparison has been made of the structural features found in selected specimens prepared by the two mechanical procedures described above. Numerous similarities were found between the two specimen types, but there were also some significant differences. While there were many translucent areas in the thinned and polished specimens, the interior areas of these specimens were generally too thlck for optımum viewing, and sharp electron-diffraction patterns could not be obtained in many cases. 
In the disc specimens the limited translucent area which was created at the edge of the central hole by the cutoff wheel was relatively thin and could be easily viewed in sharp focus in the microscope. Clear selected-area diffraction patterns were also easily obtained. In general, the ratio of the areas of graphite edge planes to 001 planes exposed to view appeared to be considerably greater in the thinned and polished specimens than in those of the same orientation made with a cutoff wheel. This difference is believed to be due to the differences in specimen preparation techniques employed. The thinned and polished specimens were supported in a resin matrix during preparation and should therefore exhibit detail features of microstructure more accurately than the unsupported specimens made with a cutoff wheel. The action of the cutoff wheel would tend to produce preferential graphite cleavage between layer planes and reorient the most delicate crystallites so that 001 planes are more nearly parallel with the plane of the wheel, giving the effect observed.

Another difference observed between the two types of specimens is the amount of foreign material present. It appears that the specimens prepared with a cutoff wheel are relatively free of foreign matter. However, a considerable amount of particulate material, possibly grinding abrasive, has been seen in thinned and polished specimens. Depending upon the nature of such foreign impurities, catalytic effects upon graphite oxidation reactions will likely be produced which are not characteristic of the original graphite.

In summary, this comparison of the two types of specimens produced entirely by mechanical techniques indicates some advantages and disadvantages of each type. Thinned and polished specimens appear to give a more accurate plcture of graphite microstructure and can be used for reference purposes as controls in oxidation experiments. However, the specimens which have been prepared to date have many areas which are too thick for optimum viewing and extraneous materials appear to be present. For the present, the thinned and polished specimen will be used only as a reference, and the actual oxidations will be performed on the disc specimens prepared with a cutoff wheel.

Previously, the mechanically-formed disc specimens, were always oxidized first by microwave-excited oxygen, then examined, and later given additional microwave or thermal oxidations. In the most recent series of experiments the mechanically-prepared disc specimens were given an initial thermal oxidation for 10 minutes at approximately $600 \mathrm{C}$ in flowing oxygen at one millimeter ( $\mathrm{Hg})$ pressure. They were then examined in the electron microscope, and the same oxidation treatment was repeated and followed by reexamination. In addition to the selective thermal attack, which has been reported previously, we have now confirmed that the lacelike networks are not produced by the thermal treatment. It also 
now appears that there is considerable movement of impurities during oxldation forming the clusters which were observed earlier in AGOT-LS graphite after microwave oxidation. In the present series of experiments $1 t$ was difficult to see any impurities in either TSX or AGOT-LS graphites in the unoxidized mechanically prepared specimens. Impurities appeared to become visible to some degree after the first thermal oxidation treatment, and the effect was enhanced after the same treatment was repeated. It now seems that a clustering action takes place which causes the impurities to become more easily recognized. Recognition of impurities is still entirely dependent upon the presumed association of the random diffraction spot patterns, described previously, with nongraphite materıals.

After the two thermal oxidation treatments described above, the specimens were given a two-minute oxidation in the glowing region of flowing microwave-excited oxygen at a pressure of 100200 microns. Subsequent microscoplc examination revealed that the effect of this treatment is qualitatively similar to that described previously, resulting from the same kind of treatment, and involves the formation of lace networks and many straight-edge structures with sharp angles.

\section{Irradiation Damage to Reactor Metals (A.L. Bement)}

\section{Alloy Selection}

Negotiation with Firth-Vicker, an English firm, for purchase of 500 feet of $\frac{1}{2}$-inch diameter bar FV-548 stainless alloy is nearly complete. In addition, arrangements have been made with FirthVicker to supply a Britısh tubing manufacturer with redraw material from the same heat as the $\frac{1}{2}$-inch bar in anticipation of a tubing order. Specifications for procurement of 0.210 inch OD $x 0.014$ inch wall, FV-548 tubing are being written.

An expression of interest in fabricating a one heat order of nickel-base alloy In-102 has been requested from Al legheny-Ludlum. Investigation of this material would parallel studies of Inconel 625 now under procurement from Huntington Alloys.

Efforts to improve design of the liquid metal capsule are continuing. A dye penetrant check of the vacuum cylinder weld areas revealed the cause of sodıum penetration of the vacuum annulus. A large circumferential crack in the heat affected zone adjacent to the top weld was responsible. This crack on the ID surface was probably caused by shear stresses created by differential thermal expansion between the inner and outer walls of the cylinder. A preirradiation stress relieving anneal did not sufficiently reduce inservice stresses to prevent fallure. A new design incorporating a 
bellows section as part of the interior wall should eliminate the shearing stresses in the top weld region.

A program to select materials for an in-core pressure device for the FFTF is continuing. Flat, tensile, and creep-rupture specimens of 304,316 , and 348 stainless steels, and JS-700 and Incoloy 800 alloys are being machined out of both 0.010 and $0.015-$ inch sheet. Stalnless steel (304 and 316) specimens subjected to $1060 \mathrm{~F}(571 \mathrm{Cl}$ sodium for 30 days in an 1sothermal loop had a heavy corrosion fllm. The $f_{1} l \mathrm{~m}$ is being examined to determine the nature of the corrosion products present. Attempts are being made to determine when and how the corrosion occurred and how such corrosion could affect the test program.

In-Reactor Measurements of Mechanical Properties

The purpose of the in-reactor measurements program is to determine the effects of irradiation on the mechanical properties of reactor structural materials. The effort is involved in measuring creep in AISI 304 stalnless steel and nickel-base alloys during neutron irradiation.

A plot of the Zener-Holloman parameter-versus-stress was made on logarthmic coordinates for in-reactor and control creep data for 304 stainless steel over the temperature range of 450 to $900 \mathrm{C}$. The plot is linear for both in-reactor and control data, except for a deviation below 500 C. This deviation represents either a change In the temperature dependence or the stress dependence of the second stage creep rate. Further analysis will be directed toward differentiating between these two dependencies.

Irradiation Effects in Structural Materials

Stainless Steels. The purpose of this phase of the program is to determine the combined effects of irradiation and environment on the mechanical properties of stainless steels. Padiation-induced property changes will be determined from irradiations and tests conducted at various temperatures on several alloys. Particular emphasis will be placed on determining the existence of metallurgical instabilities and the mechanisms by which they are affected by a nuclear environment.

Tensile tests at temperatures from room temperature to $750 \mathrm{C}$ have been conducted on AISI Type 316 stalnless steel irradiated to a fast neutron fluence of about $1.38 \times 10^{21} \mathrm{n} / \mathrm{cm}^{2}(\mathrm{E} 1 \mathrm{MeV})$ in liquid sodium capsule $\mathrm{GEH} 22-3$. The capsule was designed to operate at $1200 \mathrm{~F}(649 \mathrm{C})$, but the actual operating temperature has not yet been determined. Evaluation of the tensile data is in progress. 
Ex-reactor control tests for 1 rradiation quadrants 201,257 , and 258 have been performed over the temperature range from room temperature to $750 \mathrm{C}$. In-reactor quadrant 201 contained annealed AISI 304 stainless steel tensile specimens and was irradiated at $290 \mathrm{C}$ to a fast fluence of about $1.5 \times 1.020 \mathrm{n} / \mathrm{cm}^{2}, \mathrm{E} 1 \mathrm{MeV}$. Quadrants 257 and 258 contalned AISI 348 stalnless steel tensile specimens and were irradiated to about $1.0 \times 10^{20} \mathrm{n} / \mathrm{cm}^{2}(\mathrm{E} I \mathrm{MeV})$ at $290 \mathrm{C}$. The ex-reactor quadrants were held at $290 \mathrm{C}$ for a period of time corresponding to the in-reactor times. Evaluation of the tensile data is in progress.

Nickel-Base Alloys. The purpose of this program is to determine the effects of modified microstructures on the irradiation stabllity of nickel-base alloys. Mlcrostructural modifications are made by pre-irradiation thermal or thermomechanical treatments and are evaluated by tensile tests, stress-rupture tests, and microstructural examinations.

Stress-rupture tests at $1350 \mathrm{~F} 1735 \mathrm{C}$ ) are nearing completion on Inconel 600 and Inconel $X-750$ specimens held as controls for specimens irradiated at $540 \mathrm{~F}\left(280^{\circ} \mathrm{C}\right)$ to a fluence of $1 \times 10^{20} \mathrm{n} / \mathrm{cm}^{2}$ ' 1 Mev' and previously tested. Comparison of avallable data for both alloys indicates that irradiation decreases rupture lite by at least one-third, as was found to be true in earlier tests on Hastelloy $x-280$. The exact extent of this effect is dependent on the preirradiation treatment given the specimen, but a thorough analysis awaits completion of the tests.

Creep data from tests at $1350 \mathrm{~F}: 735 \mathrm{Cl}$ on unirradiated, pretreated, Hastelloy $\mathrm{X}-280$ specimens, held as controls for those 1 rradiated at $540 \mathrm{~F}(280 \mathrm{C})$, are being examined. The data indicate that thermomechanical treatments can lead to increased rupture life by reducing creep rates. A tenfold reduction in creep rate, compared to the standard treatment, was achieved.

Intercalıbratıon Test of counting Laboratorıes. To date, six of eleven laboratorles have reported counting results to PNL. A spectrum has been calculated for the MTR Rabbit Facility and forwarded to all participating laboratories to aid in calculating fluence from the monıtors. The spectrum was calculated using a twodimensional transport-theory code, 2DXY. Elghteen energy groups, sixteen above $0.183 \mathrm{MeV}$, were used for the calculations. The cross sections were obtained from the HRG cross section library.

Postirradiation Examination of Titanium and Nioblum Corrosion Specimens. Coupons of titanium and nioblum were irradiated in the ETR G-7 loop to compare the in-flux corrosion properties with phenomena observed on zirconium aliloys. Two coupons of each metal were irradiated four cycles in the $\mathrm{G}^{-}$loop in $\mathrm{pH}-10 \mathrm{NH}_{4} \mathrm{OH}, 0.05 \mathrm{ppm}$. oxygen at 270-280 C. The samples are undergoing postirradiation examination in Radiometallurgy. After removal of a black crud 
deposit, the samples will be weighed, sampled for hydrogen, and examined metallographically to study oxides and hydriding.

Fracture Mechanics

A program is under way to determine size and side-groove effects in A302-B pressure vessel steel using the DCB specimen. A major portion of the testing effort has now been completed, and the results are being analyzed. One of the more important findings pertains to the fracture toughness ' $\mathrm{K}_{\mathrm{I}} \mathrm{C}$ ' behavior of the A302-B plate. A very strong gradation in fracture toughness across the thickness of the plate resulted in a factor-of-two greater toughness at the plate surface than at the center. In addition, the static transition temperature is approximately $70 \mathrm{C}$ higher at the center of the plate than at the surface. These behaviors are in contrast to the yleld strength data which are quite uniform across the plate thickness. Differences in microstructure across the plate thickness are thought to cause the toughness gradation, and efforts are now being made to correlate microstructure with fracture toughness.

Unfortunately, because of the large toughness variations, portions of the data obtalned from the plate cannot be unambiguously interpreted in terms of size effects. For example, if a size effect exists, one anticipates a decrease in the measured fracture toughness with increasing size. In the course of this investigation, it was found that, for an increase in specimen size, a slight increase in measured fracture toughness occurred for any given position in the plate. It is believed that this effect may reflect the fact that larger specimens include material having both higher and lower toughness properties than smaller specimens. Thus, if the tougher regions of the specimen control the over-all toughness behavior of the specimen, one would indeed find the measured toughness to increase with specimen size. Further analysis of this behavior will be made from test results for 3 -inch $D C B$ and notch bend specimens. The thickness of these specimens spans nearly the entire thickness of the plate. Preparation of these specimens for testing is now in progress.

Determination of the fracture toughness of zircaloy-2 containIng 50,100 , and $400 \mathrm{ppm}$ hydrogen has shown that there is very little difference in toughness between the three hydrogen levels after $280 \mathrm{C}$ irradiation to $3 \times 10^{20} \mathrm{n} / \mathrm{cm}^{2}$ ( $\mathrm{E} 1 \mathrm{MeV}$ ). The fracture toughness ranged from 25 to $35 \mathrm{ksi}$ inch over the entire temperature range, and very little temperature dependence was observed in any of the specimens. The presence of the hydride platelets seems to have been the cause for the loss in temperature dependence and tends to decrease toughness at the higher temperatures where plastic behavior limits toughness measurements. Cold-worked Zircaloy-2 specimens irradiated to $1 \times 10^{21} \mathrm{n} / \mathrm{cm}^{2}(\mathrm{E} / \mathrm{MeV}$ ) (five cycles in the ETR) have been tested recently, and the fracture toughness data are belng analyzed. 
Fast Reactor Studies

Test Facilities. Creep-rupture test stands equipped for static sodium environment are now ready for operation in the 32l-A Building. Operation of these units is awalting completion of the liquid metal measuring station. All parts for this station are on hand, and assembly has been inltiated.

Bids have been requested for a liquid metal storage and loading facility which will include an inert gas glovebox and gas purifier. The liquid metal measuring station mentioned above will be used with this facility; and, together, they will enable operators to load and unload alkali metals into any type of chamber up to the largest size accommodated by the glovebox. The measuring station can be used independently of an inert atmosphere to fill chambers which are equipped with satisfactory seals.

Design for bullding renovation and installation of support facilities is being performed by Hanford Englneering Services. Approximately $30 \%$ of the design work has been accomplished, and completion is scheduled for August 1967.

Review of the different types of creep-rupture apparatus for which tests will be performed has shown that there are four different sets of requirements:

1. Bench operation, unırradıated samples, environment of low vacuum or inert gas.

2. Hot cell remote operation, irradiated samples, environment of low vacuum or inert gas.

3. Remote operation, irradiated samples, environment of flowing sodium with cover gas.

4. Remote operation, irradiated samples, environment of high vacuum.

From a design standpoint, the first requirement is the simplest. The design for this situation is complete, and space is avallable for installing four units of this type. Design work will continue on the other three types, and It is expected that as space and sultable building services become avallable, the appropriate test units will be avallable for installation.

Design has been completed on the vacuum manlfold system to be placed in the prototype cel1. Specifications and a request for bids for this equipment will be issued next month.

The support system for the flowing sodium test loop will be shipped from the vendor's plant during the last week of the month. 
The commercial solvent Dowanol "EB" has been very successful for removing small quantities of sodium from test samples and equipment. Two small capsules originally filled with test specimens and sodium were each drilled to provide two 1/16-inch holes in the side wall, then immersed in the solvent. The solvent removed all of the sodium from within the capsules within a 24-hr period. Upon removal of the outer shell of the capsule, only a few small white spots of sodlum oxide were found in the crevices of the specimen holder. It is felt that even these would have been removed if ultrasonic agitation had been used. In another case a large test specimen, exposed to flowing sodium for 30 days, was cleaned by immersion in the solvent. After cleaning, the test specimen could be handled and examined directly with only minor precautions required for the minute amounts of sodium oxide remaining.

Fast Neutron Mechanisms. Steady state hydrogen permeation studies of fast reactor alloys are continuing with current emphasis on the austenitic stainless steels. A preliminary investigation of the effect of a surface carbide layer on the effusion behavior of hydrogen from AISI 302 stainless steel has been completed for the 250-600 C temperature range. No significant reductions in permeability or other evidences of appreciable surface effects were noted, nor were there any indications of the formation of hydrocarbonaceous reaction or desorption products.

A second permeation cell that will substantially extend the present system capabilities for dynamic and high sensitivity gas permeation studies is under construction and will be in operation by mid-June. Special features have been incorporated in the cell design to permit studies of the effect of temperature cycling and elastic and plastic deformation on the hydrogen solubility and diffusivity characteristics of reactor alloys.

ATR Gas Loop Supporting Studies

Model Gas Loop Studies. The model gas 100 is a 2100 F (1093 C), recirsulating helium loop which is being operated to determine the effect of helium atmosphere on high temperature materials and specimen holders and to see if prolonged use will affect the operating characteristics of the new heater. This loop is a one-tenth size model of the gas loop that is being constructed in the Advanced Test Reactor at Idaho Falls.

The model gas loop has operated a total of 3929 hrs since installation of the new heater and has sustained 74 thermal cycles from room temperature to various heater out let temperatures (52I hrs of operation have been completed this past month). The horizontal test assembly, which has accumulated a total of $2054 \mathrm{hrs}$ at operating conditions $2100 \mathrm{~F} / 1093 \mathrm{C}$ ) was removed once during the month for inspection and sample exchange. 
Further tests have been conducted during the month in an effort to locate and identify sources of gas contamination through outgassing and in-leakage. These tests are being conducted because the test specimens have shown substantial effects of contamination even though the loop gas purity has been malntalned below the minimum detectable limits of $0.1 \mathrm{ppm}$ each of $\mathrm{H}_{2}, \mathrm{~N}_{2}, \mathrm{O}_{2}, \mathrm{CH}_{4}$, and $\mathrm{CO}$.

Test Assembly. The nickel-base alloy test assembly achieved an additional 240-hr exposure at $1700 \mathrm{~F}(927 \mathrm{C}$ in the model gas loop; total exposure time of this assembly is now 470 hrs. Performance of the assembly remained satısfactory.

Superalloy and Refractory Metal Corrosion Studies. Corrosion coupons placed in the heater discharge section of the model loop have exposure times to $1930 \mathrm{hrs}$ at temperature $(2100$ to $2025 \mathrm{~F}$ ) $(1149$ to $1105 \mathrm{C})$. The table illustrates the evaporation tendency of the superalloy samples exposed to model loop conditions as well as the gettering tendency of the niobium and tantalum samples.

Initially, the weight gains noted for the $\mathrm{Nb}$ and $\mathrm{Ta}$ specimens were attributed to oxygen and nitrogen contamination. Additional data from $\mathrm{Nb}$ and $\mathrm{Nb}$ alloy tensile specimens exposed in the $2100 \mathrm{~F}$ $(1149 \mathrm{C})$ heater section now suggest the presence of carbides.

Vacuum fusion analysis for oxygen and nitrogen in a $\mathrm{Nb}$ sample exposed 504 hrs at $2100 \mathrm{~F}(1149 \mathrm{C}$ ) has been made. The total contamination of the sample, determined by weight change, was 3960 ppm. The average oxygen and nitrogen concentrations found were 2650 and $78 \mathrm{ppm}$, respectively. Oxygen apparently is the major contaminating agent.

Samples recently taken from the loop will be inspected by a number of analytic methods to verify preliminary findings regarding the nature and source of sample contamination.

Corrosion Specimens Exposed to Model Loop Conditions

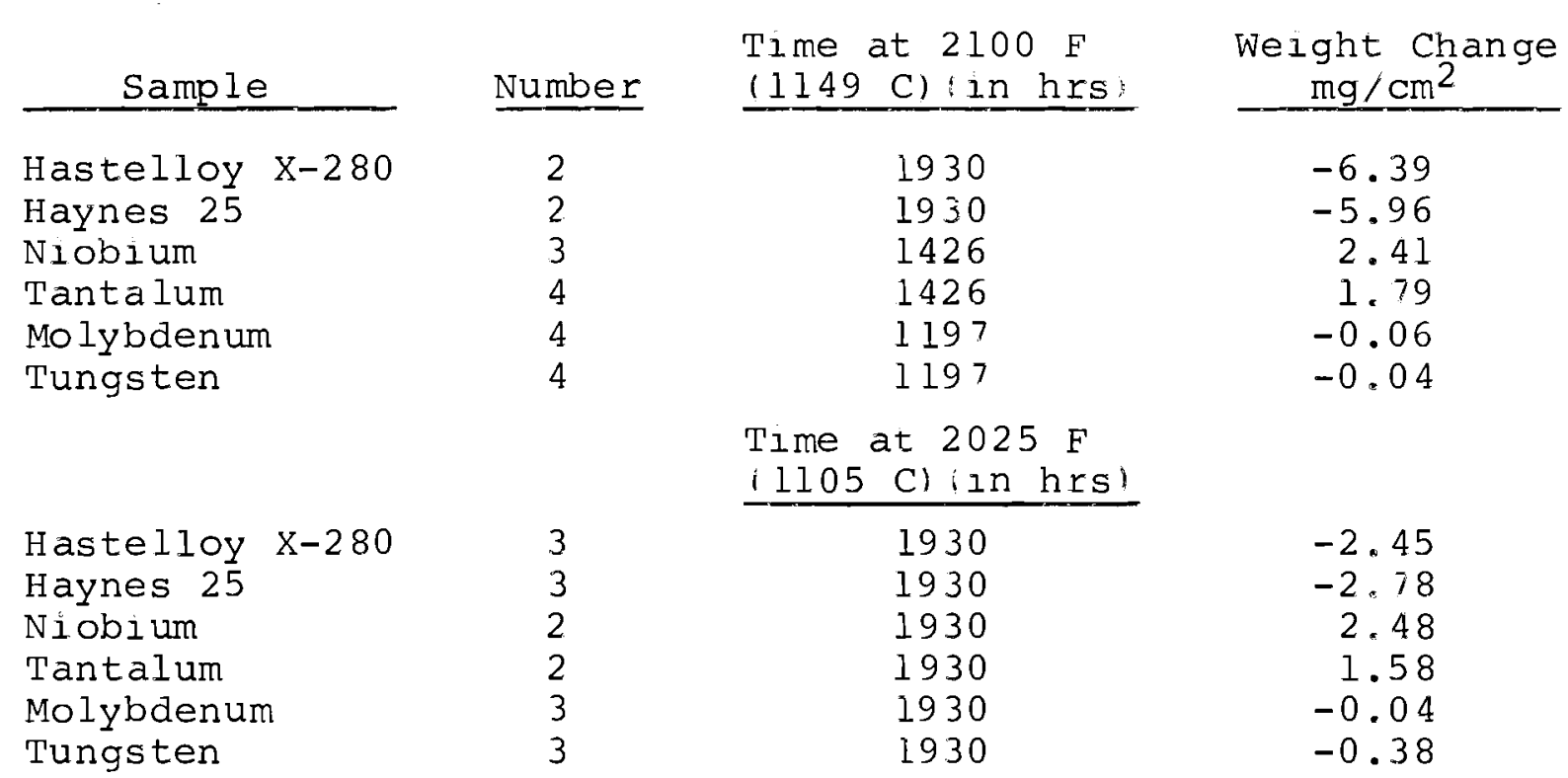


Specimen Surface Behavior and Contamination. X-ray diffraction analysis reveals that the surface reaction layers on $\mathrm{Nb}$, after model gas loop exposure, are composed of $\mathrm{Nb}_{2} \mathrm{C}$ and $\mathrm{NbC}$, not $\mathrm{Nb}-\mathrm{N}-\mathrm{O}$ as previously reported. Ta2C and TaC plus unidentified phase(s) are formed on Ta. Vacuum fusion analysis of $\mathrm{Nb}$ and $\mathrm{Ta}$ corrosion samples from which the surface reaction layers were removed shows that oxygen is the major contaminant in the bulk of the sample; the oxygen dissolved in the metal and the carbon in the carbide layers account for total weight gain of the specimens.

New tensile specimens of $\mathrm{Nb}, \mathrm{Nb}-1 \mathrm{Zr}$ and $\mathrm{Nb} 752$ were exposed for $170 \mathrm{hrs}$ at $2100 \mathrm{~F}(1148 \mathrm{C})$ in the model loop. The yield and tensile strengths of $\mathrm{Nb}$ were higher than the values obtained for the 60-hr exposure, while the ductility was slightly lower. Yield and tensile strengths and ductility of Nb-lir were the same for the 60- and 170hr exposures. The yield strength of $\mathrm{Nb} 752$ was also the same for the 60- and 170-hr exposures and the drastic reduction of ductility in this material as a result of contamination was confirmed.

Refractory metal samples in the $1700 \mathrm{~F}(927 \mathrm{C})$ section of the model loop reached an exposure of $475 \mathrm{hrs}$. The $\mathrm{Nb}$ sample showed an increase in Cr surface contamination over the 230-hr exposure, and $\mathrm{Mn}$ and Fe surface contamination also became detectable. Tantalum exhibited slight $\mathrm{Mn}$ and $\mathrm{Cr}$ contamination, and Mo showed no detectable contamination, although a trace of $\mathrm{Ni}$ was detected after the 230-hr exposure.

Corrosion samples of Inconel $600, \mathrm{Hastelloy} X$, and Incoloy 800 were attached to the nickel alloy test assembly during the second exposure of $240 \mathrm{hrs}$. Again, the Inconel 600 exhibited a slight surface tarnish, while the other alloys were discolored. X-ray diffraction patterns from the surface of Hastelloy $x$ and Incoloy 800 showed three and one extra lines, respectively, but positive identiflcation of the surface contamination could not be made. Electron microprobe analysis revealed the presence of oxygen on the surfaces of Hastelloy $X$ and Incoloy 800 , but not Inconel 600. Thus, Hastelloy $X$ and Incoloy 800 are oxidızing during model loop exposure in the $1700 \mathrm{~F}(927 \mathrm{C})$ section. Once again, the Mo specimen attached to the same assembly showed no weight change indicative of oxidation or contamination.

During all these exposures the total impurity content $\mathrm{IO}_{2}, \mathrm{~N}_{2}$, $\mathrm{H}_{2}, \mathrm{CO}, \mathrm{CH}_{4}, \mathrm{H}_{2} \mathrm{O}$ ) of the helium is less than 1 ppm. This inventory of contaminants is not sufficient to produce the observed effects unless some replenishment occurs. To date, no significant air leakage into the loop has been detected. Additional studies to identify the source of contaminants will be an important part of future experimentation. 
Heat Transfer studies. Gas temperatures and maximum specimen temperatures in the ATR helium loop were calculated for an assumed gamma heating profile, with a peak heating rate of 25 watts/gm at the midpoint of the test section length. Two representative test assemblies were considered in the calculation. The first had twelve tiers with eighteen columbium specimens in each, and the second had three tiers each of tungsten, molybdenum, columbium, and tantalum. The hanger rod and test section liner were columbium in both cases.

Results were calculated for helium flow rates of $2000 \mathrm{lb} / \mathrm{hr}$ and $4000 \mathrm{lb} / \mathrm{hr}$, with in let temperatures of $1200 \mathrm{~F}, 1500 \mathrm{~F}$, and $1800 \mathrm{~F} 1648 \mathrm{C}, 815 \mathrm{C}$, and $982 \mathrm{Cl}$. Heat generation in the hanger rod and test section liner accounted for $60 \%$ or more of the total heating at any cross section,

Damage Mechanisms in Iron

The objective of this program is to determine how irradiationinduced defects interact with moving dislocations to modify the mechanisms of plastic deformation in a metal. The role of interstitial impurities in alpha iron is currently under investigation.

It has been established that the primary influence of neutron irradiation on the mechanism of deformation in iron is to increase the long range internal stresses which a moving dislocation encounters. This is seen as an increase in the athermal component of flow stress and is found to be a function of interstitial impurity content and exposure. There appears to be a correlation between the density of defect clusters observed by transmission electron microscopy and the increase in athermal stress which can be explained by the Orowan mechanism of precipitation hardening. In this mechanism the stress to bow a dislocation between two pinning points is given by $=a b / \bar{k}$, where, is the shear modulus, $b$ the Burgers vector, and is the separation between obstacles in the slip plane; and $x=(\mathrm{Nd})-1 ; 2$, where $\mathrm{N}$ is the volume density of defects and $d$ is the average dıameter.

Folls to be ixradiated and examined in the electron microscope have been prepared from program materials of two purities on which tensile data are available. Additıonal work is in progress to perfect techniques for sectioning tensile specimens for microscope observation to quantitatively test this hypothesis.

Experiments are also under way to study the aging characteristics of iron contalning several levels of carbon and to compare the results from these controls with irradiated iron. These samples will be studied by both tensile testing and resistivity recovery. These. experiments should resolve some of the confusion which exists in the 
field as to whether the motion of carbon atoms or vacancies is being observed in recovery experiments in the temperature range from $25 \mathrm{C}$ to $350 \mathrm{C}$.

A paper, entitled "Thermally Activated Dislocation Motion and Its Application to the Study of Radiation Damage," was presented at the Battelle Colloquium on Dislocation Dynamics held at Harrison Hot Springs, Canada, May 1-6, 1967.

\section{ATR Gas Loop Operatıon and Maintenance (G.A. Last)}

ATR Gas Loop Support

Gas-Cooled Loop Vendor Data Review. Gas-cooled loop contract submittals from Montek (analytical instruments), Johnson service Company (main instrument panel), Atomics International (inpile tube), and calmec (gas-cooled loop valves), have been reviewed and comments submitted to Ebasco Services, the architect-engineer.

Analytical Instrumentation. A meeting was held with personnel of Montek, Salt Lake City, Utah, to discuss a number of details on the most recently submitted drawings and to review the test procedures to verify the acceptability of the equipment.

Montek's proposed test procedure was reviewed, and agreement was reached as to the general test procedures to be employed; namely, standard mixtures of helium with $\mathrm{CO}, \mathrm{CO}_{2}$, and $\mathrm{O}_{2}$ to be fed to the sample manifold that would be previously dried with dry nitrogen. Several such mixtures will be used to permit direct checking of the instruments and the operation of the helium diffusion cells (dilution box system). The accuracy of the operation of the combined analytical and diffusion cell package will be difficult to test because the limited output of the diffusion cells makes dilution by factors of 500-1000 beyond the range of measurement of the flow meters in the dilution train box.

The moisture will be checked in a manner similar to that used in the Transfer Facility unless a more convenient standard based on salt hydrates can be established. This is a standard method of checking meteorological type humidity sensors but has not been extended to the low moisture levels at which we are expecting to operate. Additional testing will be completed in order to confirm the applicability of the method.

Montek was informed that PNL would supply mixed gases for the final test to be completed at their plant. PNL will prepare detailed test procedures to ensure the equipment meets our specifications. 
Gas-Cooled Loop Heat Exchangers. On April 24, 1967, a meeting. was held at the offices of Teledyne Materials Research (TMR) with representatives of Fansteel corporation to discuss comments made by TMR on the Fansteel heat exchanger stress reports.

The stress reports had been transmitted to the GCL reviewing agencies for approval and were subjected to a third party review by TMR under a contract to PNI. TMR comments had been transmitted, together with other comments from the reviewing agencies, to Fansteel at the April 7 meeting in Los Angeles.

As a result of agreements reached at the meeting concerning content, methods, and scope for an acceptable section III stress report, the review of the Fansteel retransmittal is expected to generate, at most, only minor comments. It is PNI's intent that the resubmittal of all three stress reports will be reviewed by TMR.

The meeting discussion followed the format and content of the TMR comments which consisted of the appendices to their April 3 letter to D. C. Kaulitz, and individual comments were resolved in one of the following ways:
a. TMR agreed that the Fansteel method and calculations were valid.
b. Fansteel agreed that the TMR comment was valid.
c. Fansteel agreed to substantiate in the report areas that to them were satisfactory by inspection and to which TMR agreed.

d. Fansteel agreed to supply addıtıonal calculatıons.

In general, TMR agreed that all but one or two areas covered by their comments were undoubtedly satisfactory, and inclusion of the relevant information in the stress report would satisfy their objections. In the areas requiring further work, TMR reserved their opinion but said that the calculations would probably show that the desıgn was acceptable.

Transfer Cask. Meetıngs were held at Ebasco offices in New York City with representatıves of Babcock and Wilcox, LockheedGeorgia, $A E C$, INC, Fluor Corporation, and PNL in attendance. The purpose of the meetings was to discuss reviewing agencles' comments on the ATR gas loop transfer cask. The comments had been transmitted to Lockheed-Georgla earlier so they would have time to review them prior to the meeting. The first day was used to discuss the comments on the stress analysis and the mechanical aspects of the drawings. $B \& W^{\prime} s$ comments were used as an outine since they were the only ones transmitted by Fluor. Other agency comments were inserted as the relevant subjects were introduced. Discussed, but not reported in the minutes, were possible changes to the order required by the addition of support cradle and trunnion modification 
requirements. An additional desirable change would be to remove the motor-generator set from the body of the cask to a permanent stationary location in the ATR bullding. At the time the specifications were written, it was not anticipated that a motor-generator set would be required, and the specifications called for a selfcontained system with a single power supply lead. This was inconsistent with the $400 \mathrm{cps}$ power requirements of the clrculator; therefore, Lockheed-Georgia designed the cask with an integrally mounted motor-generator.

They also stated that the request for special flanges would require field installation, since the Rateau circulator has been built and is presently being tested.

A complete review of the electrical and control portion of the design was conducted. Lockheed-Georgia accepted the comments from the review and will change the drawings.

Gas-Cooled Loop Program. A meeting was held on May 17 , atten $\overline{d e d}$ by representatives of Idaho Nuclear, PNL, AEC-ID, and AEC-RDT to discuss operation of the GCL transfer faclilty and its anticipated role in the development of the GCL irradiation program.

A. L. Bement, PNL, discussed the present status of the program plans, including examples of material and contaminant behavior at elevated temperature, and the importance of the observational and manipulative capabilities of the facility to the development of a successful program. He also pointed out that personnel who perform the necessary work in the facility must be permanent, continuing members of a research team, whose involvement is at the program level, rather than a unit operation level.

INC, prior to the meeting, was concerned that the PNL objectives might not have considered areas such as safety, responsibility or knowledge of operations in the facility which they, as the site operating contractor, have as a primary consideration. They also desired to offer the services of their own skilled hot cell techniclans, rather than have a sponsor organization duplicate the function.

PNL concurred with the INC objectives and pointed out how the areas causing concern had been considered. The desired sponsor interface was designated as the inside perimeter of the faclity, with all transfer and air handling functions completely INC's responsibility. Existing working agreements provide for INC cognizance and over-all responsibility for sponsor activities through their Project Engineering Branch. It was also agreed that it was desirable for PNL to secure the technical services of INC for transfer facility operations which become sufficiently routine to establish operating procedures. 
Metallic Fuels Development (G.A. Last)

Irradiation of Thorlum-Uranium-Zirconium Fuel Elements

Three thorıum - 2.5 wto uranium (93.2\% U-235) - 1.0 wto zirconium tubular fuel elements clad in Zircaloy-2 are under irradiation in the P-7 pressurized water loop in the ETR. Three fuel elements which were being irradiated are being stored in the viewing basin at the ETR site.

The current status of the six test elements is summarized in the table. The temperature data for fuel elements GEH-10-64, 65, and 71 are corrected for a temperature rise across an oxide buildup on the clad. The temperature data for the other fuel elements are not corrected for oxide buildup. Visual examination of fuel element GEH-10-65 during the last shutdown indicated that some of the oxide buildup on the clad had sluffed off. No other detectable changes in the external appearance have occurred. The behavior of the elements continues to be excellent with only 3.4 응 swelling being observed on the element with the maximum exposure of more than 2 at. $\%$ BU.

\section{Irradiation Data on Th-2.5 wto U - 1 Wto Zr Fuel Elements}

\begin{tabular}{|c|c|c|c|c|c|c|}
\hline $\mathrm{GEH}-10$ & $\begin{array}{c}\text { Percent } \\
\text { Fuel } \\
\text { Swelling } \\
\end{array}$ & $\begin{array}{l}\text { Fissions/ } \frac{\text { Burnup }}{3} \\
\text { (Mwd/tonne) }\end{array}$ & At. & $\begin{array}{l}\text { Max. } \\
\text { Core } \\
\text { Temp. } \\
\text { OC } \\
\end{array}$ & $\begin{array}{l}\text { Specific } \\
\text { Power } \\
\text { w/gm } \\
\end{array}$ & $\begin{array}{l}\text { Surface } \\
\text { Heat Flux } \\
\text { Btu/hr-ft }\end{array}$ \\
\hline 65 * & 3.4 & $\begin{array}{l}6.1 \times 10^{20} \\
(18,100 !\end{array}$ & 2.07 & 440 & 35 & $5.1 \times 10^{5}$ \\
\hline 64 * & 1.7 & $\begin{array}{l}4.4 \times 10^{20} \\
(12,600)\end{array}$ & 1.44 & 400 & 27 & $4.0 \times 10^{5}$ \\
\hline $71 *$ & 1.2 & $\begin{array}{l}3.1 \times 10^{20} \\
(8,800)\end{array}$ & 0.99 & 460 & 39 & $5.6 \times 10^{5}$ \\
\hline 72 ** & 0.1 & $\begin{array}{l}1.5 \times 10^{20} \\
(4,300)\end{array}$ & 0.49 & 490 & 43 & $6.2 \times 10^{5}$ \\
\hline $70 * *$ & -0.5 & $\begin{array}{l}1.3 \times 10^{20} \\
(3,900)\end{array}$ & 0.45 & 470 & 39 & $5.6 \times 10^{5}$ \\
\hline $84 * *$ & 0.1 & $0.9 \times 10^{20}$ & 0.29 & 440 & 33 & $4.8 \times 10^{5}$ \\
\hline
\end{tabular}

* Temperatures, corrected for oxide buildup, and heat generation conditions during ETR Cycle 88.

**Temperatures, not corrected for oxide buildup, and heat generation conditions during ETR Cycle 84 . 
High Exposure Uranium Irradiation Test

Hollow core uranium fuel elements being tested in the $\mathrm{M}-3$ hot water loop of the ETR have successfully completed their fourth cycle of irradiation and are now approximately half way through the fifth cycle. At the end of the fourth cycle, ETR Cycle 88, the accumulated exposures ranged from 4123 MWd/tonne to $553 \mathrm{MWd} /$ tonne. The maximum fuel temperatures range from $350 \mathrm{C}$ to $500 \mathrm{C}$, a decrease of approximately $40 \mathrm{C}$ from previous maximum fuel temperatures. Maximum exposure at the end of the fifth cycle, ETR Cycle 89, wlll be approximately $5000 \mathrm{MWd}$ /tonne. These fuel elements, 0.45 inch diameter by 6.25 inches long and clad with $\mathrm{Zr}-2$, are part of an irradiation test that has been designed to operate uranium fuel rods at elevated alpha phase temperatures to burnups greater than 10,000 MWd/tonne $\left(6 \times 1020\right.$ fissions/ $\left.\mathrm{cm}^{3}\right)$. The variables being studied in this test include fuel composition, external restraint, and internal void volume. The combined effects of the plastic character of uranium during irradiation and the restraints from the cladding and system pressure are expected to cause the uranium swelling to be accommodated by a central hole. Two uranium compositions are being used: Alloy 1 , containing $U+350 \mathrm{ppm} F e-800 \mathrm{ppm} \mathrm{Al}$, and Alloy 2, containing $\mathrm{U}+150 \mathrm{ppm} \mathrm{Fe}-100 \mathrm{ppm} \mathrm{Si.} \mathrm{A} \mathrm{fuel} \mathrm{enrichment} \mathrm{of} 4.5 \% \mathrm{U}-235$ is being used to achieve the desired burnup rate $(10,000 \mathrm{MWd} / \mathrm{tonne}$ in one calendar year) and temperatures. Fuel rods of both compositions were fabricated by coextrusion to 0.450 inch diameter with 0.025 inch and 0.050 inch thick Zr-2 cladding.

During ETR Cycle 88 there were 24 fuel elements in the test assembly. Fol lowing that cycle of irradiation, these elements were visually examined and welghed while submerged in the ETR basin. The submerged weights were used for calculating the bulk fuel volume changes. The most signficant results from the observations and measurement were:

1. All elements continue to show a small accumulated volume decrease.

2. There continues to be agreement with previous data from this irradiation test in that the volume decrease stops or reverses at an exposure that is dependent on initial void volume and cladding thickness.

3. There are still no visible changes in the diameter of the elements.

4. Qualitatively, the warp does not appear to be changing with increased exposure.

5. There was no indication of accelerated Zr-2 corrosion on any of the elements irradiated during this cycle. 
It appears, by extrapolating the present data on the highest exposure elements having 0.050 inch thick $\mathrm{Zr}-2 \mathrm{cladding}$ and an initial vold volume of $20 \%$, that the external volume changes will remain negative at least to exposures of $5000 \mathrm{Mwd}$ tonne. There does not appear to be any fuel assoclated problems to prevent the continued good performance of these fuel elements to their intended high goal exposure of 10,000 MWd, tonne or higher.

Elght elements were shipped to the Battelle Research Reactor for neutron radiography at the end of ETR Cycle 88 . Seven of these elements were examined by neutron radiography following the second cycle of Irradiation. At the exposure of the first examination, the bulk external volume was decreasing, but the internal vold hole did not show indications of closing. Now at somewhat higher exposures, the decrease in bulk external volume of these elements has stopped or reversed. It will be of extreme value to know whether the stopping and reversal of external volume change is associated with filling of the central vold. The elghth element is one that showed the largest volume decrease, 1.8\%, and had warped considerably.

Fabrication of additional fuel elements for this test is continuing. These elements will be used for intermediate exposure, destructive examination, and for extension of the test goal exposure beyond 10,000 MWd/tonne.

Fast Reactor Dosimetry and Damage Analyses

(R.E. Nightingale)

EBR-II Dosimetry Experiment

Analysis of the fist neutron dosimetry test conducted in the EBR-II core has been completed. The experimental test and data reduction procedures have been described in previous monthly reports.

The most important result is that reliabllıty of spectral calculations has been established. The same neutron flux (within Il5\%) was calculated from five monitors with widely divergent spectralaveraged cross sections, regardless of whether they were irradiated at the core center or at the core edge. For example, the ratio of the flux calculated from the $63 \mathrm{Cu}(\mathrm{n}, \mathrm{r})$ reaction and the $58 \mathrm{Ni}(\mathrm{n}, \mathrm{p})$ reaction remain constant within $\pm 15 \%$ from core center to core edge; however, the ratio of the spectral-averaged cioss sections for the same reactions from core center to core edge varies by a factor of 2 .

The average total flux at the center of the reactor for this low power test is about $3 \times 1013 \mathrm{nv} / \mathrm{MW}$ at the core center, but it drops to $2 \times 1013 \mathrm{nv} / \mathrm{MW}$ at the core edge. The flux is relatively flat for the central zone of the core $\div 2$ inches axialiy and \pm ? inches radially). Calculation of $f l u x$ from the 59 Coin, : and $45 \mathrm{sc}(\mathrm{n}$, were. not included in the average flux values. Flux calculated from these monitors was a factor of three hıgher and 50\% higher, respectively, 
than the average flux determined from the $58_{\mathrm{Ni}}(\mathrm{n}, \mathrm{p}), 54_{\mathrm{Fe}}(\mathrm{n}, \mathrm{p})$, $63 \mathrm{Cu}(\mathrm{n}, \mathrm{y}), 58 \mathrm{Fe}(\mathrm{n}, \mathrm{y})$, and the $27 \mathrm{Al}(\mathrm{n}, \alpha)$ reactions. Cobalt, which has been used for fast reactor dosimetry, was found to be unreliable due to uncertainties in the cross section data at high energies. As tests continue, an effective cross section for cobalt will be determined in order that it can be used. Similar but smaller uncertainties exist for scandium, but it looks promising as a fast reactor monitor.

A second EBR-II low level dosimetry experiment has been conducted. The monitor materials for this test were selected on the basis of the first low level test. Capsules were in the same reactor positions (rows), but monitors extended about 25 inches above the core. The monitors are being analyzed.

\section{ENGINEERING DEVELOPMENT}

Neutron Flux Monitors (W.G. Spear)

Regenerative Detectors (Thermal Neutron Flux)

Preparations were continued on the comprehensive test program for evaluating regenerative thermal neutron flux detectors at the ETR. An in-line instrumentation system is being developed to provide continuous monitoring of the various detector output signals and to measure detector characteristics. Purchase orders were placed for needed components, including microammeters and voltmeters. Four 0-300 V adjustable power supplies were obtained, and delivery is expected soon on the precision resistors. The final two detectors for the test capsule were received, thus all detectors for the test capsule are on hand and detailed fabrication of the capsule can proceed.

In the regenerative detector, the U-234 transmutes by thermal neutron capture to U-235, thereby replacing the burnup loss. By this technique the useful life of the neutron detector is extended considerably. As demonstrated in the original experiments, such detectors will maintain relatively constant sensitivity to a neutron fluence exposure of $5 \times 10^{21}$.

Microwave Detectors (Thermal Neutron Flux)

The use of microwaves for measurement of thermal neutron fiux is based on the change of the resonant frequency of a resonant cavity in which a plasma has been created. The resonant frequency of a microwave cavity is a function of the free electron density of the plasma, which can be created by ionization of a contained gas by the 
$(\mathrm{n}, \mathrm{p})$ reaction in $\mathrm{He}-3$ (the contalned gas;. It may also be possible. to use the lonization caused by the fission fragments from an isotope or mixture of isotopes, such as the regenerating mixture of U-234 and U-235. The equilibrium density established by the generation of electrons and various dissipation mechanisms will be a function of the neutron flux density.

For experiments performed previously, a significant difference occurs between the theoretical electron density and the value calculated from experimental data. The resulting loss of sensitivity of the neutron flux monitor is believed to be related to the perturbation of electromagnetic fields by the quartz gas container, which is inserted into the metal microwave cavity to contain the gas. Because of this, gas tight microwave cavities without the quartz ampoule wlll be used in subsequent reactor in-core tests. Gas-tight cavities being developed should permit operation at selected gas pressures. High temperature brazing techniques are being investigated to allow outgassing of the cavity at temperatures up to $500 \mathrm{C}$. Because of difficulties encountered in obtalning a gas-tight seal at the high temperature, a cavity waveguide seal assembly was fabricated using a silver solder which melts at $185 \mathrm{C}$. This cavity was initially processed for several days at $175 \mathrm{C}$ and 10 microns pressure prior to introduction of $\mathrm{He}-3$ gas. Transmission waveguides with supports are assembled and ready for final connection to the cavity sensor.

A description of electromagnetic fields within a cavity containing a dielectric ampoule is being derived to estimate the effect of the dielectric on the unperturbed cavity resonant frequency and on the unperturbed fields. This derivation should permit an estimate of the loss of sensitivity due to an inserted dielectric.

Regenerating Detectors (Fast Neutron Flux)

The nuclear physics characteristics of possible candidate nuclei are being investigated in an attempt to find a suitable combination of isotopes for development of a fast neutron regenerative detector. The goal is to find a combination of fertile and fissile emitter material, such as U-234 - U-235 combination successfully used in the thermal neutron ilux detector. A difficult problem in Identifying suitable isotopes is due to the paucity of fast fission cross section data needed to provide a basis for analytical work. The literature is being carefully screened to identify appropriate cross section data currently avallable.

Beta Current Generator Detectors (Fast Neutron Flux)

The Be-9 isotope shows promise as a possible detector material for measurement of fast neutron flux under the difficult environmental conditions anticipated in future reactors. This isotope 
undergoes an $(n, a)$ reaction, with a 0.1 barn cross section at $3 \mathrm{MeV}$, to provide a beta particle emission ( $3.5 \mathrm{MeV})$ with a relatively short half life of 0.8 second. The beta emission generates a signal current proportional to the neutron flux level to yield an estimated signal current of approximately 1 x $10^{-6}$ A from about one $\mathrm{cm}^{3}$ of Be exposed in a flux of $10^{15} \mathrm{nv}$. In an experimental chamber, beryliium in a metal oxide state can be encapsulated in a suitable sheath opaque to the alpha particles but transparent to the generated betas, which would escape for signal generation. To avoid interference signals due to the anticipated high gamma levels of $1010 \mathrm{R} / \mathrm{h}$, the balanced twin-lead, twin-chamber concept, as developed in the thermal flux detector investigations, is being considered for use.

Evolved Gas Detection Concept (Fast Neutron Flux)

In this unique concept for fast neutron detection, an evolved gas, such as helium, would be collected through a simple evacuation tube connected to a chamber assembly inserted into the reactor core. Gamma interference problems would be minimized by the location of the electronic instrumentation in the less destructive environment external to the core. In the detector chamber, $(n, \alpha)$ or $(n, p)$ reactions with $B-10$ or other materials would release gas in quantities proportional to the neutron flux. Calculations indicate that about 1011 atoms/sec of helium gas would evolve from one gram of $B-10$ in an incident fast neutron flux of $1013 \mathrm{nv}$. At these levels the evolved gas could be measured by mass spectrographic or optical spectrometry methods. It is expected that neutron flux levels down to $10^{10} \mathrm{nv}$ could be detected using the evolved gas concept.

\section{Microwave Detectors (Fast Neutron Flux)}

By extending microwave techniques proven useful for thermal flux measurements, it is anticipated that fast neutron flux may be measured in a similar manner. A cavity containing materlal with a neutron sensitive dielectric constant will induce a measurable frequency shift of the microwave cavity. By measuring the frequency difference between a microwave generator llocked electronically to a reference cavity, and the sensing cavity, the incident neutron flux may be determined. The reference cavity would provide compensation for temperature and gamma effects.

Other neutron initiated reactions causing a frequency shift of a microwave cavity are also being considered. Frequency shift of the microwave cavity can be induced by injecting gas into the cavity. Therefore, materials such as $B-9$ which evolve gas in their reactions with fast neutrons are candidates for this technique. Sensitivity of the sensor would be directly related to the gas evolution rate as 
the frequency shift depends upon the number of gas molecules in the. cavity. For example, neutron flux measurements down to about $1011 \mathrm{nv}$ should be possible for a reasonable gas evolution rate of $10^{-2}$ atoms/ sec/nv.

Microwave and Infrared Detection of Coolant Impurities and Measurement of in-Reactor Temperatures (W.G. Spear)

Microwave Detection of Impurities in Coolant Gases

By using the change of resonant frequency of a microwave cavity as included helium laden with varying amounts of water vapor changes the over-all dielectric constant of the medium, a detection sensitivity of $125 \mathrm{ppm}$ water vapor in helium at $300 \mathrm{C}$ and $950 \mathrm{ppm}$ at $436 \mathrm{C}$ has been achieved to date. The time of response of such a detector is small, being limited by the time constant of the associated phase lock amplifier. For the experıments performed, time constants of one second were used. To achleve improved sensitivity at high temperatures, very stable microwave generators and heterodyne techniques are required. An alternate technique would first cool the sample of gas, but this introduces a short additional response time, depending on the heat exchanger characteristics.

A second promising method involves use of microwave phase shift in a section of waveguide. This may be a section of the process tubing or a special structure within a coolant tube which would allow free flow of coolant, thus becoming a truly in-line detector. Components have been acquired and preparations made to perform experiments of phase shift within standard waveguides. These components and other designed instruments are being assembled into a measurement system to allow measurements at $300 \mathrm{C}$ prior to extension to high temperatures. Propagation of waves in large (oversize) tubes will also be investigated to establish a basis for using process tubing for carrying microwaves in the phase shift measurement system.

High Temperature Measurements

Problems of long term measurement of high temperature within an operating nuclear reactor are related to the sensor environment which is detrimental to most materials. Several microwave techniques of measuring temperature are being developed to alleviate sensor problems.

Several successful experiments conducted with a laboratory furnace indicate that cavity shift-of-frequency techniques are Iinearly related to temperature change and provide sensitivity on the order of $350 \mathrm{kHz} / \mathrm{OC}^{\mathrm{C}}$. During the most recent of these experiments, quartz rods were inserted into the copper transmission waveguide so that it would remain undistorted even at $1000 \mathrm{C}$ and with 
the interior evacuated. This support technique proved adequate; however, furnace temperature was inadvertently increased to $1050 \mathrm{C}$ and the input waveguide collapsed. Additional development of this temperature measuring method will require the use of higher melting point waveguide (especially circularly shaped) and sensors.

A microwave radiometric method of measuring temperature is also being considered. The major equipment required for laboratory measurements is completed and should be operating within a month. Auxiliary equipment (e.g., input waveguide, black body emitter, and evacuation section) is being fabricated. The maximum temperature measurable with the radiometer will again be related to the melting point of the metals from which the input waveguide is fabricated.

Infrared Techniques

Modification to the sample chamber has been completed, giving the desired air flow through the chamber, and both design and fabrication of the wedge filter wheel were finished. This holder will hold the rectangular wedges used on the first experimental system. Using the instrument, analysis of the wedge filter is being conducted. Several filters are available for use as both zero and wedge filters. Further work will dwell on calibration and determination of the $\mathrm{CO}_{2}$ sensitivity of the chopper wheel.

\section{Upstream Boiling Burnout (D.R. Dickinson)}

The analysis of data obtained in recent upstream boiling burnout tests was continued. In these tests an electrically heated test section 0.435 inch ID and 70 inches long was used. Data were taken at 1500 psig discharge pressure and steam-water mass velocities of 3.5 and $7 \times 10^{6} \mathrm{lb} / \mathrm{hr}-\mathrm{ft}^{2}$. In some of the test runs the heat flux was increased beyond the first indication of boiling burnout until the burnout condition had spread to cover the entire heated surface of the tube. For each such run, the surface temperature indicated by each of 24 thermocouples was plotted as a function of heat flux. The discontinuity of slope of this graph was taken as the indication of boiling burnout. In these tests bolling burnout first occurred at a point upstream of the center of the heated length and spread in both directions as the heat flux was increased. The heat flux required to place the entire heated length in burnout was 50 to $100 \%$ higher than that at the initial indication of burnout. This behavior was generally similar to that encountered with previous heated test sections. However, the present tests were performed with a thinwall nickel test section which had a much lower temperature drop across the wall. Therefore, more accurate measurement of surface temperature and burnout heat flux were possible. 
Certain significant conclusions about the mechanism of upstream burnout were derived trom these data. Under those conditions when the burnout region was spreading with increasing heat flux, there were regions at the upstream and downstream ends of the heated length that were in a preburnout condition with wetted surface. This condltion was indlcated by surface temperatures only a few degrees above the bolling polnt of the coolant. Between these two regions was a region in the postburnout state where the surface is not wetted by the liquid. This reglon was indicated by surface temperatures about $100 \mathrm{~F}$ above the bolling point. At the high mass velocities and qualities considered, annular flow should exist in the test section. Since there can be no liquid film flow through the postburnout region, a liquid surface film and nonburnout condition can exist downstream only if deposition rate of liquid droplets from the core of the annular flow pattern is greater than the deposition rate in the burnout region. Therefore, upstream burnout requires that the droplet deposition rate be greater at the downstream end of the tube. The reason for such an increase in deposition rate is not evident. A reduction in the liquid fraction as heat is added to the fluid would suggest a reduced liquid deposition rate. However, the increased vapor fraction will give a higher linear velocity at the downstream end which will promote deposition. The deposition rate may also depend on the sizes of the liquid drops, which can change along the length. Highfrequency flow oscillations, produced downstream and damped out upstream, might also produce greater turbulence and liquid deposition at downstream locations. Further study is required to determine which of these mechanisms is signiticant in promoting higher downstream deposition.

\section{PLUTONIUM UTILIZATION PROGRAM (F.G. Dawson)}

\section{Fuels Development}

High Exposure Plutonium Studies

It is apparent that the growth of Am-24l from the beta decay of Pu-24l will provide a significant contribution to the surface dose rate of high exposure recycled plutonium within a relatively short time after separation. The Am-24I build-in is being followed by observing the count rate of the $59.6 \mathrm{keV}$ photons / due to Am-24l decay) at monthly intervals on two Shlppingport and four Yankee plutonium product samples.

The dose rate for any plutonlum sample will increase as some function of the Am-24l bulld-in and to determine this function surface dose rates of three $\mathrm{PuO}_{2}$ samples from high exposure 
Shippingport fuel are measured at approximately monthly intervals. Theoretically, the plutonium isotope decay would cause a dose rate decrease with time; however, the net change is an increase due to the daughter product activity and particularly the Am-241. The table lists the gamma x-ray surface dose rate increase as measured and gives the total percent increase in dose rate.

$\underline{\mathrm{PuO}}_{2}$ Surface Dose Rates

\begin{tabular}{|c|c|c|c|c|c|c|c|c|}
\hline \multicolumn{3}{|c|}{61 grams } & \multicolumn{3}{|c|}{73 grams } & \multicolumn{3}{|c|}{7976 grams } \\
\hline & Dose Rate & $\frac{\circ}{0}$ & & Dose Rate & \% & & Dose Rate & $\frac{9}{0}$ \\
\hline Date & $\mathrm{Rad} / \mathrm{hr}$ & Increase & Date & $\mathrm{Rad} / \mathrm{hr}$ & Inc. & Date & Rad/hr & Inc. \\
\hline $3 / 8$ & 2.46 & & $2 / 3$ & 2.07 & & $2 / 3$ & 1.9 & \\
\hline $4 / 18$ & 3.29 & 34 & $4 / 18$ & 3.65 & 76 & $4 / 18$ & 4.26 & 124 \\
\hline $5 / 22$ & 3.59 & 46 & $5 / 22$ & 4.26 & 106 & $5 / 22$ & 4.40 & 132 \\
\hline
\end{tabular}

Insufficient data have been accumulated to draw definite correlations, particularly in that it was not possible to get all samples through the separations processes and oxide conversion steps at the same time. The isotopic concentrations of the two primary dose rate contributors $\mathrm{Pu}-238$ and $\mathrm{Pu}-24 \mathrm{l}$ (via decay to Am-24l) were approximately $0.5 \%$ and $7.5 \%$, respectively.

It is evident that the surface dose rate will at least double within the first year after separations ifor plutonium from most thermal reactor fuels with 25,000 to $30,000 \mathrm{MWd} /$ tonne exposures or more) and will increase at a relatively steady rate for several years thereafter.

Neutron yield measurements and surface dose rate readings were also made on a 942-gram sample of shippingport metal. The approximate isotopic distribution in weight percent was: $\mathrm{Pu}-238-0.58$, $\mathrm{Pu}-239$ - 65.19, $\mathrm{Pu}-240$ - 23.2, $\mathrm{Pu}-241$ - 7.75, and $\mathrm{Pu}-242$ - 3.28. The surface dose rate was $2.25 \mathrm{rad} / \mathrm{hr}$ through three layers of polyethylene bagging material. The extrapolated dose rate for the bare metal would be about $4.5 \mathrm{rad} / \mathrm{hr}$.

The measured and calculated neutron yields of the 942-gram plutonium metal source agree quite well. The metal was about three inches $O D$ by one-half inch thick. The measured neutron yields were $4.23 \times 10^{5} \mathrm{n} / \mathrm{sec}$ from the flat surface and $2.71 \mathrm{x} 10^{5}$ from the edge of the source. The true yield is probably closer to the flat surface measurement since some neutron attenuation would occur through three inches of material in the edge-on reading. These values compare to a calculated spontaneous fission yield of $2.94 \times 10^{5} \mathrm{n} / \mathrm{sec}$. The calculated and measured values compare favorably when the $(x, n)$ contribution of the impurities in the metal are considered.

An attempt to obtain neutron spectra data was unsuccessful due to the lack of available machine time and the relatively few neutrons. Sources on the order of $10^{7} \mathrm{n} / \mathrm{sec}$ are required to obtaln spectral data in reasonable counting times. 
The plutonium source wlll be converted to an oxide and all measurements repeated. The $(x, n)$ contribution from the oxygen will be particularly valuable, and the increased neutron yield should provide sufficlent source strength for neutron spectral data.

Isotopic analyses are continuing on the Yankee samples which are nearly complete, and a $20 \% \mathrm{PuO}_{2}-\mathrm{UO}_{2}$ sample was obtained from the EBR-II which will be analyzed for correlative information. Dresden plutonium product was received with approximately $21.5 \%$ Pu-240 content which will also be analyzed.

Erratum to March Monthly Report (BNWL-425)

Page 70, fifth paragraph, third sentence should read:

"If one assumes the neutron spectra for the neutrons of $\mathrm{PuO}_{2}$ as being similar to fission neutron spectra, the dose rate at one meter would be $0.022,0.023,0.023$, and $0.063 \mathrm{~m}$ rem/hr, respectively, for the sources listed in the table."

Fourth sentence should read:

"For masses of $\mathrm{PuO}_{2}$ of 500 grams and greater the neutron dose rates will be significant and when compared to the gamma dose rate at one meter will be the major contributor to personnel exposure."

Page 71, third column of table should read:

$\frac{\text { Neutrons/C }}{0.265}$

Underwater Profilometer

The underwater profilometer, for inspecting FERTF fuel rods, will be delivered on plant on month's end. The instrument will be tested to detect shipping damage before installation in the PRTR basin. Installation will be completed during June 1967. It will be mounted adjacent to the tray assembly.

Underwater Tray, FERTF Fuels

The underwater tray for the assembly of FERTF fuel elements has. been installed in the PRTR basin. Underwater lights, handing tools, and other accessories are being fabricated. 
Instrumented Fuel Rods

Four fuel rods instrumented to measure fuel rod gas temperature and pressure are operating satisfactorily in PRTR. The fuel rods have operated at reactor power levels to 57 megawatts and fuel temperatures in the range of 2400-2600 C without operational difficulties.

Fuel rod pressures seem to be sensitive to reactor power, and hence fuel temperature, but no significant gas accumulation has occurred because of the low fuel exposures (:300 MWd/tonne).

ETR Loop Testing

An intentionally defected, Zircaloy-clad, 7-rod cluster (approximately 33 inches long) was fabricated and sent to the ETR for irradiation testing in the $\mathrm{P}-7$ loop. The vibrationally compacted rods contained pneumatically impacted enriched $\mathrm{UO}_{2} \cdot$ one rod was defected with an 0.060 inch diameter hole through the cladding at the maximum power position. The purpose of this test is to investigate the irradiation behavior of an intentionally defected fuel rod operating under high performance conditions.

The irradiation, which is scheduled to start on June 6, 1967, will be conducted at a maximum linear rod power generation of approximately $29 \mathrm{~kW} / \mathrm{ft}$ with $60 \%$ of the radius molten at the plane of the defect. Future tests will be conducted in the FERTF in PRTR under approximately the same operating conditions.

TREAT Transient Testing

Six fuel capsules were fabricated and shipped to NRTS for irradiation testing in TREAT. Except for shortened fuel lengths, shortened plenums, and simple cylindrical end plugs, the capsules are prototypic of PRTR-HPD fuel rods. The core of each capsule consists of one depleted $\mathrm{UO}_{2}$ pellet at each end of a $13.92 \mathrm{~cm}$ (5.48") long vibrationally compacted UO2 (5.01\% U-235 enriched) fuel column. The bulk fuel density in each capsule is about $86 \%$ of theoretical. Each capsule contains a $1.82 \mathrm{~cm}(0.72 ")$ long fission gas plenum.

Two of the six capsules were irradiated in the TREAT transparent autoclave. One capsule was used to obtain calibration data; the other capsule was subjected to an energy input between 300 and $400 \mathrm{cal} / \mathrm{g} \mathrm{UO}_{2}$. The results of these experiments are not yet available. 
An additional calibration experiment was conducted on a fuel capsule containing vibrationally compacted $\mathrm{UO}_{2} 19.54 \%$ U-235 enrlched). Preliminary analysis of the calibration data indicates that the energy input values previously reported for similar capsules is about $20 \%$ too high.

\section{$\underline{\text { PRTR Testing }}$}

Three vibrationally compacted HPD fuel rods were destructively examined in Radiometallurgy after irradiation in PRTR at maximum linear rod power generations of $16.8,17.0$, and $17.9 \mathrm{kw} / \mathrm{ft}$, respectively. Fuel structures were evaluated in an effort to estimate the maximum fuel temperatures during irradiation. This evaluation is being done to establish the maximum allowable PRTR power level. PRTR power is limited by maximum permissible fuel temperature just below melting.

The observed fuel structures and estımated fuel temperatures were compared with calculated values using the best avaliable thermal conductivity data for packed-particle oxide fuels. The irradiations at each power level step were conducted for 48 to 80 hours to permit structural equilibrium to occur. Estimated maximum fuel temperatures for the vibrationally compacted fuel rods have been in the range of 2200 to $2600 \mathrm{C}$. Data developed thus far suggest that the indicated or actual fuel temperatures in vibrationally compacted fuels during irradiation are lower than the calculated values. This apparent discrepancy between calculated and observed fuel temperatures could be caused by any one or a combination of the following reasons: (1) the effective conductivity curve used in the calculations is too low although the calculated power to produce melting seems to be reasonably accurate (within 5\%:, 12) the estimated temperature used for the onset of columnar grain growth $(1800 \mathrm{C}$ is low, (3) the core-clad contact coefficient used in the calculations 1500 Btu/hr-ft2-OF) is low, and/or (4) the maximum rod power values used are low. The apparent discrepancles between estimated and calculated fuel temperatures will be clarified as more data are developed.

A 19-rod HPD element contalning hot pressed $\mathrm{UO}_{2}-2$ wt $\mathrm{PuO}_{2}$ pellet fuel has been irradiated in the FERTF to an average burnup of approximately $300 \mathrm{MWd} /$ tonne at a maximum linear rod power of approximately $20.5 \mathrm{kw} / \mathrm{ft}$. Estimated maximum fuel temperatures were $2500 \mathrm{C}$. Underwater examination of the element showed it to be in excellent condition, and irradiation is continuing. 
A thin crud deposit has been observed on the surfaces of HPD elements irradiated in PRTR during some fuel examinations. The crud formation is caused by corrosion of reactor components by the pH-7 coolant. The occurrence of the loosely adhering, reddish colored film is related to the oxygen and hydrogen concentrations in the coolant even though the concentrations were maintained well within the maximum allowable limits. The degree of crud formation observed thus far has been judged to pose no operational problem from a fuels standpoint.

The 8-rod FERTF test element design has been approved for irradiation in the PRTR at a maximum linear rod power of about $20 \mathrm{kw} / \mathrm{ft}$. A prototype assembly is undergoing long-term fretting and wear tests under FERTF coolant conditions in the out-of-reactor EDEL test loop. The element has been exposed in the loop for 21 operating days at the following coolant conditions:

$\begin{array}{lr}\text { Coolant pressure } & 1075 \mathrm{psig} \\ \text { Coolant temperature } & 475 \mathrm{C} \\ \text { Loop flow } & 100 \mathrm{gpm} \\ \text { Coolant pH } & 7.5\end{array}$

Periodic examination of the element has not revealed any noticeable fretting or wear condition between element components. Loop exposure has shown that tolerances between some components needed to be increased to permit easier assembly and disassembly. Some superficial fretting marks of unknown origin were observed on the zircaloy pressure tube. Exposure of the element is continuing.

\section{Reactor Physics}

\section{$\underline{D_{2} 0}$ Moderated Systems}

Thorium Loading in the PRTR. Reactivity and flux distributions have been calculated with the HFN code for two-zone loadings in the FRTR. One type of fuel is a tube-in-tube geometry containing thorium - 3.7 wto U-235 metal. The other is a 19-rod cluster geometry containing $\mathrm{UO}_{2}-2 \mathrm{wt} \% \mathrm{PuO}_{2}$ irradiated to an average exposure of $12,000 \mathrm{MWd} / \mathrm{tonne}$.

Calculations performed with the $\mathrm{HFN}$ code indicate that $30 \mathrm{UO}_{2}-$ $\mathrm{PuO}_{2}$ fuel elements surrounding 55 Th-U fuel elements would receive an average exposure of $200 \mathrm{MWd} /$ tonne for every average exposure of $1000 \mathrm{MWd} / t$ tonne on the Th-U. If the $30 \mathrm{UO}_{2}-\mathrm{PuO}_{2}$ fuel elements are surrounded by the $55 \mathrm{Th}-\mathrm{U}$ fuel elements $(6 \%$ less reactivity), the average exposure on the $\mathrm{UO}_{2}-\mathrm{PuO}_{2}$ is $650 \mathrm{MWd}$ / tonne for every average $1000 \mathrm{MWd} /$ tonne received by the $\mathrm{Th}-\mathrm{U}$.

Previous burnup calculations for a loading of 55 Th-U fuel elements indicate that the average attainable exposure is 15,000 MWd/ 
tonne. During the life of the core it is estimated that the 30 $\mathrm{UO}_{2}-\mathrm{PuO}_{2}$ fuel elements would attain an additional $6000 \mathrm{MWd}$, tonne if lt were surrounded by $55 \mathrm{Th}-\mathrm{U}$ fuel elements.

A burnup calculation with ZODIAC has been instiated for a loading of $19 \mathrm{UO}_{2}-\mathrm{PuO}_{2}$ Iuel elements surrounded by $66 \mathrm{Th}-\mathrm{U}$ fuel elements.

Batch Core Experiment in the PRTR. Analysis of the Batch Core Critical Tests in the PRTR has continued. Plots have been made of the moderator level coefflclents of reactivity for the core at various moderator helghts, core sizes, and boron concentrations. Integral plots of moderator reactivity worth versus height have been used to analyze other experimental data such as the reactivity worth of coolant volds, for both a single channel and the entire core. The data on boron worth have also been analyzed, and a dıfferentıal curve of milli-k/wppm B-l0 versus boron concentration has been derived.

Calculation of Rod Bowing in the FERTF. Calculations have been made to determine the effect of rod bowing in the new 8-rod version of the FERTF. For the FERTF with a 0.125" Zircaloy basket, the expected power increase if a rod bowed outward until it touched the basket would be $8.0 \%$. With a $0.125 " \mathrm{Z}$ Ircaloy basket and a $0.114 "$ stainless steel Iner, the expected power increase would be $4.5 \frac{0}{\circ}$.

Reactivity Oscillator Tests. Analysis of the reactivity oscillator experiments performed in the Batch core in the PRTR is nearly complete. Data were recorded at power levels of 250 watts and 1 Megawatt. The experimental data were fitted using program LEARN to obtain the ratio of the effective delayed fraction (E) to the prompt neutron lifetime i.". The $i$, i ratios from the two experiments agreed to within their experimental errors. Using the average of the two experimental values of $\sigma / 2$ and a calculated value of $3.08 \times 10^{-3}$ for s, a value of $11.6 \pm 0.1 ; \times 10^{-4}$ seconds was obtained for $i$. The concentration of $B-10$ in the moderator was 25 wppm. This result agrees quite well with the value of $1.57 \times 10^{-4}$ seconds for i which was calculated (BNWL-221) for the PRTR core with 27 wppm B-l.0 in the moderator.

Application of the Nd-148 Isotopic Dilution Technique to Determine Fuel Burnup. The fuel burnup of two Irradiated samples cut from the PRTR element $5237\left(\mathrm{UO}_{2}-1\right.$ wt: $\mathrm{PuO}_{2}$ ! has been analyzed by measuring the amount of Nd-148 in the sample, using isotopic dilution techniques. An alternate determination of burnup by our standard technique of Cs-137 analysis was simultaneously carried out as a check on the Nd-148 results. Agreement of the two methods is good ror one sample and poor for the other. Further analysis of the data which is in progress should yield information as to the nature of the discrepancy for this one sample. It is intended that 
future burnup analyses will utilize the Nd-148 method with some samples being checked by the Cs-137 analysis. The uranium and plutonium contents of the two samples were also determined by isotopic dilution techniques. The raw data gathered from each sample are converted into more useful numbers by utilizing the computer program ISODIL. Program ISODIL has been expanded to include the Nd-148 analysis, and testing of this part of the program is now in progress.

UO2 Burnup Data Analysis. Experimental burnup data from 156 $\frac{1}{2}$-inch $\mathrm{UO}_{2}$ samples are presently being processed to deduce cross section ratios of the fuel as a function of U-235 depletion. The fuel was initially natural $\mathrm{UO}_{2} \frac{1}{2}-1$ nch diameter rods, 88 inches in core length, bound together as a standard Mark I 19-rod fuel element and irradiated in the PRTR. Grouping of the data in order to characterize the neutron spectrum in the outer ring of 12 rods as opposed to the spectrum in the middle ring of 6 rods or the center rod has not proved advisable since it has not been possible to detect data differences resulting from spectrum differences in the $\mathrm{UO}_{2}$ samples. A spectrum difference may be seen by comparing the Pu-240/Pu-239 versus U-235/U-238 atom ratios for the outer ring rod data and the middle ring rod data. However, the cross section ratio analysis is formulated to use the $\mathrm{Pu}$ isotopic concentrations ratioed to the $\mathrm{U}-235$ concentration, $\mathrm{Pu}-239 / \mathrm{U}-235, \mathrm{Pu}-240 / \mathrm{U}-235$, etc., and since the $\mathrm{Pu} / \mathrm{U}$ ratio was not determined by isotopic dilution techniques for this data, weight data must be introduced to determine the Pu-239/ U-235 ratio, etc. The errors of the welght data are large enough to mask any spectrum differences whlch would produce different cross section ratios.

Fabrication of PRCF Fuel Rods

Critical experiments in the PRCF require fabrication of about 1000 ( 4 wt: $\mathrm{PuO}_{2}-\mathrm{UO}_{2}$ test fuel rods. Because commercial procurement of test rods could not be accomplished during FY-1967, approximately 250 rods are being fabricated onsite. Offsite commercial procurement to obtain the balance of the rods during FY-1968 is now being completed.

Seven possible commercial fabricators have been informed of the proposed work. Information submitted included the test fuel rod design drawings, specifications of fuel, and instructions about the two-step procedural requirements. Under Step I, which is now in progress with commercial vendors, technical proposals are being considered. It is expected that the technical proposals will be received by June 12, 1967. Prices will be considered at Step II of the purchasing procedure. About 200 test rods are being requested for delivery on November 1, 1967; other options are included concerning possible delivery date for additional fuel rods. Since the market price is presently unknown, it is difficult to predict the 
number of test rods which will be purchased; however, 400 to 600 rods seems to be a reasonable estimate.

Other work accomplished included the evaluation, location, and delivery of $50 \mathrm{kilograms}$ of uniform isotopic plutonium. The isotoplc content is about $18 \% \mathrm{Pu}-240$ and was obtalned as the nitrate. Such a supply is required for uniformly fabricated offsite and onsite fuel rods for use in the PRCF critical experiments.

$\mathrm{PuO}_{2}$ Particle Size Studies

As a result of recent development work, emphasis on preparation of $\mathrm{PuO}_{2}$ spheres has been changed from pneumatic-impaction and jet-miliing to arc-fusion and induction-plasma spheroidizing. This is considered to be a major process improvement both from the standpoint of particle quality and fabrication costs. Ceramographic examination of $\mathrm{PuO}_{2}$ spheres revealed that arc-fused $\mathrm{PuO}_{2}$ feed material was superior to sintered $\mathrm{PuO}_{2}$ and pneumatically-impacted $\mathrm{PuO}_{2}$. Particles, 50 to $300 \mathrm{mlcrons}$ in diameter and having a density of $98 \% \pm 2 \% \mathrm{TD}$, were prepared from arc-fused $\mathrm{PuO}_{2}$.

A series of rods contalning $\mathrm{PuO}_{2}$ spheres from the pneumaticimpaction and jet-milling sequence has been tested in the PCTR to determine the reactivity effect in graphite caused by increasing the $\mathrm{PuO}_{2}$ particle size through the range of $0,100,200$, and 350 microns. The fuel contains 2.0 wto $\mathrm{PuO}_{2}$ in $\mathrm{PuO}_{2}-\mathrm{UO}_{2}$ with a nominal 8 wto $\mathrm{Pu}-240$ and natural uranium.

Preliminary analysis of the experiments show a general decrease in reactivity with increasing particle size. A discrepancy exists in the data at present due to an apparent discontinuity between the data representing the zero micron size and the values obtained for the three larger sizes. Effects due to density variations in the rods have been measured and do not explain the discrepancy.

Code Development

The recent changes in BARNS-II to permit numerical integration of resonance region contributions to group cross sections are still being debugged. As a convenience to HRG users, the NUTAPE part of BARNS-II has been modified to provide an alphabetic, as well as numerical, listing of the nuclides on an HRG data tape.

The programs ETOM, CRECT, EDIT, Flange-II, and Retrieval Subroutines that were received from Brookhaven National Laboratory, were compiled, absoluted, and placed on tape.

The program ETOM, whlch processes neutron cross section data from the ENDF/B Library Tape and produces library decks for the program MUFT4 and MUFT5, was successfully executed for the lsotope lithium-6. 
A program, "RIFF RAFF, for Computation of Resonance Integrals in a Two-Region Cell," (ANL-7033) written by P. H. Kier for the CDC-3600 at Argonne National Laboratory, is now available on the Univac 1107 and 1108 . A sample case accompanying the program has been successfully executed. A difference of approximately 0.16\% was noted in the value of the resonance integral. This is believed to be caused by the smaller word size of the Univac 1107. The code and input instructions may be obtained by contacting $W$. L. Purcell.

A computer code, PLTAPE, has been written for use with the neutron scattering code, NUTSCT. The code PLTAPE generates a plotting tape of the double differential cross sections versus beta $(\beta)$; the scattering law $S(\alpha, \beta)$ versus alpha; and $S(\alpha, \beta) / \alpha$ versus $\alpha$ for linear, log-log, and semi-log scales, respectively. Any sequence of these may be plotted with the versatility of multiple plots per case and/or multiple cases on the same graph. Plots may be handled to a maximum 30-inch paper range. Errors on all values are included, along with symbol head marking designation sequence.

The most intricate part of the program utilizes a portion of subroutine MAPS from program LIKELY (BNWL-390) with slight modifications.

NAMELIST is used to input plotting ranges along with tape input which contains all the possible plotting arrays.

It was discovered that the method used by the RBU Monte carlo code to account for absorption introduces extra statistical uncertainty to results of a calculation. The effect of this is not large but should be eliminated. Methods of changing the RBU Monte Carlo to remove this unnecessary source of statistical fluctuation are being studied.

A program called FSD has been written to calculate the fractional standard deviation $(\sigma / \bar{x})$ of a number of counts taken on a decaying radioactive source as a function of counter dead time ( ) . An option is included which will find the value of "which gives the minimum value of $c / \bar{x}$. This eliminates the need to estimate the range of : in which the minimum will occur.

Mater:als Development

Postirradiation Examination of Tube 5690

Six specimens were cut from PRTR process tube 5690 at 20-inch intervals through the flux zone. Oxide thicknesses on the specimens are being determined metallographically. Thickness measurements are not yet available, but the examination shows evidence of accelerated oxidation on the inside surface of the tube. The magnitude of the accelerated oxidation appears to be similar to that observed for PRTR tube 5696 (March 1967 monthly progress report). 
Primary System Ion Exchanger

The primary system ion exchange bed (IX-1), removed from service during April, was examined to determine the reason for an abnormally high pressure drop when in service. A vertical core sample of the bed, 7/8 inch in diameter and 25 inches long, was tested for pressure drop and flow characteristics. The observed pressure drop across the coring did not explain the operationally observed pressure drop of the (IX-1) bed. A screen test of the resin showed 1.4 vol\% passed a 50-mesh screen. Some of the fines were broken beads.

\section{Component Examination}

The stem and seat of a primary system valve (P-16) were examined to determine the cause of leakage. The valve is normally closed against $1050 \mathrm{psig}$ of $\mathrm{D}_{2} 0$. An embedded particle in the gold seating surface was probably the initial cause of leakage. Cavitation erosion could then have produced the remaining observed damage to the stainless steel and gold seats.

\section{Reactor Engineering Development}

\section{FERTF Support Work}

Rupture Loop Partıcle Separator. Work is under way to replace part of the axlal flow separator with a transparent plastic tube so that the swirl angle may be observed and measured. Special flanges have been completed, and the plastıc tube has been ordered.

Plans are to obtain additional performance data with $\mathrm{UO}_{2}$ of accurately known particle size distribution. This testing is being delayed because equipment has not been received for making this analysis (this equipment is $1 \frac{1}{2}$ months late in being received).

Fuel Element Testing. Testing of the 8-pin, FERTF basket-type element continued during the month. It now has accumulated $489 \mathrm{hrs}$ of testing, of which 456 hrs were at operating conditions of $120 \mathrm{gpm}$, 1075 psig, and $475 \mathrm{~F}^{*}$.

The element has been removed and inspected weekly. During each of these outages the tube has been visually inspected. During the most recent inspection an attempt was made to photograph selected spots inside the pressure tube. This attempt was not successful. The equipment is being modified and will be used again during the next tube inspection. 


\section{Test Reactor Operation}

\section{Operating Experience}

Pertinent data for the month are as follows:

$$
\begin{aligned}
& \text { 1. Production.............. } 518 \mathrm{MWd} \\
& \text { 2. Hours Critical. . . . . . . . . . } 292.9 \\
& \text { 3. Critical Efficiency .......... . 40.68\% } \\
& \text { 4. Total Experimental Time Efficiency . . . . 49.64응 } \\
& \text { 5. } \mathrm{D}_{2} 0 \text { Losses } \\
& \text { a. Indicated Stack Loss }(4 / 26-5 / 25 / 67) \text {. 1,855 lbs } \\
& \text { b. Physical Inventory (4/27-5/25/67) . . 1,434 1bs } \\
& \text { 6. Helium Loss ........... .. 87,625 scf }
\end{aligned}
$$

The PRTR power level was increased from 50 MW to 57 MW to provide rod powers of $16.8,17.7$, and $18.6 \mathrm{kw} / \mathrm{ft}$ in a test fuel element which was located in process channel 1649 (ring one). The $18.6 \mathrm{kw} / \mathrm{ft}$ part of PRTR Test 136-1 was interrupted twice. During the startup of 5/9/67, the primary system flow indication decreased substantially. Actual primary system flow was normal, but because the flow signal was low, the power calculator signal was also low, and when the reactor power was increased to an indicated $45 \mathrm{MW}$, the actual power was $58 \mathrm{MW}$. The test fuel element was discharged and the test rod replaced. The erroneous reading was caused by a transmitter equalization valve being partially open. Flow through the valve caused a false signal because of temperature dependent density and pressure drop effects. During the shutdown period 5/15/67, a replaceable rod from an inappropriate position in the fuel element was removed from the PRTR Test 136-1 fuel element and sent to the Radiometallurgy Laboratory. A new rod was installed in the test fuel element, and the irradiation at $18.6 \mathrm{kw} / \mathrm{ft}$ is in progress at the end of the month.

The PRTR operation was interrupted by 15 shutdowns. Two were scrams caused by flow monitor trips, two were scheduled outages, three were planned shutdowns for liquid shim adjustments, and eight were intentional shutdowns to correct operating conditions.

There were nine major outages as follows:

Date

Apri 128

May 3

May 7
Reason for shutdown

Shut down from 45 MW (for 22.2 hrs) to correct erratic control of secondary coolant system.

Scheduled shutdown to remove rod for PRTR Test 136-1. The seal on primary pump \#3 had failed, and the pump was replaced. New bearings and seals were installed in moderator pumps 2 and 3 . The outage required 57.9 hrs.

Shut down (for 49.5 hrs) to correct excessive leakage through primary valves $\mathrm{P}-77$ and 78 . 
May 10 Shut down (for 23.3 hrs) to correct the cause of a low primary bulk flow indication.

May 15 Scheduled shutdown for 24.2 hrs to remove one rod for PRTR Test 136-1.

May 16 Shut down for 56.5 hrs to repair $\mathrm{D}_{2} 0$ leak on $\mathrm{H}-95$ valve.

May 18 Shut down for 15.4 hrs to correct excessive leakage through primary valves $\mathrm{P}-77$ and 78 . The $\frac{1}{2}$ " trim was replaced with $\frac{1}{4} "$ trim and a thermocouple installed to provide a continuous monitor of the $\mathrm{D}_{2} 0$ leaking to the primary storage tank.

May 19 Shut down for 14.2 hrs to correct leaks in primary valve $\mathrm{P}-78$.

May 21 Shut down for 122.6 hrs to correct cause of high $\mathrm{D}_{2} 0$ losses to the stack.

During these major outages the general program of reducing $\mathrm{D}_{2} 0$ leaks continued. Two more angle valve leakage collection lines were disconnected, the valve bodies plugged, the leak collection lines capped, and the valve packings tightened. A total of 30 angle valve leak collection lines have now been capped.

Solids (crud) levels in the PRTR primary system continued under good control with $\mathrm{pH} 7$ operation at power levels above $50 \mathrm{MW}$. Noticeable red crud was present on a central fuel element examined after several short periods of operation with $\mathrm{O}_{2}$ levels of $0.02 \%$, or more, in the primary system offgas, and with $\mathrm{H}_{2}+\mathrm{D}_{2}$ levels of 0.6 to $0.8 \%$. However, no crud was visible on the same element after one week (including four days of steady operation) with $\mathrm{O}_{2}$ levels in the range 0.004 to $0.015 \%$ and $\mathrm{H}_{2}+\mathrm{D}_{2}$ levels 1 to $1,5 \%$. With continued fuel exposure at $\mathrm{O}_{2}$ levels in the range of 0.015 to 0.025 \% and $\mathrm{H}_{2}+\mathrm{D}_{2}$ levels of 0.6 to $1 \%$, a thin layer of dark reddish-violet crud was again visible on the elements.

The primary system filters steadily removed crud from the system with an over-all flow decrease of 4 to 5\% per day until they were removed for remachining of the flow bypass opening. The filters were chemically cleaned and reinstalled and are again removing crud at about the same rate as before.

Samples of primary crud obtained at operating temperatures and pressures indicate that the concentration of crud clrculating in the coolant is less than $0.5 \mathrm{ppm}$. Further measurements and isotopic analyses are being done on these samples. Other samples, obtained by filtering primary coolant through 0.45 micro filters in the laboratory, also continue to show less than $0.5 \mathrm{ppm}$ crud. Samples of primary crud from several of the small filters that were removed from the Fuel Element Rupture Detection System were obtained for isotopic analyses. 
Operations personnel were trained to operate the pneumatic facility. During one of the training experiments the cap separated from the sample carrier bottle, and some strips of polyethylene weighting material were spilled. Although this happened while the PRTR was critical, there were no adverse effects on reactor operation. The weighting strips were swept out through the exhaust air system.

\section{Process Technology}

The total accumulated exposure to date on the PRTR is 754 MWd, of whlch 641 MWd was accumulated by the basic 55-element batch core.

The two fission gas pressure measuring fuel elements (PRTR Test 124) continue to perform satisfactorily. Pressure and temperature measurements were obtained from each of the four instrumented rods. The maximum temperature and pressure were $518 \mathrm{~F}$ and 32 psig in channel 1548 when the reactor was operating at 57 MW. The pressure in each rod drops to about $4 \mathrm{psig}$ when the reactor is not operating.

The traveling flux wire has been used routinely during the performance of PRTR Test 136-1 to determine the axial peaking factor and thereby improve the performance of the reactor.

Irradiation of the 19-rod 2 wto $\mathrm{PuO}_{2}-\mathrm{UO}_{2}$ pellet fuel element continued in the Fuel Element Rupture Test Facility under FERTF Test 22 .

Revision 1 to Batch Core Power Test No. 6 (Measurement of Transient Fission Product Poisoning) was prepared to allow performance of the test with the primary system and the FERTF cold and depressurized.

\section{Improvement Work Status}

Work Physically Completed:

DC-292, Pressurizer Level Control. Controls for P-16 valve have been modified so they take their level signal from the pressurizer level instead of the ring header. Tests had previously demonstrated that this gives a more stable liquid level while the reactor is shut down.

$$
\text { DC-304, Moderator Leve1--Shutdown Valve Interlock. Due to }
$$
initial physics characteristics of the batch core, it is undesirable to operate with a moderator level of over 100 inches. An operator response is expected before the level reaches 102 inches. However, 
to provide a positive limitation, an interlock has been installed which opens the shutdown valve if the moderator level reaches 104 inches.

DC-RL-24, Rupture Disc Removal. Rupture discs were at one time installed to protect ion exchange units in the FERTF. Higher pressure ion exchangers were later installed along with compatible relief valves, but the discs were not removed. The rupture discs failed twice due to low back-pressure which buckled unsupported discs and permitted early fallure. The line containing the disc has been removed.

NPC-438, Ion Exchanger for D20 Addition Station. An ion exchanger has been installed at the emergency $\mathrm{D}_{2} 0$ addition station in the service basement. This treatment permits pumping new $\mathrm{D}_{2} 0$ direct from the basement storage area to the primary system. Handling and contamination problems associated with moving $\mathrm{D}_{2} 0$ drums in and out of the reactor hall have been eliminated.

\section{Work Partially Completed:}

Modification jobs currently in the design or construction phase which have reach significant milestones include:

Decontamination and waste control (Project BCP-013). This project provides improved contamination and waste control during accident situations at PRTR. Design is 95\% complete, and construction funds were authorized 5/1/67. Procurement is under way, but physical work has not started.

Fire Protection Improvements (Project AEC-193). This project provides sprinkler protection in the PRTR service areas and alarms for the containment vessel. A lump sum contract was awarded to Fire Protection Service, Inc., of Spokane on 4/26/67. Construction work is scheduled to start in July or August 1967.

\section{EBWR Demonstration Program}

A set of pins ( 17 total) irradiated in the EBWR has been shipped from ANL and received at PNL. These pins were irradiated in the plutonlum zone of the EBWR to an exposure of $1400 \mathrm{MWd} / t o n n e$. These pins will be used in nondestructive physics measurements and subsequently undergo destructıve analysis. 


\section{NUCLEAR SAFETY}

\section{Containment Systems Experıment (J.M. Batch)}

Containment Leakage Studies - Task A

Leakage Rate Test Analysis. Leakage data analysis this month consisted of investigation of the laminar flow regime extrapolation of leakage rate data. Each of the individual leaks showed a variation of flow rate with pressure close to laminar flow except for one of the larger penetrations which has a flow rate greater than the laminar prediction at intermediate pressures. This is attributed to a reservoir effect in the volume between seals at this leak point.

The laminar flow extrapolation formula was used at test pressures below the maximum to compare the extrapolated and actual integrated leak rates at the maximum pressure. A tabulation of the results is shown below for the tests at a nominal leakage rate level of $0.1 \% /$ day at $60 \mathrm{psig}$. The observed leakage rates are results of observations by the reference vessel method.

Comparison of Extrapolated and Observed Leakage Rates

\begin{tabular}{|c|c|c|c|c|}
\hline $\begin{array}{l}\text { Test } \\
\text { Pressure } \\
\text { (psig) } \\
\end{array}$ & $\begin{array}{l}\text { Observed } \\
\text { Leakage } \\
\left.\text { Rate ( } \frac{\circ}{6} / \text { day }\right) \\
\end{array}$ & $\begin{array}{l}\text { Extrapolated } \\
\text { Leakage Rate }\end{array}$ & $\begin{array}{l}60 \text { psig } \\
(\% / \text { day }) \\
\end{array}$ & Ratio $\left(\frac{\text { Extrapolated }}{\text { Observed }}\right) 60$ \\
\hline 60 & 0.14 & 0.14 & & 1.0 \\
\hline 30 & 0.11 & 0.17 & & 1.2 \\
\hline 15 & 0.06 & 0.20 & & 1.4 \\
\hline 10 & 0.026 & 0.12 & & 0.9 \\
\hline 5 & 0.013 & 0.11 & & 0.8 \\
\hline 1 & 0.008 & 0.33 & & 2.4 \\
\hline
\end{tabular}

The agreement between the actual leakage rate at 60 psig and the rate extrapolated from data at the lower pressures is considered to be rather good.

Fission Product Transport Studies - Task B

Aerosol Behavior studies. Run P-82, a mixed aerosol liodine, ruthenium, and cesium) release to containment test was performed in the $1.54 \mathrm{~m}^{3}$, phenoline 302 , painted vessel. A primary purpose of the test was to expose phenoline 302 painted coupons for use in the evaluation of decontamination measures for the CSE containment vessel. Pressure spray systems with and without chemical additives are being evaluated with respect to pressure, temperature, chemical concentrations and spray duration. 
Preliminary data from mild detergent spray systems at $50 \mathrm{C}$ and nozzle pressures to $150 \mathrm{psl}$ and at a 4-tt spray distance have shown no real benefits over extended steaming of the painted surfaces. Coupons exposed to $80 \mathrm{C}$ condensing steam inoncondensing coupon surfacel for 8 days resulted in lodine, ruthenium, and cesium DFs of $1.6,1.1$, and 8.5 , respectively, excluding radioactive decay, whereas one minute spray exposure at above conditions gave DFs of $1.2,1.2$, and 2.6. Painted coupons when mildly brush scrubbed gave DFs of $1.2,2.0$, and 4.4, whereas stainless coupon DFs were 30,17 , and 20. From these initial data it appears that ruthenlum and cesium as well as rodine will penetrate painted surfaces. This penetration may be solely due to paint porosity and roughness in the case of cesium whereas ruthenium, like lodine may chemically react with the paint to a certain extent.

Airborne lodine in this test was largely particulate and 20 to 88\% of the lodine in early condensate liquids could be removed by filtration through glass fiber filters. Alrborne cesium was 99.9+\% particulate and was soluble in the aqueous samples. Airborne ruthenium was 99+\% particulate and 75-90\% of the ruthenium activity in liquid condensates was retalned on glass fiber filters following filtration.

Tests conducted in the Aerosol Development Facility (ADF) to define the amount of condensate held as a film on tank walls under equilibrium steam-air atmosphere conditions were described in the previous month's report. Two additional tests during the past month confirmed earlier findings. No further tests are planned at this time,

Data Acquisition System. Gamma energy analytical data were accumulated for Run P-82 (a mixed ae rosol containment test) containing radionuclides of cesium, iodine, and ruthenium. The on-line computed analytical results were filed on magnetic tape and then tabulated a second computer program after all sample counting was complete. This was the first actual test of the entire gamma energy analytical program and excluding a few minor program bugs all systems operated effectively.

Miscellaneous. A major effort this month was preparation for the first fission product transport test in the CSE drywell vessel. This will be a shakedown test of the aerosol injection, sampling, and analysis systems. Pre-run equipment testing involving the use of steam was kept to a minimum to avold high temperature aglng of the paint. The steam jet was tested with 32 psig back pressure and was found capable of maintaining a delivery line flow of 2 cfm at about 4" Hg vac.

All electrical connections from Lab \#l to the contalnment vessel for Maypack cluster control were tested. No wiring errors were found. 
The coaxial transmission line for the $50 \mathrm{kw}$ lepel induction heater and the capacitor matching station was installed. The factory workmanship seems good; however, satısfactory adjustment and heating of the $\mathrm{UO}_{2}$ at the hot cell has not yet been obtained.

Maypack Behavior. Examination of lodine retention on CSE Maypa $\overline{\mathrm{ck}}$ Components continued. In previous reports the retention of lodine on filters in dry air was covered. Similar tests have now been made in humid (99\% $\mathrm{RH}$ air at $25 \mathrm{C}$. The following table shows the effect of treating the standard Gelman type A filters with Dri-film. The reduced retention on TFE fiber filter is also shown. The TFE has lower retention than the treated type $A$. Treated type A retains about ten times more than it does in dry air; the TFE fiber about twice as much. This work will continue to include steam atmosphere.

Filter Behavior; of Elemental I2 Retalned; 5.9 Total (Humid Alr $99 \% \mathrm{RH} ; 25 \mathrm{C} 1 / 2 \mathrm{cfm}, 6 \mathrm{mln}$ )

\begin{tabular}{|c|c|c|c|c|c|}
\hline \multicolumn{2}{|r|}{ Filter } & Type A & TFE & Drl-El lmed-A & Type A (dry air) \\
\hline A & 1 & 8.5 & 1.56 & 1.97 & 5.8 \\
\hline & 2 & 7.2 & 0.54 & 1.17 & 4.4 \\
\hline & 3 & 6.4 & 0.33 & 1.23 & 4.9 \\
\hline & 4 & 6.6 & 0.40 & 1.28 & 4.1 \\
\hline B & (Ag Screens) & 52.8 & 76.4 & 76.7 & 74.3 \\
\hline $\mathrm{C}$ & (Ag Membrane) & 4.5 & 5.6 & 4.40 & 3.9 \\
\hline $\mathrm{D}$ & (Char. Paper? & 13.5 & 14.6 & 12.8 & 2.4 \\
\hline $\mathrm{E}$ & (Char. Bed) & 0.4 & 0.46 & 0.48 & 0.1 \\
\hline
\end{tabular}

Coolant Blowdown Studies - Task C

Blowdown Experiments. An instrumented blowdown was made in the reactor simulator vessel which is mounted in the 277-T Building. The purpose of the run was to test further the installed instrumentation under conditions for which reliable calculation of expected results is possible. A nitrogen dome at 1550 psig was used to expel cold water through a 3.438" ID orifice plate in the bottom blowdown nozzle of the simulator.

The results were similar to those described last month. Pressure and liquid level agreed with calculations based on adiabatic expansion of nitrogen.

As noted in the preceding blowdowns, the liquid level at which nitrogen began to be ejected was about one foot above the nozzle opening. A vorticity detector was designed to test the assumption that a vortex is responsible for the early gas venting. 
Inltial Flow Requirements for Blowdown Simulation. An analysis. was pertormed to evaluate the effect of normal recirculating coolant flows in the core of a bolling water reactor on the primary coolant system blowdown behavior following the rupture of an external coolant line. This analysis was performed to determine the necessity of providing large recirculating capacity in the CSE reactor simulator to accurately simulate an actual reactor blowdown.

For the purpose of this study, the Brown's Ferry BWR was considered. The rate of efflux of the primary coolant was determined for this reactor following a complete rupture of one of two recirculating water outlet lines. It was found that the initial critical flow rate at blowdown would be approximately twice the pumped core flow rate before the rupture and ten times that in the other recirculating water out let line that would continue to operate after rupture, Core flow momentum would be approximately $3-4$ times Its momentum before rupture while the momentum of flow at the point of rupture would be 100-200 times its value at the same point before rupture. Also, it was determined that no signiflcant flow reversals would occur within the primary vessel. Therefore, based on this analysis, It was concluded that the internal flows within the primary vessel before blowdown would not affect the rate of blowdown and may be neglected during blowdown simulation.

Decontamination

Recent contalnment system decontamınation actıvities have been directed toward determining the compatibility of phenoline 302 * paint in various candidate decontamination reagents. Solutions of $0.001 \mathrm{M}$ sodium lauryl sulfate, $0.4 \mathrm{~g} / \mathrm{l} \mathrm{N}-1$ auryl myristyl-f-aminopropioñı acıd, $10 \%$ Turco $452 \mathrm{l}$ and standard OPG a buffered solution of hydrogen peroxidel, like water, produced no harmful effects on painted surtaces during $7-\mathrm{hr}$ exposure tests at $80 \mathrm{C}$. Solutions of 10 vol\% Turco 4512, $10 \% \operatorname{Turco} 4513,10 \% \mathrm{NaOH}+3 \frac{\circ}{2} \mathrm{KMnO}_{4}$, and $0.1 \mathrm{M}$ $\mathrm{NaOH}+0.01 \mathrm{M} \mathrm{NaF}+1 \mathrm{~g} / \mathrm{l}$ sodlum carboxy methyl cellulose led to palnt damage $r a n g i n g$ trom lifting of the palnt to discoloration. Since any gross IIlm changes are unacceptable, these solutions are unacceptable as decontamination reagents. Decontamination efficiency studies for those solutions causing no paint damage are planned for the near future.

*Trade name, Carboline Company, St. Louls, Missourı. 
Pressure Vessel Crack Monitoring (J.C. Spanner)

Detection of Metal Overstress by Acoustic Emission

A work outline reflecting increased emphasis on signal analysis, signature definition, and transducer development has been prepared for the program to utilize acoustic emission to detect flaw growth in reactor pressure piping. This comes as a result of recent program review meetings with DRD\&T personnel.

Four burst specimens containing installed flaws have been tested to failure to study the attendant acoustic emission. The specimens were fabricated from 3" diameter, 3/4" wall, Type A-106-B carbon steel pipe. Two were heat treated in an effort to produce brittle fracture, but this was unsuccessful--all four failed in a ductile manner. Accelerometers and PZT-5 transducers were used to detect the acoustic emission. New low nolse, broadband amplifiers were used with the PZT-5 transducers to give an upper frequency detection limit of $300 \mathrm{kHz}$. Preliminary analysis of the data indicates that the basic frequency of many of the signals was above $200 \mathrm{kHz}$. The fallure sequence on each specimen was recorded on $35 \mathrm{~mm}$ movie film to provide visual correlation of the failure sequence with acoustic emission information. Data analysis and compilation are in progress.

Fixtures to adapt an existing electrodynamic shaker table to perform fluxural fatigue tests were designed and are being fabricated. This system will be used to study acoustic emission produced as a metal is failed by fatigue.

The emission rate analyzer was used directly to monitor acoustic emission detected by a sensor mounted on a zirconium-niobium alloy tube as it falled in fatigue by cycling internal pressure. (The test was being run by the Engineering Development Department for other purposes. The amount of acoustic emission produced during each fatigue cycle varied with the total number of cycles. During the early stages of the test, emission was relatively high and then dropped by approximately $50 \%$ for several hundred cycles. As the test entered the last 2000 cycles " 3 hrs before failure), emission increased again until it saturated the system during every cycle. Although the true amount of count rate increase could not be determined because of system saturation, the results were significant due to the indicated variations in count rate during the course of the test. Another similar test is being monitored in an effort to determine more accurately the relative changes in emission rate.

Investigation of digital analysis techniques for application to studies of acoustic emission has produced an opportunity to process samples of data through a relatively sophisticated digltal analyzer at the Naval Ordinance Laboratory in Corona, California. Data obtained from the four burst tests described above, and data from selected earlier tests, will be analyzed with this system later this month for comparison with information obtalned by analog analysis of the same data. 
A market search for low nolse, broad band amplifiers, to 1 mprove the capability of the acoustic emission study monitor system, has produced two promising products. One has an extremely low noise level and a $300 \mathrm{kHz}$ upper frequency limst, while the other has a somewhat higher noise level with an upper frequency limit of $1 \mathrm{MHz}$. One each of these amplifiers was obtained on loan and was used in monitoring the recent burst tests to study their response under the intended application, Their relative merits are being evaluated.

The first three multilayer electrostatic transducers fabricated locally by vapor deposition using $\mathrm{Si}_{1} \mathrm{O}_{2}$ and chromium in alternate layers on a quartz substrate were unsatisfactory due to fabrication problems. A fourth attempt was successful, however, and this transducer is being tested to establish functional parameters. The lead wire installation technique has been modified to overcome a problem arising from thermal expansion of the lead wires. Three more substrates have been prepared for local fabrication of transducers, and three are being sent to Thermionics, Inc., Hayward, California, for processing. The purpose of this parallel effort is to establish multiple source capability, coincldent with arriving at the finished prototype design for this transducer.

Lithium-niobate crystals are belng procured for evaluation as an alternate transducer concept for detection of acoustic emission. This is a relatively new, high temperature $1000 \mathrm{~F}$ ! piezoelectric material.

Fission Product Aerosol Containment

Removal of Organic Iodided) with Hydrazine (L.C. Schwendiman)

Two additıonal spray demonstratıon runs were performed in the 3.6 cubic meter spray chamber. One objective was to evaluate the significance of the wetted walls in removal of methyl iodide. Hydrazine, 6.35-6.6\% by weight in water was sprayed down the walls at a rate approximately equal to that in effect there during the earlier spray experiment lHS-2. The rate of removal of methyl lodide by the wetted walls was about that expected if equilibrium had been rapidly established between an equivalent volume of water alone passed down the wall of the chamber with no recirculation. The wetted wall was approximately as eftective as the chamber droplets in the previous experiments. Because liquid residence times in the spray chamber are on the order of a few seconds, extremely fast reactions will be required to increase the rate of absorption. Greater spray throughput and higher concentrations of hydrazine will increase the removal rate, and these will be investi-. gated. Reaction rates and partition coefficients at the higher temperatures are needed before good estimates of the effects of these 
parameters can be made. Recirculation of the hydrazine and the irreversible nature of the reaction, even with 5\% solutions, yield removal rates of significant worth in reactor accident situations.

A second objective was to determine if the two different spray nozzles used under essentially the same operating conditions gave different removal rates. For the same flow through the two different nozzles, insignificant difference in the methyl iodide removal rate was observed, suggesting that the total spray volume may be more important under these circumstances than droplet size.

Physical Chemistry of the Hydrazine-Methyl Iodide Reaction ( $L$. L. Burger)

The importance of the distribution coefficient of methyl lodide between water and air at temperatures higher than heretofore measured prompted a study to determine this coefficient at temperatures above $50 \mathrm{C}$. The rather few references in the scientific literature suggest that concentration will also change the distribution coefficient. A distribution coefficient of 1.4 ( $\mathrm{g}$ mol/liter water)/(g mol/ liter alr) was determined at $50 \mathrm{C}$ in preliminary experiments when methyl lodide concentration was $2 \times 10^{-7} \mathrm{M}$. This compares with a literature value of 1.3 for a $10^{-5} \mathrm{M}$ methy $\bar{l}$ lodide solution at $50 \mathrm{C}$. Measurements were planned for highe $\bar{r}$ temperatures using gas chromatographic methods.

\section{Columbia River Sedimentation Studies (D.R. Kalkwarf)}

Plans for routine sampling and radiochemical analysis of water and sediment in the Columbia River Estuary were agreed upon with the U.S. Geological Survey, and sampling will begin at the Beaver Army terminal upstream from Astoria and at Astoria during June 1967. Biweekly samples will be taken at both of these stations and at Vancouver, Washington, together with supplementary samples to determine the lateral distribution of radiolsotopes in the Estuary.

\section{Disposal of Reactor Off-Gas into Soil Systems (W.A. Haney)}

Results of air injection tests at NRTS have been requested in order that permeability values can be selected for modeling the chosen injection site there.

Geophysical Exploration of Rattlesnake \#l Well (W.A. Haney)

The Taylor Drilling Company has signed and returned the contract for reopening and reconditioning the Rattlesnake \#l well. A move to the site from western Washington began May 19. Reopening began on May 29. 
Simulation Modeling of Expected Thermal Generation in Selected Rlver Systems (R.F. Foster)

Statistical analysis of simulation data, using 1964 weather, was completed for Marseilles $(31 \mathrm{mile}$ ) and Ottawa (4l mile) locations on the Illinois River. The simulation data calculation, using the digital simulation model, was analyzed using the MisfitLearn program developed from other AEC activities. The resulting one-term sinusoidal functions are then compared for parametric variables. These comparisons indicate that, for continuous operation with a net thermal output of 3541 megawatts, the following deviations from the annual average could be expected:

$\begin{array}{ll}\text { Location } & \text { Increase in Annual Average } \\ \text { Marseilles } & 3.04 \mathrm{C} \\ \text { Ottawa } & 3.13 \mathrm{C}\end{array}$

The slightly increased difference at the downstream location results from the normally cooler background temperature at that location, since the Illinols River is in a cooling trend below Chicago until it reaches Peorla. Additional values have been computed for load-cycling cases and other conditions.

Arrangements were completed to have two thermographs installed on the Illinois River to improve modeling capability. One will be located just below the Dresden plant and the other at ottawa, Illinols, some 45 miles downstream of the upstream instrument. Calibration of the instruments in situ will be made by Hanford personnel.

Key punching of Deerfield River information is in progress. Knowledge of the differential of the Deerfield is somewhat speculative, but these are not expected to influence the results materially.

Radioactive Waste Solıdıfication (A.M. Platt, G.J. Alkire)

Phosphate Glass Design Verıfication Tests

The final phosphate glass design verification run was completed successfully during the week of May 8. The flowsheet used was PW-1 with 6.17 moles $\mathrm{P}$ and 2.46 moles $\mathrm{Na}$ as additives per liter of feed. Major objectives for this run were to show process capacity with air sparging in the melter, gather operating criteria for PW-1, and finalize all items on process control and operating parameters. Average processing rate with air sparging was about 1 ft 3 /day of glass which is equivalent (for this flowsheet) to 0.35 tonnes $U$ per day. Previous processing rates had been 0.6 to $0.7 \mathrm{ft}^{3} / \mathrm{day}$ without air sparging. Average rates of $1.3 \mathrm{ft} /$ /day will be feasible, since 
rate checks of $1.7 \mathrm{ft}^{3} /$ day were received during periods of high processing.

Difficulties were experienced with dip tube plugging throughout the run (similar to past PW-1 runs). Corrosion caused a hole in the airlift steam jacket and caused shutdown of the run after 70 hours of operation. The corrosion was probably not major this run (as lab tests indicate) but may have occurred during earlier runs which had very high $P$ contents (about 7.5 moles/liter $P$ additive). The equipment is now being prepared for radioactive services.

\section{Spray Calciner Development}

Analyses available from Run DSC-4 reported last month indicate that the injection of a $700 \mathrm{~g} / \mathrm{liter}$ sugar solution into the calciner feed system to provide sugar concentrations in the feed of 24 and $53 \mathrm{~g} / \mathrm{liter}$ (feed at $120 \mathrm{gal} / \mathrm{tonne}$ ) resulted in ruthenium decontamination factors (feed to condensate) of 2.2 and 5.0 , respectively, as compared to 1.8 achieved with no sugar addition.

A temperature probe is being incorporated into the calciner system which will allow radial and longitudinal temperature traverses to be made of the calciner barrel. The objective is to define the spray or wet zone in the calciner and determine the effect upon this zone resulting from changes in operating variables. This approach should provide further insight regarding the heat transfer and fluid dynamics within the unit and should also provide information regarding the operating conditions which would make steam as reliable an atomizing medium as air.

Preliminary testing of the WSEP vibrating trough solids feeder at voltages ( 20 volts) necessary to attain the low solids addition rate required when running the spray calciner on a $\mathrm{PW}-2$ flowsheet indicated a reproducibility in rate of 10-20\%. It may be necessary to reduce the frequency instead of the amplitude of vibration or a combination of the two factors in order to improve the reproducibility of the vibrator at low solid addition rates. In any event, the observed inconsistency in the addition rate demonstrates the desirability of continuous indication of the hopper inventory in the form of a hopper weight or an improved level indicator.

A filter test chamber is being fabricated which will allow evaluation of candidate filters for the spray calciner.

\section{Atomization studies}

One series of tests was made to measure the effect of both axial distance and air temperature upon droplet size. The results are tabulated below: 
Axial

Water Rate: $151 / \mathrm{hr}$

Distance Air Rate Air Temp. No. Avg. Drop Max. Drop Size

\begin{tabular}{|c|c|c|c|c|}
\hline$(1 \mathrm{n})$. & (SCFM) & $\left({ }^{\circ} \mathrm{C}\right)$ & Size (Microns) & (Mlcrons) \\
\hline 24 & 6.7 & 25 & 30 & 90 \\
\hline 48 & 6.7 & 25 & 36 & 80 \\
\hline 24 & 5.6 & $135-155$ & 32 & 76 \\
\hline 48 & 5.6 & $135-155$ & 37 & 100 \\
\hline
\end{tabular}

A second series of measurements was made with the air temperature constant at approximately $25 \mathrm{C}$ with the following results:

Axial

Liquid Rate 20 l/hr, Alr Rate 7 SCFM

$\begin{array}{cccc}\begin{array}{c}\text { Distance } \\ \text { (1n-) }\end{array} & \begin{array}{c}\text { Radial Dist. } \\ \text { (In.) }\end{array} & \begin{array}{l}\text { No. Avg. Drop } \\ \text { Size (Microns) }\end{array} & \begin{array}{c}\text { Max. Drop Size } \\ \text { (Avg. Microns) }\end{array} \\ 22 & 0 & 46 & 102 \\ 22 & 0 & 45 & 88 \\ 22 & 0 & 35 & 100 \\ 22 & 0 & 37 & 115 \\ 22 & 3.4 & 25 & 58 \\ 44 & 0 & 45 & 120 \\ 44 & 0 & 30 & 110\end{array}$

These tests show no signiflcant change in drop size with axial distance, but they do show some decrease in drop size when sampled away from the spray core axis. The effect of atomizing gas temperature is obscured because of a simultaneous change in atomizing air flow rate.

A simulated nozzle deposit which could be slipped over the nozzle was made from sheetmetal and a plastic cement. The simulated deposit had approximately the same dimensions as the deposit which was formed on the nozzle during run CSCM-4, $1 . e, 3 / 8$ Inch ID by about $\frac{1}{2}$ inch long. An internal obstruction was also made by inserting a 2-inch long wire $1 / 32$ inch in diameter into the gasliquid mixing chamber. The drop size distributions were measured with the following results:

Water Rate 20 1/hr, Air Rate 6.9 SCFM

\begin{tabular}{|c|c|c|}
\hline $\begin{array}{l}\text { Simulated } \\
\text { Deposit }\end{array}$ & $\begin{array}{l}\text { No. Avg. Drop } \\
\text { Size (Microns) }\end{array}$ & $\begin{array}{l}\text { Max. Drop Size } \\
\text { (Microns }\end{array}$ \\
\hline & $16-23$ & $67-75$ \\
\hline External & $29-35$ & $56-92$ \\
\hline Internal & $21-29$ & $56-66$ \\
\hline
\end{tabular}


There was apparently a slight decrease in the relative amount of small droplets due to external nozzle deposits. The simulated internal obstruction in the nozzle had no effect. In all cases there was no discernible change in the maximum drop size.

In early experiments it was noticed that drops moved around in the kerosene layer for several seconds before resting on the heavy oil substrate. During the time the drops are mobile they could coalesce, producing a disproportionate number of larger droplets. To obtain some idea of the magnitude of coalescence, two $\mathrm{kinds}$ of droplets were sprayed into the sample cell, each kind containing a colorless component, elther FeCl 3 or KCNS, so that deep red droplets formed when unlike droplets coalesced.*

For a typical sampling density, 3-4\% of the droplets were colored, which means the total percent of all coalesced droplets was more than three times as great. This information shows that our present drop sampling method does have a blas and shifts the size distribution of the droplets to a larger size than actually exists in the spray.

In order to approach spray calciner conditions more closely, spray nozzles were operated Inside a 12-inch by 4-foot covered cylindrical chamber. The data given below show that the maximum drop sizes were unchanged, and there was a slight and perhaps insignificant reduction in the proportion of smaller droplets, increasing the number of average drop size.

\section{Effect of Spray Confinement}

\begin{tabular}{lcc} 
& $\begin{array}{c}\text { No. Avg. Drop } \\
\text { Size (Microns) }\end{array}$ & $\begin{array}{c}\text { Max. Drop Size } \\
\text { (Microns) }\end{array}$ \\
\cline { 2 - 3 } Confined & $27-34$ & $68-73$ \\
Unconfined & $18-23$ & $66-73$
\end{tabular}

Waste Solidification Englneering Prototypes

Approximately 420,000 curies in a representative Purex (PW-1) flowsheet were successfully processed in the WSEP Spray solidifier: A volume of 790 liters, representing waste from 1.7 tonnes, was converted to a "ceramic" solid by filling an 8-inch diameter container to a depth of 5 feet in 60 hrs. Television inspection of the calciner after the run indlcated the use of an internal mix nozzle had maintained a clean barrel

${ }^{*} \mathrm{E}$ : H. Lucassen-Reynders Kolloid Zeitschrift $197(1-2)(137-42)(1964)$. 
Run objectives included: (a) testing a $\mathrm{PW}-1$ feed made from Purex IWW (modified with $0.42 \mathrm{M} \mathrm{Na}+0.42 \mathrm{M} \mathrm{BI}$ and $\mathrm{H}_{3} \mathrm{PO}_{4}$ to give a final $\mathrm{M}^{+} / \mathrm{P}=2.75$ and a radiocerium spike, (b) filing an 8-inch dlameter storage pot with product having a heat generation rate of 43 watts/liter, (c) establishment of the path of fission products with a modified B operating mode, (d) demonstration of the use of sugar reducing solution for ruthenium retention in the condensate evaporator and acid fractionator, (e) demonstration of an internal mix spray nozzle with air atomization, (f) testing melt discharge techniques. Most objectives were accomplished, but data are being evaluated.

A total of 420,000 curies, 1 ncluding 390,000 curies of purified radiocerium-praseodymium were processed during the run. Feed rate to the spray solidifier averaged 13.2 liters/hr. The melter, operating with a furnace temperature of $1150 \mathrm{C}$, was dumped in batches of about 5 liters through the freeze valve every five or six hours, since the weir furnace was inoperable during the run. The receiver pot was filled evenly to a depth of five feet without stalagmite formation or wall deposition, Inltially, the dumps of melt overheated the pot wall above $900 \mathrm{C}$ during filing with batches of $1100 \mathrm{C}$ melt. Shutting off the zone of the pot furnace at the melt level about an hour prior to melt dumping prevented the excursions.

Early in the run the spray nozzle plugged twice due to reasons yet unknown but was unplugged by using the nozzle cleanout needle and by adjusting the atomizing air pressure. After this, atomizing air was not preheated, and no further plugging occurred. No evidence of calcine deposits in the calciner barrel and cone was revealea by televiewing into the calciner barrel after the run. In this respect the internal $\mathrm{mlx}$ nozzle performance was far superior to that of the external mix nozzle used in run SS-l and eariıer "cold" runs.

Feed flow fluctuations which contributed to a high filter pressure drop in the calciner occurred every 10 to 15 minutes during the last half of the run. The cause of the fluctuations has not been determined. The filter pressure drop increased from 13 to 18 inches of water during the last few hours of the run causing the solidifier to pressurize by about two inches of water during tilter blowback. The fllters were cleaned after the run with a steam and nitric acid flush.

As in previous spray solidifier runs, about $3 / 4$ of the ruthenlum in the feed volatilized to the waste evaporator. The over-all fission product decontamination factor ' $\mathrm{DF}$ ' to the fractionator condensate was $2.5 \times 10^{7}$ or about two times better than that achleved in run SS-1. Although the over-all DF improved, the ruthenium DF decreased by a factor of ten $3 \times 10^{5}$ from SS-1. How ever, the concentration of ruthenium in the evaporator bottoms was a factor of two higher during $\mathrm{SS}-2$. 
The addition of sugar reductant to the fractionator tower did not suppress ruthenium volatility since DF's with and without sugar addition during the run were not significantly different.

Run SS-2 was successfully monitored with the GE-412 computer. One day prior to the start of the run, a relay fallure on one of the four input signal multiplexing circuit boards forced a shuffle of the input signal connections to the computer and some minor program changes. As a result about $10 \%$ of the input signals had to be omitted.

Minor program modifications to the data logging program were made following run SS-2 to realize increased utilization of the data to be obtained from run SS-3, scheduled for the first part of next month.

\section{Product Characteristics and Storage}

Pot Sampling by Core Driling. Vendor drawings for the drill unit have been reviewd, BNW and vendor drawings conformed, and design comments relayed to the vendor. Drill unit shipment by June 15 is expected. The redesign resulted in the incorporation of the baseplate into the vendor's assembly, with resulting savings to BNW.

Batch Melting in the Waste Container. Little or no corrosion of the 304L waste container, as determined by ultrasonıc wall thickness measurements, took place during the radioactively cold PW-2 spray calciner run reported last month. No changes in wall thickness were detected in excess of 0.005 inch whl ch was the accuracy limit of the instrument.

The pot was recently cut open, and no corrosion was seen. The solidifled waste looked fairly homogeneous; however, it should be pointed out that the melt was stirred with a rod toward the end of the run. Another run is planned using the same flowsheet but with more carefully controlled rate of flux addition.

It was also determined that about one liter of water is adequate to flush the underside of the powder valve to prevent excessive dust dispersion when uncoupling the container.

Solids Storage Englneering Testing. The first phase of design verification tests on environmental test pods \#l and \#2 have been successfully completed. The first phase tests include incell handling, load deflection, and the following heat transfer studies:

1. Heatup tests no cooling at $1200 \mathrm{~F}$.

2. Reboller tests, with cooling water in the upper coll and the pod filled with water covering the lower coll on ly. 
3. Lower coil cooling capacity tests with the pod filled with water and cooling water passing through the lower $\operatorname{coil}$.

4. Lower coll cooling capacity tests with the pod dry and cooling air passing through the lower coll.

5. Air sparger cooling capacity tests.

Preliminary analysis of results indicates that the pod design is conservative, both from the heat transfer and mechanical points of view.

A pot and pod wlll be assembled under simulated remote handling tests in second phase testing.

Highlights concerning the status of Project BAP-016, Solids Storage Engineering Test Facility include:

1. Approved window specifications were issued May 5; the due date for bid opening was set as June 30 .

2. Manipulator specifications are being held pending a radiation analysis of simplified tape slots.

3. Sheet for the wall liner has been purchased.

4. First- and second-floor window openings have been knocked out, except for the 6 -inch thick retaining slab on the cell side of the second floor opening.

5. The second-floor window has been recelved.

Englneering Analysis. Several charts were prepared to simplify calculation of heat transfer relationships in WSE solidified waste containers The fission product quantities were determined to give data on molten core operation. Charts prepared were:

1. Conversion of volumetric heat generation to total heat in pot.

2. Temperature drop from centerline to pot wall.

3. Pot wall temperatures in air.

4. Pot wall temperatures required for specific molten core configurations.

5. Isotope requirement for pots in various environments.

6. Molten core volumes as a function of wall temperature, remelt temperature, and heat generation rate.

An interesting fact indicated by the charts is that molten core. data can be obtained from WSEP runs PG-6 and SS-6 if 8-inch recelver pots are used for a solid product of the planned volumetric heat generation rate. It may be possible by a combination cold experiment. 
and limited radioactive data to cover the range of operation of a pot filled with short-cooled waste generating 20 to $30 \mathrm{~kW}$ in an 8-inch pot. Calculated data show that such a molten core consideration is reasonable if the containers are kept in water.

Supporting Activities

Waste Melter Materials of Construction. Haynes LT. 1 and LT. IB cermets (Cr-Mo-A ${ }_{2} \mathrm{O}_{3-\mathrm{T}} \mathrm{O}_{2}$ ? suffered calculäted mean attack rates of 7,5 and $6.7 \mathrm{mils} /$ week, respectively, when exposed to a $\mathrm{PW}-1$ melt (DSC-3) at $1200 \mathrm{C}$ for one week.

Waste Container Welding Development. Remote manual TIG welding was demonstrated using a standar $\overline{d i n} \overline{d e} \mathrm{HW}-20$ torch held with a model E manipulator. Viewing was through a 25-power spotting scope equipped with a 12-foot focal length adapter; à \#10 welding lens was taped over the scope lens to prevent arc tlashing. Successful welds were made on a 12-1nch diameter, 16-gauge, carbon steel waste can with an 1l-gauge, 304 stainless steel top, which was fitted to the can inside diameter with a flush joint. Prior tests using carbonsteel tops proved unsuccessful due to the high oxygen and impurity content of low grade carbon steel.

Several attempts at welding using the Sclaky SWA-6 torch in the automatic position proved unfruitiul due to excessive oscillation in the automatic arc voltage servo system. A work order has been issued to move the sensitivity and dampening controis trom the Mechanical Development Laboratory to the remote welder console. This relocation should aid in setting up the torch in the atomatic position

In-Pot Melting. Additive compositions that will yield PW-l and PW-2 melts which fuse at low temperatures are being sought for in-pot melting flowsheets. A number of sultate- and borate-based additive compositions were evaluated for this purpose.

Colemanite rominally $\mathrm{Ca}_{2} \mathrm{~B}_{6} \mathrm{O}_{1} \mathrm{I} 5 \mathrm{H}_{2} \mathrm{O}$ is a ilexible additive for both $\mathrm{PW}-1$ and $\mathrm{PW}-2$, produaing glasses over a wide $\mathrm{r}$ ange of waste: colemanite ratios. Meiting points below about $875 \mathrm{C}$ cannot be obtalned with colemanite as the single additive, however. With PW-2: borate melts, a microcrystalline. sulfate-containing, second phase was always present. Perhaps because of this phase separation, the borate-based melts possess superior sulfate-retaining characteristics.

Silfate-based melts appear promising for $\mathrm{FW}-2$ iwhich al ready contalns sulfatel. Compositions which melted at less than $700 \mathrm{C}$ were produced over a wide range of sulfate and ilthium additive concentrations. Minimum concentrations of these additives required to produce a low temperature $700 \mathrm{C}$ melt appear to be about $0.2 \mathrm{M}$ IIthium and $0.4 \mathrm{M}$ sulfate. At these concentrations, a viscous melt $\overline{w i}$ th ar: oxide sTag floating on top was produced. 


\section{DISTRIBUTION}

Number of Copies

8

3

1

1

1

1

1

7

1

1

3

55 $\frac{\text { AEC-AECL, Chalk River, Canada }}{\text { M. H. Hudson }}$

AEC Division of Technical Information Extension

Aerojet-Nucleonics

P. O. Box 77

San Ramon, Calıfornıa

F, W. Titua

Aeroprojects, Inc.

W. B. Tarpley

Alr Force Materials Laboratory

W'right-Patterson AFB

S. W. Bradstreet

Alis Chalmers Manufacturing Co.

Virginia D. Rose

Ames Laboratory

F. H. Spedding

Argonne National Laboratory

R. M. Adams

L. R. Link (4)

C. E. Stevenson

R. C. Voge 1

Armour Research Foundation

W. Loewe

Atomic Energy Commission Division of Compliance Region IV, P. O. Box 15266, Denver

Atomic Energy Commission, DRD\&T Site Representative

P. G. Holsted

Atomic Energy Commission Washington

Advisory Committee on Reactor Safeguards

R. F. Fraley (17)

Division of Compliance

L. Kornblith, Jr.

Division of Licensing and Regulation (7)

S. S. Paw licia ill 
Division of Operations Analysis and Forecasting

Division of Production

F. P. Baranowski

Division of Reactor Development \& Technology

R. A. Brodsky

Col. K. Cooper

A. Gi ambusso

J. E. Robb

S. A. Szawlewcz

M. Shaw (16)

G. W. Wensch

Division of Research

G. A. Kolstad

Division of Safety Standards

M. Bolotsky

A. B. Holt

Office of Assistant General Counsel for Patents R. A. Anderson

Space Electrical Propulsion Office

Col. G. K. Dicker

$\frac{\text { Atomic Power Development Associates, Inc. }}{\text { w. H Jens }}$

Atomics International

A. A. Jarrett (2)

H. Pearlman

Babcock and Wilcox Company

Lynchburg, Virginia

H. S. Allen

R. A. Webb

1

Battelle Memorial Institute

D. L. Morrison

1

Bechtel Corporation

R. F. Griffin

4

Brookhaven National Laboratory

A. E. Castleman

Elizabeth J. Edwards

C. J. Raseman

D. G. Schweitzer 
$\frac{\text { Canoga Park Area Office }}{\text { R. W. Richards }}$

Carolinas-Virginia Nuclear Power Associates H. T. Babb

Chicago Operations Office

Argonne, Illinois

D. M. Gardiner

Columbia University, New York

J. E. Casterline

Combustion Englneering

$\mathrm{P} \cdot \mathrm{O} \cdot \mathrm{BOX} 500$

Windsor, Connecticut

W. P. Chernock

$\frac{\text { Dow Chemical Company, Rocky Flats }}{\text { J. R. Seed }}$

11

DUN

P. A. Carlson

J. R. Carre 11

R. E. Dunn

G. C. Fullmer

D. R. Hogle (Atomics International)

C. G. Lewis

W. M. Mathis

J. H. Soehnlein

H. G. Spencer

J. R. Spink

W. K. Woods

1

$\frac{\text { Ebasco Services, Inc. }}{\text { T. A. Flynn, Jr. }}$

E. I. duPont de Nemours and Co., Aiken

General Atomic Division
D. B. Coburn
E. Creutz
A. J. Goodjohn
S. L. Koutz
D. V. Ragone

General Electric Company, Cincinnati

S. Naymark, NMPO

General Electric Company, Pleasanton

L. P. Bupp

E。 A. Evans 
General Electric Company, Richland

W. J. Dowis

A. E. Guay

M. Lewis

J. S. McMahon

J. W. Nickolaus

J. W. Riches

General Electric Company, San Jose

K. P. Cohen

E. R. Kilsby

R. B. Richards

C. H. Robbins

E. L. Zebroski

General Electric Company, Schenectady

W. M. Cashin, KAPL

J. L. Michaelson, Advanced Technology Lab., Bldg. 5

6

Idaho Operations Office

Nuclear Technology Div.

J. F. Kaufman

D. S. King

D. E. Williams

1

IIT Research Institute

P. O. Box 327

Argonne, Illinois

W. J. McGonnagle

1

IIT Research Institute

10 W. 35th Street

Chicago, Illinois

T. A. Zaker

3

Isochem, Inc.

H. H. Hopkins

H. P. Shaw

R. E. Tomlinson

Los Alamos Scientific Laboratory

H. F. Redman

D. B. Hall

1

Massachusetts Institute of Technology Manson Benedict

1

National Bureau of Standards

C. Muehlhause 
2

2

1

1

2

9

4

1

1

1

8

1

1

National Reactor Testing Station (INC)

J. A. Buckham

D. R. de Bolsblanc

New York Operatıons Office

A. J. RIzzO

C. Stahie

Nuclear Development Corporation of America W. A. Loeb

Nuclear Materials and Equipment Corporation C. S. Caldwell

Oak Rıdge Operations Office

D. F. Cope

W. J. Larkin

Phillıs Petroleum Company

Atomic Energy Division, Idaho Falls

G. O. Bright (2)

S. G. Forbes (2)

E. O. Meals

F. Schroeder (2)

T, R. Wilson (2)

Richland Operations Office

P. M. MIdkıff

C. L. Robinson

R. K. Sharp (2)

Sandia Corporation

J. Jacobs

San Franclsco Operatıons Office

Sargent and Lundy

W. A. Chlttenden

Union Carbide corporation (ORNL)

F. L. Culler

W. B. Cottrell

J. H, Frye

R. W. MCClung

O. Sisman

D. B. Trauger (2)

M. S. Wechsler

United Nuclear Corporation

C. Graves

University of California

V. E. Schrock 
1

1

4

84 $\frac{\text { University of Minnesota }}{\text { H. Isbin }}$

$\frac{\text { University of Texas }}{\text { G.W. Watt }}$

Westinghouse Electric Corporation

R. H. Fillnow

E. J. Kreh

R. G. McGrath

R. A. Wiesemann

Battelle-Northwest

F. W. Albaugh

G. J. Alkire

R. J. Anicetti

J. M. Atwood

J. A. Ayres

Q. L. Baird (ANL Liaison, Idaho Falls)

J. M. Batch

A. L. Bement

C. A. Bennett

T. K. Bierlein

J. G. Bradley

S. H. Bush

G. J. Busselman

J. J. Cadwell

T. T. Claudson

E. D. Clayton

T. B. Correy

R. E. Dah 1

F. G. Dawson

L. J. Defferding

D. R. de Halas

R. F. Dickerson

R. L。Dillon

K. Drumhel ler

E. A. Eschbach

P. L. Farnsworth

S. L. Fawcett

J. R. Fishbaugher

J. C. Fox

M. D. Freshley

E. P. Galbraith

S. M. Gill

s. Goldsmith 
L. A. Hartcorn

H. Harty

R. E. Heineman

R. J. Hennig

H. L. Henry

P. L. Hofmann

R. R. King, Jr.

D. D. Lanning

H. V. Larson

G. A. Last

R. D, Leggett

B. R. Leonard

R. C. Lijkala

C. W. Lindenmeier

W. W. Little

$J=E$, MInor

C. E, Newton

R. E Nightingale

H. M. Parker

R. S. Paul

L. T. Pedersen

A. M. Platt

W. D. Richmond

W. E. Roake

G. J . Rogers

C. A. Rohrmann

L. C. Schmid

L. C. Schwendiman - C. E. Linderoth

R. J. Sorenson

W. G. Spear

A. J. Stevens

R. W. Stewart

G. L. Tingey

C. R. Tıpton, Jr.

L. D. Turner

C. M. Unruh

F. W Van Wormer

J. B. Vetrano

E. E. Voll and

R. G. Wheeler

O. J. Wick

F. W. Woodfield

D. C. Worlton

$\mathrm{H}$. H. Yoshikawa

BNW Patent Office (2)

Technical Information Files 2

Technical Publications (2) 